\title{
TEST ITEM CONSTRUCTION AND VALIDATION: DEVELOPING A STATEWIDE ASSESSMENT FOR AGRICULTURAL SCIENCE EDUCATION
}

\author{
A Dissertation \\ Presented to the Faculty of the graduate School \\ of Cornell University \\ in Partial Fulfillment of the Requirements for the Degree of \\ Doctor of Philosophy
}

by

Jennifer Elaine Rivera

January 2007 
(C) 2007 Jennifer Elaine Rivera 


\section{TEST ITEM CONSTRUCTION AND VALIDATION: DEVELOPING A STATEWIDE ASSESSMENT FOR AGRICULTURAL SCIENCE EDUCATION Jennifer Elaine Rivera, Ph.D.}

Cornell University 2007

In 2001, the New York State Board of Regents approved the New York State Regents Career and Technical Education Policy. Through the process of program approval, career and technical education (CTE) programs can provide students greater flexibility in attaining graduation credits in the areas of math, science, English and/or social studies for students completing such programs. The policy also states that individual career and technical completers can receive a technical endorsement on their Regents diploma. Part of the process for CTE program approval is to administer a technical assessment certifying that students meet current industry standards.

The impetus for this study was addressing the need of one secondary career and technical education program, agricultural science education, which does not have a statewide exam. Currently, the Department of Education at Cornell University in collaboration with New York Agricultural Education Outreach is in the process of developing a statewide exam for use as the technical assessment to certify students. Once approved, this exam will meet the technical assessment requirement for program approval. This study focuses on the written multiple-choice portion of the statewide exam, specifically two aspects of developing an exam, item construction and item validation. Based on criterion-referenced test construction procedures two of the nine sections of the exam were developed, animal systems and plant systems. 
The results of this study outline a process for developing and validating items. They highlight some of the benefits and disadvantages faced when developing test items for a diverse audience without the aid of a testing institute. Further consideration is given to procedures used to validate test items, specifically expert judgment and analytical data. The results from this study provide guidance to test developers related to aligning items to content, writing and editing items, and revising items. 


\section{BIOGRAPHICAL SKETCH}

Jennifer "Jeno" Elaine Rivera is an assistant professor at Michigan State University in the Department of Community, Agriculture, Recreation, and Resource Studies. She graduated from the Department of Education at Cornell University with a degree in Learning, Teaching, and Social Policy in January 2007. While at Cornell her research focus was on standardized testing for agricultural science education programs at the secondary level. Her teaching and advising focus was on teacher preparation for agricultural science and science pre-service educators at the secondary level. Before pursuing a doctorate, Jennifer was a high school agricultural science educator at a small rural school in Page County, Virginia. Her summer months were spent working with the Virginia Governor's School for Agriculture at Virginia Tech. Jennifer holds a Master of Science degree in Career and Technical Education and a Bachelor of Science degree in Crop and Soil Science with a concentration in international agriculture, both from Virginia Tech. 
I wish to thank my parents, Ozzie and Lillie Rivera.

They bore me, raised me, supported me, taught me, and loved me. To them I dedicate this dissertation. 


\section{ACKNOWLEDGEMENTS}

It is a pleasure to thank the many people who helped made this dissertation possible. I would like to express my gratitude to my Ph.D. supervisor, Dr. William G. Camp. He has served as a mentor, role model, and friend for many years. His support, encouragement, and sound advice led me through two degrees and great teaching experiences. Without his guidance I would not be where I am today.

I wish to thank my committee members and colleagues Dr. John Sipple and Dr. Thomas Di Ciccio for stimulating discussions that have helped to broaden my knowledge and understanding of education. I am especially grateful for their friendship and intellectual advice.

I would like to give my special thanks to my editor and best friend Jeb whose patient love enabled me to complete this work.

Lastly and most importantly I wish to thank my family, especially my sister, Jayka without whom none of this would have been even possible. 


\section{TABLE OF CONTENTS}

$\begin{array}{lll}\text { Chapter } 1 & \text { Introduction } & \text { Page 1 } \\ \text { Chapter } 2 & \begin{array}{l}\text { Review and Synthesis of the } \\ \text { Literature }\end{array} & \text { Page 18 } \\ \text { Chapter 3 } & \text { Research Methods } & \text { Page } 96 \\ \text { Chapter } 4 & \text { Results } & \text { Page 103 } \\ \text { Chapter 5 } & \text { Summary and Discussions } & \text { Page 129 } \\ \text { Appendices } & & \text { Page 143 } \\ \text { References } & & \text { Page 158 }\end{array}$




\section{LIST OF FIGURES}

Figure 1.1 Agriculture, Food, and Natural Resource $\quad$ Page 7 Cluster

Figure 2.1 Norm-referenced distribution curve vs.

Page 55

criterion-referenced distribution curve

Figure 2.2 Ideal NRT frequency distribution

Page 56

Figure 2.3 Designing criterion-referenced certification Page 61 tests

Figure 2.4 Item characteristic curve with three different Page 90 levels of difficulty and the same discrimination

Figure 2.5 Three-item characteristic curve with the same Page 91 difficulty but with different levels of discrimination

Figure 4.1 Frequency distribution of test scores on Page 109 animal science pilot

Figure 4.2 Frequency distribution of test scores on plant Page 120 science pilot 


\section{LIST OF TABLES}

Table 2.1 Mapping a sentence for measuring a skill Page 64

Table 2.2 Steps for preparing criterion-referenced tests Page 66

Table 4.1 Animal Systems- item difficult and Page 110 discrimination

Table 4.2 Animal systems - frequency of alternatives Page 118

Table 4.3 Plant Systems- item difficulty and Page 121 discrimination

Table 4.4 Plant systems - frequency of alternatives Page 127 


\section{LIST OF EQUATIONS}

$\begin{array}{llc}\text { Equation 2.1 } & \text { KR-20 formula } & \text { Page 82 } \\ \text { Equation 2.2 } & \text { KR-21 fomula } & \text { Page 83 } \\ \text { Equation 2.3 } & \text { Cronbach's alpha formula } & \text { Page 84 } \\ \text { Equation 2.4 } & \text { Cronbach's alpha formula } & \text { Page 84 } \\ \text { Equation 2.5 } & \text { Hoyt's coefficient formula } & \text { Page 85 } \\ \text { Equation 2.6 } & \text { IRT 2-parameter model } & \text { Page } 88 \\ \text { Equation 2.7 } & \text { IRT 3-parameter model } & \text { Page 89 } \\ \text { Equation 2.8 } & \text { Formula for true score } & \text { Page 93 } \\ \text { Equation 2.9 } & \text { Multiple-choice model } & \text { Page 94 }\end{array}$




\section{CHAPTER 1 \\ INTRODUCTION}

Currently in the United States, the educational landscape is undergoing a decades old reform movement led predominately by proponents of content standards and high stakes testing. With the reauthorization of the Elementary and Secondary School Act (ESEA) now known as No Child Left Behind (NCLB), educational accountability is being measured more and more by proficiency on standardized state tests. Increasingly within the past decade, the standards that drive curriculum and test development are typically generated at a national level and focus on core academic areas. For example, the National Councils of Teachers of Mathematics (NCTM) developed the math standards for K-12. Under NCLB, states are required to meet testing standards or make demonstrable Annual Yearly Progress toward meeting those standards. Data gathered from standardized testing provides accountability measures for student, school, district, and state performance, which are being used to measure Annual Yearly Progress.

\section{Educational Accountability}

\section{National Level}

In 1991, America 2000: An Educational Strategy proposed an educational reform strategy based on national goals (Bush, 1991). Goal 3 states that, "The academic performance of all students at the elementary and secondary levels will increase significantly in every quartile, and the distribution of minority students in each quartile will more closely reflect the student population as a whole" (U.S. Department of Education, 1991; p. 3). Since that time, the push for standardized educational accountability has produced a narrowing of curriculum with the stated aim of closing the 
achievement gap existing between the bottom and top quartiles of students (Dillon, 2006). Based on performance rankings from the National Assessment of Educational Progress, the gap is widening and there is lack of progress closing the white/minority, high/low socioeconomic status achievement gap (US Department of Education, n.d. a). With an emphasis on core academic performance standards, Career and Technical Education (CTE) programs have taken on a lesser significance, often times being phased out entirely. In attempts to remain relevant, CTE programs have been undergoing a "metamorphosis"-- from superficial changes such as renaming "Vocational Education" to "Career and Technical Education" to more fundamental changes that attempt to synthesize CTE programs with core academics (Castellano, Stringfield, \& Stone, 2003).

The reconstruction of CTE programs leads to a question of accountability. Currently, national tests are not available for all CTE programs. A premier not-for-profit organization, National Occupational Competency Institute (NOCTI), offers student "job ready" examinations in a large number of occupational areas measuring student achievement in CTE (National Occupational Competency Testing Institute, 2005). Board certification examinations based on industry standards, such as those offered in cosmetology and plumbing, have been another alternative to measure student performance. As educators in CTE programs address integration and accountability they face a number of challenges. One of those is diversity across state lines and localities. Another challenge is the misalignment between hands-on performance-based learning and standardized testing.

As the nationwide academic proficiency deadline of 2014-- imposed by NCLB-- fast approaches, states are turning to a system of high-stakes student 
testing to hold their academic programs accountable. Examples of the predominant educational "high-stakes" based on student performance are grade retention and promotion, funding provided to schools and districts, and school closure until schools measure up to their annual yearly progress, as required under NCLB. To meet the challenges that these stakes place on students and schools, remediation is being offered to students providing them further instruction in the academic areas. This increases the urgency that CTE programs are facing to remain a part of the nationwide curriculum.

\section{New York State}

New York State (NYS) was a forerunner in competency assessment testing by way of Regents examinations that began in 1865 . The state used these exams to "provide a basis for the distribution of State funds allocated by statute to encourage academic education" (State Education Department, 1987, ๆ 3). Initially, Regents exam requirements focused on core academic curricula, but in 1927 vocational education was added. In 1970, changes in high school curriculum contributed to the discontinuation of a number of Regents requirements, including agricultural education. In May 2000, following the national accountability movement, the Board of Regents in New York State implemented a System of Accountability for Student Success (SASS). This system puts mandates on the requirements for a high school diploma- with a concentrated focus on the five core academics of English (four years), mathematics (three years), global history and geography (two years), U.S. history and government (one year), and science (three years). Based on high academic learning standards Regents testing continues to drive accountability in the NYS educational system. 
In 2001, the New York State Education Department (NYSED) crafted the Career and Technical Education Policy Initiative allowing a student's career and technical coursework to apply towards his or her core academic requirements by way of a state endorsement and/or career and technical endorsement. The thinking behind this initiative was to "preserve the rigor and integrity of academic and technical education without duplication of course work" (MAGI Education Services, 2004, p. i). The objective of this alternative pathway to graduation is to:

- Help every youth receive an academic education that prepares him/her for future education and career success,

- $\quad$ Offer a smooth transition into a postsecondary program leading to a technical certificate, associates or baccalaureate degree, apprenticeship, or a job, and

- Connect to workforce investments systems to strengthen regional workforce quality and economic competitiveness. (MAGI Educational Services, 2004, p. 2)

Aside from granting career and technical endorsement to students diplomas, the Career and Technical Education Policy also allows CTE programs to be accredited in the areas of science, mathematics, English, and/or social studies. Part of the requirements for both endorsement and accreditation is the administration of a technical assessment to measure student performance. Technical assessments can be based on nationally accepted tests or industry standards appropriate to the occupations served by the respective CTE program, such as the occupational competency exams offered by National Occupational Competency Testing Institute (NOCTI). If no nationally accepted technical assessment 
exists, a technical assessment system can be developed by local programs or a consortium of programs.

\section{Background}

\section{Situation in NYS}

In 2003 the Central New York (CNY) Agricultural Education Consortium and Cornell University Agricultural Education Outreach (AEO) program assumed the task of developing a technical assessment for the Natural and Agricultural Science Core Curriculum in accordance with the NYSED requirements for accreditation. However, the instrument developed was not based on research and consequently could not be considered a valid measure of student achievement. At that point AEO staff members, in conjunction with members of the Cornell University Department of Education took the lead to develop an assessment model consisting of standards and competency measures that would meet the Career and Technical Education Program Approval Guidelines. The main objective of this model is to advance secondary agricultural education to a more rigorous, scientific-oriented curriculum supporting the NYS Career Development Occupational Standards (CDOS). This would ultimately allow students to use this course and exam as one of the three required science credits for high school graduation. To develop a successful model two objectives must be accomplished-1) develop and propose a core curriculum framework for agricultural science education appropriate for New York State, and 2) develop a valid and reliable technical assessment system based on the core curriculum framework for program accreditation. 


\section{Career Clusters Model}

The first objective was completed in 2005 with the completion of a core curriculum framework based on the US Department of Education's Career Clusters Model. The goal of the Career Clusters model is to- 1) prepare all students for college and careers, 2) connect employees with education, and 3) deliver multiple educational benefits to high schools, educators, guidance counselors, employers and industry groups, parents, and students. (Office of Vocational and Adult Education [OVAE], 2006). The Career Clusters Model is comprised of sixteen occupational clusters preparing pathways for secondary students to transition into 2-year or 4-year post secondary programs or the workplace. The Agriculture, Food, and Natural Resource (ANR) cluster was used as the foundation to develop the NYS core curriculum framework as it represents the diversity of NYS agricultural education. The ANR cluster consists of seven pathways: (1) agribusiness systems, (2) animal systems, (3)

environmental service systems, (4) food products and processing systems, (5) natural resource systems, (6) plant systems, and (7) power, structure, and technical systems, see Figure 1.1.

A validation team examined the ANR model for use in New York State and concluded it would be appropriate, with the addition of two content areas: Agricultural Education Foundations and Safety in Agriculture Education. Thus, the NYS core content framework for agricultural science education would consist of nine content areas, seven coming directly from the ANR Pathways model and two added specifically for this state. With the completion of the NYS Core Curriculum framework for New York State in 2005, the task of developing a valid and reliable technical assessment system for program accreditation is currently being addressed. 


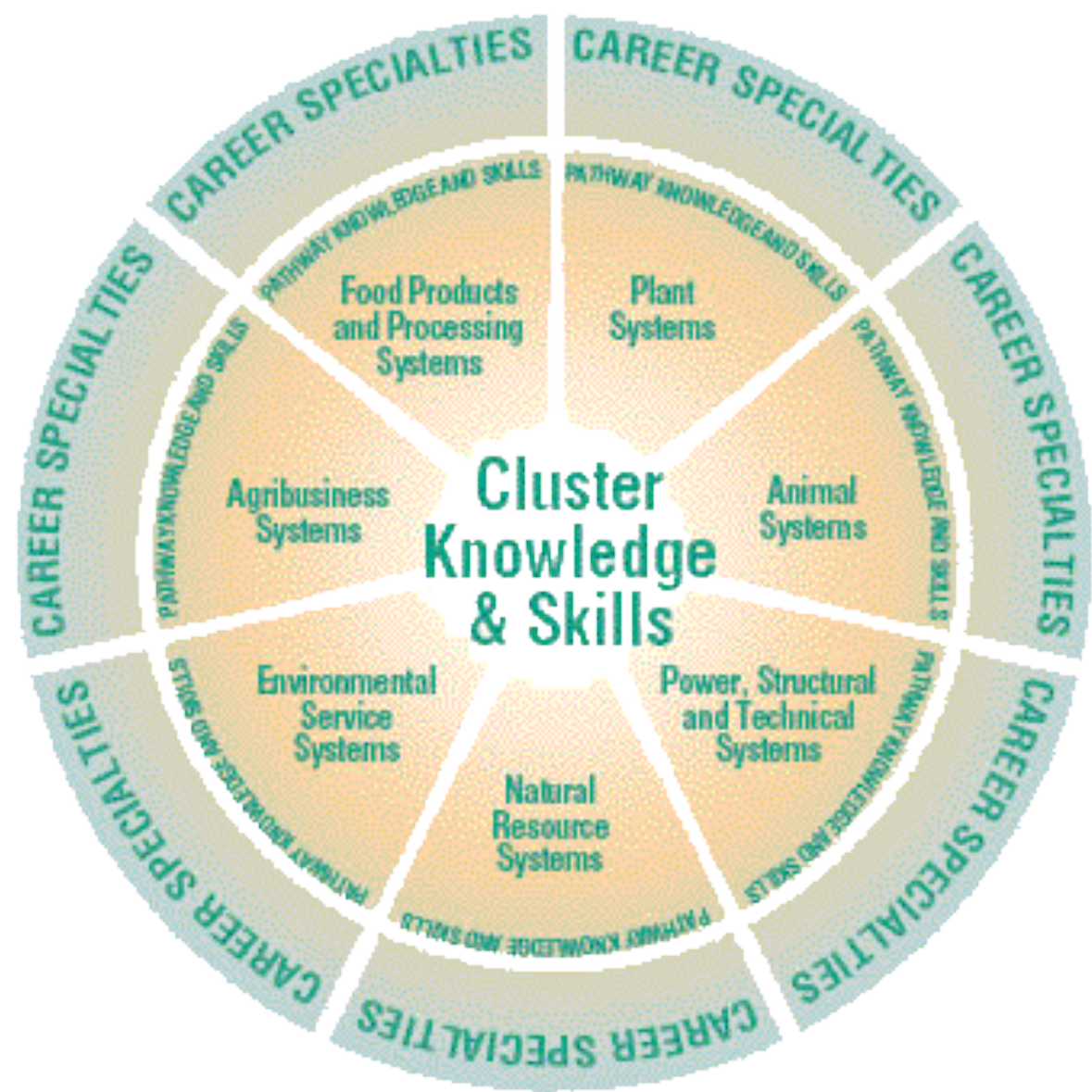

Figure 1.1. Agriculture, Food, and Natural Resource Cluster

Graphic taken From Career clusters- Focusing education on the future: Preparing for career success in agriculture, food, and natural resources. The Career Cluster Pathway Model diagram is being used with permission of the:

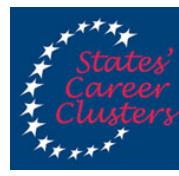

States' Career Clusters Initiative, 2006, www.careerclusters.org 


\section{Theoretical Framework}

\section{Theories of Assessment}

Norm-referenced testing (NRT) and Criterion-referenced testing (CRT) represent two of the main assessment models used historically in education. CRT offers advantages over NRT. CRT provides more meaningful data and a more accurate interpretation of performance. It assesses competency on certification exams, evaluates programs, and monitors an individual's progress or deficiency in objective-based instruction (Hambleton, Swaminathan, Algina, \& Coulson, 1978).

During the 1960s, Glaser (1963) and Popham and Husek (1969) introduced the field of criterion-reference measurement, later also referred to as objective-based or domain-based measurement. Glaser (1963) was among the first to discuss the use of CRT in systematic instruction. Popham (1993) highlighted the work of Glaser and provided a set of guidelines to follow when constructing criterion-referenced measurements. Similar to Popham, Roid and Haladyna (1982) described a five-step process as ideal for developing CRT. More recently, Shock and Coscarelli $(1998,2000)$ developed a 13-step systematic model to follow.

Since the 1960s, CRT has been interpreted many ways. Linn (1984) highlighted the links of CRT to behaviorist learning theory to include the cognitive measure of higher-order thinking skills. Hambleton (1984) viewed $\mathrm{CRT}$ as a form of authentic measurement and performance assessment based on standards. Millman and Greene (1989) linked the term criterion to domain, specifying each test item of a certain behavior to a specific domain. 


\section{Criterion-referenced item construction.}

A number of procedural methods and methods based on substantive theories have been offered by measurement specialists and used to develop criterion-referenced items. During the early 1960s, the Instructional Objective Exchange (IOX) specialized in using an objectives-based approach to develop criterion-referenced measurements. Using item forms (Hivey et al., 1968), IOX was able to develop amplified objectives. The amplified objectives were not widely utilized so IOX found success by delimiting the amplified behavioral objectives and developing test specifications.

Guttman (1959), Guttman \& Schlesinger (1967), Castro \& Jordan (1977), and Berk (1978) developed the theory of mapping sentences, similar to developing item forms, based on the Structural Facet Theory (Guttman, 1959; Foa, 1968). Engle and Martuza (1976) and Berk (1978) developed six steps in creating an item based on facet design using the instructional objective as the basis for mapping sentences. Another approach to develop items is testing concepts, rules, and principles, a technique that can be applied to almost any discipline (Markle \& Tiemann, 1970; Tiemann \& Markle, 1983). The last well-known theory is the factor-based construction method, generating items through factor-analysis (Guliford, 1967; Meeker, Meeker \& Roid, 1985). There is no concrete "rule book" that instructs the item developer on how to generate criterion-referenced measurements, though Hambleton and Rogers (1991) offered the most detailed steps.

\section{Technology for generating multiple-choice test items.}

No generally accepted approach to generating multiple-choice (MC) items with theoretical underpinnings exists (Guttman, 1969); rather, there are numerous guidelines, rules, and recommendations based on empirical studies 
(Bormuth, 1970). Roid and Haladyna (1982) addressed the need for item writing that connected teaching and testing. They provided guidance on methods that were based on the systematic relationship of instruction and evaluation. Popham (1990) provided a set of guidelines for creating selectedresponse items focused on a practitioner's perspective. Popham (2003) also offered item-writing guidelines for $\mathrm{MC}$ items developed from the work of Haladyna (1999) and similar to his previous work.

\section{Item validation.}

Writing the test item does not produce an item ready to be tested until it is validated. Hambleton and Rogers (1991) and Haladyna (2004) provided features to focus on when reviewing a CRT item's content. Messick (1989) emphasized the importance of item reviews, strengthening validity. Hambleton (1994) provided a summary of methods used to review and validate items.

There have been multiple techniques established for reviewing item-objective congruence based on large-scale assessments to small classroom assessments, such as the use of empirical techniques similar to normreferenced testing, expert judgment used to calculate the index of itemobjective congruence, a rating of item-objective match on a 5-point scale conducted by experts, and the use of a matching task (Hambleton, 1984).

\section{Analyzing Item Responses}

\section{Classical test theory.}

Lord and Novick (1968) introduced classical test theory (CTT) approaches to the behavioral sciences. They introduced the classical linear model and its application to estimating parameters such as true score and error variances of latent trait variables. Common statistics are used to describe CTT parameters including p-values, item discrimination, point-biserial 
correlation coefficient, alpha coefficient, and variance. Analysis of these parameters provides evidence for the validity of criterion-referenced examinations. CTT statistics can also be used to determine values of reliability through the use of internal consistency methods such as split halves (Rulon, 1939; Guttman, 1945; Cronbach, 1951) and item co-variance. Other methods used to circumscribe problems inherent in split half techniques are Kuder Richardson 20 (KR 20) and Kuder Richardson 21 (KR 21) (Kuder \& Richardson, 1937), along with Cronbach's alpha (Cronbach, 1951), and Hoyt's method (Hoyt, 1941).

\section{Item response theory.}

The aim of Item Response Theory (IRT) is to understand and improve reliability of tests (Wainer, 1989). In measuring latent traits, such as ability, item characteristic curves can be modeled for each individual item, showing the item's difficulty and discrimination. The use of item response theory principles can be applied to many different types of models to help increase the reliability of items and tests. Some of the more common models include the normal-ogive model (Thurstone, 1927; Lawley, 1943; Ferguson, 1942;Moiser, 1940, 1941; Richardson, 1936), the Rasch or one-parameter logistic model (Rasch, 1960), and Birnbaum's two- and three-parameter logistic model (Lord \& Novick, 1968). These models have been further developed to include models such as the rating scale model (Rasch, 1961), the graded response model (Samejima, 1969), the partial credit model (Masters, 1988), and multiple-choice models (Thissen \& Steinberg, 1984).

The original multiple-choice model was derived by Bock (1972), which takes the multivariate logistic transformation of the nominal model to analyze item parameters. This model was further developed by Samejima (1979), 
which added a latent response category referred to don't know (DK). Thissen and Steinberg (1984) extended the model further to include trace lines for the incorrect alternatives on the item response model.

\section{Problem}

NYS agricultural science education programs are based on local needs; therefore no single approved statewide curriculum exists for agricultural science. The result of that situation is that local agricultural science education programs differ widely from one school to another. The seven pathways outlined in the Agriculture, Food, and Natural Resources portion of the Career Clusters Pathways model (Career Clusters, 2006) appear to be reasonably inclusive of the range of content being delivered in NYS agricultural science education programs with the addition of agricultural foundations and agricultural safety pathways. Complicating the lack of a statewide curriculum in agricultural science, no national standards or competency assessment systems currently exist that would be appropriate for that range of content. Clearly, developing a valid and reliable technical assessment system is beyond the resources and ability of most local teachers. Therefore, there is a need for a useable technical assessment system appropriate for NYS agricultural science education programs. It should include both performance and content components. The content component should provide objective measurements of the core curriculum domains, and should include item banks reflective of the wide range of content offered in NYS agricultural science education programs.

\section{Purpose and Objectives}

An objective content test requires a bank of test items, but no test item bank exists to measure student achievement in the content areas based on 
the domains specific to New York State agricultural science education. Developing a complete item pool for all nine content areas was well beyond the scope of this study. Therefore, the purpose of this study was to develop, validate, and field test separate banks of test items for the Animal Systems and Plant Systems content areas. The specific objectives of this study were to:

1. Develop an item construction protocol based on criterion referenced testing.

2. Organize technical teams of item writers.

3. Write draft items based on core curriculum framework domains.

4. Validate items through expert judgment.

5. Pilot test items.

6. Use classical test theory and item response theory to analyze items based on statistical measures providing further evidences of validity and reliability.

\section{Professional Significance of the Study}

The National Council for Agricultural Education (The Council) provides leadership and direction for school-based agricultural education programs. Due to the lack of national standards in existence, The Council made the development of core standards a priority within their 2004-2006 Strategic Plan agenda. They proposed to develop National Curriculum Standards for Secondary Agricultural Education. These standards would align with the career clusters pathways (National Council for Agricultural Education, 2004). Currently, their proposal focuses solely on developing standards, but they have expressed interest in developing an assessment system based on these standards. 
Outside the efforts of The Council, numerous states have expressed the need for agricultural education reform led by a system of accountability driven by standards and testing. At the 2005 American Association for Agricultural Education (AAAE) national conference, the issue of statewide standards and testing development was addressed. As many are looking to their sister states for guidance, this proposal provides these states with an item construction protocol. If these procedures are utilized by multiple states then item banks can be combined to provide a larger item pool.

Within New York State, this study will provide guidance to AEO as they assume the task of constructing an item pool for the remaining six content areas. The use of the proposed assessment based on the Natural and Agricultural Science Core Curriculum is not mandatory; however, this study can also assist consortiums or individual programs that chose to develop their own test items.

\section{Limitations and Delimitations}

The goal of NYSED is to have a full assessment system for programs to use for accreditation or certification. This constitutes developing assessments systems -- from standards to the test itself. This study delimits and limits the full assessment system in myriad ways. Delimitations are as follows:

1. Pathway Selection- Due to a lack of time and resources, focus was placed on two of the nine career content areas to ensure quality control in item construction. The remaining seven content areas will be addressed in future studies.

2. Item Construction Procedural Amendment- Due to allocation of resources received to develop a statewide assessment system, this study focuses on two aspects of test construction- item 
development and item validation. It is not an evaluation of a full test development model containing other characteristics such as constructing broad goals and test cutoff scores. The construction of broad goals was conducted in a previous study. The development of test cutoff scores will be conducted in a future study.

3. Tripart Integration-According to the NYSED, a technical assessment must be comprised of three components (1) a written portion, (2) a student project and (3) a student demonstration of technical skills. This study focuses solely on the written portion of the assessment system, concentrating on item construction and item validation. The remaining two portions have already been developed through the efforts of AEO program staff.

Limitations of the study are as follows:

1. Curriculum Specifications- Due to the focus of this study, test items being developed are based solely on the NYS agricultural science education core content. This is done to maintain consistency between standards, curriculum, and assessment measures.

2. Resource restrictions- Due to a lack of funds, professional item writers were beyond our budgetary reach. Technical instructions were provided to item writers -- NYS agriculture teachers and extension agents. To further validate the item questions they were edited and reviewed by a team of professionals in the test taking and educational fields, as this fit into the project's budget. 
3. Sample Size Restrictions- Students for the item field test were not chosen at random, restricting the sample size. In order to run IRT models, a large population of students is needed to ensure valid and reliable results. There are enough NYS agriculture students enrolled in animal and plant systems programs; however, availability of these students relies on the school schedules and their teachers' curriculum calendars. It was impossible to determine in advance whether the data gathered from the IRT models would be adequate for IRT analysis.

\section{Definitions}

Agriculture Education Outreach (AEO)- A program to support and advise local agriculture education programs in public schools so that these programs may better serve the New York State economy by preparing individuals for career opportunities in the food and fiber system and related allied fields. For more information, see http://www.nyag-ed.org/outreach.htm Annual Yearly Progress (AYP)- The Improving America's Schools Act (IASA) of 1994 defined adequately yearly progress (AYP) as, "1) continuous and substantial yearly improvement of each school and local education agency sufficient to achieve the goal of all children ... meeting the state's proficient and advanced levels of achievement; [and] 2) is sufficiently rigorous to achieve the goal within an appropriate timeframe (as cited in Elmore \& Rothman, 1999, p. 85)" (Goertz, 2001). NCLB legislation make several critical changes to the IASA. NCLB legislation requires each state to create its own definition of AYP within the parameters set by Title I. For more detail, see http://www.cpre.org/Publications/cep01.pdf 
Career Clusters- A grouping of occupations and broad industries based on commonalities. The sixteen career clusters provide an organizing tool for schools, small learning communities, academies and magnet schools.

Career Pathways- The agriculture, food, and natural resources career cluster is divided into seven pathways. Pathways are grouped by common knowledge and skills by occupation in these career fields. Each pathway provides instruction as a basis for success in an array of career and educational pursuits. The seven pathways are animal systems, agribusiness systems, environmental service systems, food products and processing systems, natural resource systems, plant systems, power, structural, and technical systems.

Program Accreditation- An approvable CTE program containing a related and continuous series/combination of courses/experiences in a career and technical area and academic and technical knowledge and skills in preparation for further education/training and/or employment in a career. Successful completion of requirements allows students to fulfill a core course requirement in English, mathematics, social studies or science after the student passes the required Regents examination(s) in that core academic subject area.

Technical Endorsement- A technical endorsement on the diploma would reflect student achievements. This would include: (a) completion of all graduation requirements and CTE sequence requirements, (b) passing a technical assessment, and (c) passing the five required Regents examinations in English, mathematics, science and social studies, or alternatives approved by the State Assessment Panel. 


\section{CHAPTER 2}

\section{REVIEW AND SYNTHESIS OF THE LITERATURE}

Assessment planted roots in education dating back to the 1200 s at the university level and the 1800s at the secondary school level (Aiken, 1994). Through the decades it has served many purposes, such as measuring student proficiency, comparing student achievement data, or determining if a student should be retained or promoted. The face of testing has undergone many changes over the years. From oral testing, to standardized testing, to authentic assessment, it has continued to change with educational policy and practices. Today testing is near ubiquitous in public education; and with advancements in test design and technology -- coupled with the advent of the so-called "Age of Accountability" -- testing is a staple of education.

\section{Organization of the Review of Literature}

This chapter is divided into three main sections. The first section focuses on the social and political debates driving assessment. There are both facts and myths behind the public view on testing. Beliefs, coupled with research, fostered changes in education policy and outlook that, in turn, led to legislation that greatly affected the role of testing in today's public schools. I paid particular attention to the importance of testing within the education system and the impact that it has had on public perception, particularly how assessment has altered public discourse about education. Integrated into this section is a focus on three federal legislative acts that have impacted accountability in education. They are the Elementary and Secondary School Act (1965), the Goals 2000: Educate America Act (1994), and the most recent, the No Child Left Behind Act (2001). Accountability is the central reform theme in all three acts. This accountability movement has increased the role of 
testing and assessment in education and at the same time heightened the role testing plays in school decisions at the federal, state, and local level.

The second section is a summary and discussion of the future of testing in agricultural science education. Research in test construction is limited. There is a need for well developed theoretical models for test design and test validation. Within the field of agricultural science education, available testing research is scant -- an issue that needs to be emphasized in the ongoing research agenda for the profession.

The remainder of the chapter focuses on theories involved in test design. I placed emphasis on item construction and item validation. I also compared two theories driving item analysis: classical test theory and item response theory.

\section{Limitations and Delimitations of the Review of Research}

Assessment is a broad term that encompasses various aspects of tests and measures. For this study primary focus is given to standardized testing, just one component within a larger assessment system. Within the standardized testing movement, review of the research literature focuses on criterion-referenced testing, with specific detail to item construction, item validation, and item analysis. Within criterion-referenced testing, the use of data collected focuses on the proportion-correct score estimates and allocation of examinee mastery. Testing will be considered in the broader framework of the general education system rather than specifically with in the area of career and technical education. This is done solely due to a lack of research evidence related to testing in career and technical education programs. By examining academic uses of educational testing, I would hope 
that career and technical educators can learn the pros and cons when developing assessment measures for their specific needs.

\section{Policy Issues}

With the rise of testing in public education, there are those that feel the existing policy of assessment is inappropriate and is wrongly enforced. Others believe that assessment policy, which drives the high-stakes accountability system, is the best way to measure student and school performance. Since the 1850s, when testing in public schools was initiated to increase educational funding, there have been strong reasons for such tests. These include warranting educational inputs and providing state and federal funds to public schools, sometimes led through an increase of taxes. As the nature of such tests has changed through the decades it has altered the societal beliefs of testing in general.

Many presidential and gubernatorial campaigns feature education as a top priority. Emphasis is usually placed on the outcomes of the educational system, essentially will every child be assured an equal opportunity and quality education throughout the nation? According to Ravitch (2005), Republicans and Democrats differ in their views of testing.

Unfortunately, the political calculations that resulted in the No Child Left Behind law adopting a strategy of letting the states choose their own standards and tests remain the reality. In general, Republicans are wary of national standards and a national curriculum, democrats have been wary of testing in general. Both parties must come to understand that the states are not competing with each other to ratchet up student achievement. Instead, they are 
maintaining standards that meet the public's comfort level assuring an efficient educational system ( $\$ 10)$.

This situation impacts beliefs held by citizens about the education system. By taking a look at the history of testing in education we can see how testing played an important part in American schools long before this recent "Age of Accountability."

\section{History of Assessment in US Educational Systems}

\section{$1840 s-1889$}

The first free public school dates back to 1639 founded in Dorchester, Massachusetts. The Massachusetts school system took the lead in testing for educational accountability when in the late 1840s the Massachusetts Board of Education administered a voluntary written examination of 30 questions to their eighth grade student body. This was a major shift from the traditional oral exams used at the local level. Results showed that most students could not pass due to the lack of alignment between the test items and the curricula taught by the schoolmasters. Shortly thereafter the district discontinued educational testing, and Massachusetts students did not see required tests until 1986 (Bolon, 2000).

Other states began to support free public education in the 1850 s and 60s such as Texas, Ohio, and New York. New York followed the testing lead of Massachusetts and administered examinations in public schools. In 1865 the New York Board of Regents administered entrance exams for their high school programs. In addition to these preliminary exams, an exit exam for graduation was developed in 1878. Regents examinations were not made a mandatory requirement for graduating with a local diploma until the start of the $21^{\text {st }}$ century. 
In 1888, superintendents in Cincinnati, Ohio replaced the traditional use of oral and written essay exams with multiple-choice testing. This change in format was mimicked by many other school districts in other states in the late 1880s. It was a more efficient was to classify and promote students (White, 1888). It also was an easier way to administer grades based on a test scores, a practice done at many colleges such as William and Mary, Yale, and Harvard to name a few.

\section{0-1919}

By the turn of the $19^{\text {th }}$ century about $80 \%$ of children ages 5 to 17 were enrolled in some sort of school system (US Department of Commerce, 1975). They included private schools, state-chartered academies, public schools, and church-run charity schools. Such diversity reflected the interest of the populace, "...motives that impelled Americans to found schools: the desire to spread the faith, to retain the faithful, to maintain ethical boundaries, to protect a privileged class position, to succor the helpless, to boost the community or sell town lots, to train workers or craftsmen, to enhance the virtue or marriageability of daughters, to make money, even to share the joys of learning." (Tyack \& Hansot, 1982; p. 30). However, population increases strained public school systems trying to meet the demands of growing student enrollment and diversity. As enrollment increased, so too did the varying levels of ability. Most students were at lower levels with lower motivation and occupational aspirations. "Whereas before the turn of the century a fairly homogeneous curriculum and simple organizational structure sufficed, it became necessary after 1900 to develop a more differentiated curricular and administrative system" (Schafer \& Olexa, 1971:5). At a time where immigration rates were rising, when compulsory-attendance laws were being adopted by 
most states, and when adolescent work rolls were declining, a free public education became the norm, overshadowing the private and religious-based schools (Butts \& Cremin, 1953).

Growth in public schools translated into a need for more public funding for education. Individual states took the lead through state taxes. The role of the federal government was not strong. "Education was regarded as a function of the states, not in any sense a function of the National Government." (Capen, 1921:20). Occasionally the federal government provided aid to develop various programs. This aid typically came through state- or locallymatched funding in support of the land grant mission. For example, the SmithHughes Act for Vocational Education of 1917 provided aid toward the development of vocational training in secondary schools.

By the 1900 s $80 \%$ of all educational spending went toward public schools, an increase of $30 \%$ from the 1850 s (Tyack \& Hansot, 1982). What was once a $\$ 15.55$ per pupil expenditure in 1870 had risen to $\$ 49.12$ per pupil by 1918 (Butts \& Cremin, 1953). This increase was viewed by some as a burden on taxpayers. There arose a need to ensure that local and state tax money applied toward secondary education was well spent; and there were arguments as to whether such spending benefited the public at large. The demand for effective schools was addressed bureaucratically by moving away from the common school ideal, where the aim was to "educate citizens of sound character," to a more comprehensive, urbanized school system that emphasized passing and failing (Tyack, 2003), "Crucial to educational bureaucracy was the objective and classification, or grading, of pupils" (Tyack \& Hansot, 1982:44). This reform movement led to an institutionalized system that divided students by grade, standardized the curriculum, and ensured a 
reliable and rational classification of pupils (Tyack, 2003). Proponents for this movement, "supported the highly structured models of schools in which students would be sorted to their tested proficiency" (Katz, 1968:179). The way to accomplish this sorting involved separating students based on ability, which was measured by standardized achievement tests.

In the early 1900 s standardized tests were the primary assessment tools for measuring student ability in the basics -- reading, writing, and arithmetic (Hoff, 2000). The term "standardized" had a somewhat different meaning a century ago. Instead of referring to a norm-reference, as it is today, it referred to a system where "...the tests were published, that directions were given for administration, that the exam could be answered in consistent and easily graded ways, and that there would be instructions on the interpretation of results." (Resnick, 1982:179). Standardized tests began to overshadow oral and essay style tests. Standardized tests offered, “.... a single standard by which to judge and compare the output of each school, 'positive information in black and white,' [in place of] the intuitive and often superficial written evaluation of oral exams." (Tyack, 1974:35).

According to Horace Mann, secretary of the state Board of Education in Massachusetts from 1837-1848, testing had two purposes: classifying children and monitoring school systems (US Congress Office of Technology Assessment [OTA], 1992). Standardized tests gave teachers a quick tool to measure the ability of one student compared to another. With achievement tests, students could be sorted into grades more efficiently and either promoted or retained based on test scores. A secondary outcome was that state-level policy makers used test results to make comparisons between 
schools in different districts and states. Such tests also helped standardized curriculum based on grade level (Tyack, 2003).

Even as the use of standardized tests grew, questions were raised. Since such tests were new, there was no assurance that they were effective. There was no proof that the test scores actually reflected student ability. When made public, the scores often highlighted or emphasized the pass/fail rate of schools or students. Other critics argued that students were not actually learning new material but simply memorized material that appeared on tests (OTA, 1992). A final broad complaint revolved around using scores to compare education performance in different districts or states. Critics felt curriculum differences across regions and borders made such comparisons meaningless.

\section{0-1949}

A major theme in education by the 1920 s responded to a rise in immigration to the United States. Public education became a tool to "Americanize" non-English speaking, foreign-born peoples (Tyack, 2003: 55). It is estimated that of the 15 million foreign-born Americans in the U.S. in the 1920s, 5 million could not speak, read, or write English, and 2 million could neither read nor write in any language. These immigrants formed communities with cultural ties to their native lands (Towner, 1921: 83). The situation presented a challenge for American public education. Instruction in civics became increasingly important. Naturalization classes taught immigrants American history, government, and citizenship. So-called "streamer classes" taught them English and were found in almost all public schools of the time (Tyack. 2005:28). 
Also in the 1920s, enrollment rates continued to climb for both upper elementary grades and high schools. One-room schoolhouses from the $19^{\text {th }}$ century were replaced by urban school structures, which featured multiple grade levels and divided classes. Larger schools sometimes had two or more classes per grade. Students were grouped into individual classes based on an XYZ grouping that measured brightness (McCall \& Bixler, 1928). State educational leaders responded to the growth by encouraging creation of more schools that allowed access to education to more children over longer periods of time (Tyack \& Cuban, 1995). From the start of the $20^{\text {th }}$ century to the start of the $21^{\text {st }}$ century, the number of high school graduates increased annually from about 95,000 to 2.5 million (NCES, 2003: table 102). At the same time, the number of school instruction days doubled from around 1900 to the present (Tyack \& Cuban: 1995).

Standardized testing became an important tool to manage the spike in enrollment and the expanded goals of public education. By 1925, 40,000 schools in 34 states were "standardized" (Tyack \& Cuban, 1995:18). That meant institutional systems were put in place that relied on quality indicatorssuch as teacher qualifications, scoring cards or report cards, guidance procedures, and a diversified curriculum with many electives.

A test regimen already existed to sort secondary students into grade levels and classes. A new use for tests responded to a boom in American industry combined with an administrative desire to place constraints on college admissions. Sometimes this sorting had racial or nativist undertones. Nicholas Butler, president of Columbia University in 1917, employed the Thorndike Tests for Mental Alertness specifically to limit the number of Jewish students admitted. He lamented that incoming students were "...depressing in 
the extreme...largely made up of foreign born and children of those but recently arrived..." (Wechsler, 1977:155).

The testing that developed from this situation helped sort students into college preparatory or vocational/occupational tracts. It also grouped students by learning styles and levels of ability. This was achieved using normreferenced standardized tests. According to McCall and Bixler, "a standard test is an instrument that has been carefully prepared, in accordance with scientific techniques, to measure intelligence, aptitude, or achievement in school subjects" (1928:1). Prominent tests from the time included Multi-Mental Intelligence, Thorndike-McCall Reading, National Intelligence, Stanford Achievement, Otis Classification, and the Illinois Examinations (McCall \& Bixler, 1928:3,). Such tests measured reading, writing, spelling, arithmetic, and intelligence; and they resulted in a cumulative score.

Testing the three R's at the secondary level was most typical; but intelligence testing gained in popularity after World War I because of the American Psychological Association's Alpha Test, a multiple-choice test used to determine the "mental age" of military personnel. Testing soldiers allowed the Army to sort enlisted men for special assignment (Resnick, 1982). The Alpha Test showed a high illiteracy rate among the draftees. "The examination of the draft registrants for service in the late war showed that of the men called between the ages of 21 and 31 , nearly 25 percent could not read a newspaper, could not write a letter home, and could not read the posted orders about the camps...one-fourth of the sons of America called to the colors are incapacitated for efficient service because of their ignorance" (Towner, 1921:82). 
Similar multiple-choice intelligence tests were adopted by schools and used from the third through ninth grades (Monroe, 1952). Testing proponents herald their effectiveness. "Psychologists are now able to tell with considerable accuracy whether a child posses an I.Q. which will ever make it possible for him to do the work of a particular school or institution or grade in school" (McCall, 1939:227). A one size-fits all curriculum did not meet the demands of a diverse student body. Intelligence tests allowed schools to separate students based on qualified scores that charted ability.

Toward the end of the 1920s, questions arose about the federal government's role in education and whether states were doing the job when it came to providing an equal education to all. Testing proponents believed emphasis should be placed on the basics, goals that every child should be able to achieve. They also believed states should continue to control education; but go about it more efficiently. Testing was seen as major component of this mission. "It was not a far leap to embracing methods that, because they were purported to measure differences, could be used to classify children and get on with the educational mission...the American pursuit of efficiency would become the hallmark of a generation of educationalists, and would create the world's most fertile ground for the cultivation of educational tests" (OTA, 1992:111).

The use of testing grew over the next few decades. Intelligence testing continued to increase, and tests that measured everything from vocational skills to athletic ability gained in popularity. Educational researchers viewed standardized tests as a way to gather data from hundreds of thousands of subjects through a controllable medium. Test scores were used to support administrative decisions and helped legitimize the classification of students. 
Not everyone, however, viewed testing as valid and reliable solution for running efficient public schools. The tests were fashioned as a way to identify different abilities and needs in children. In practice, the tests instituted the sorting, the labeling, and the ranking of children starting as early as the third grade (OTA, 1992).

The evaluations drawn from testing broadened in the 1930s when E.F. Lindquist developed the lowa Test of Basic Skills and the lowa Test of Educational Development. These tests were voluntary for state high schools; but incentives were offered to high performing schools. Throughout the '30s more states followed the lowa model. Unlike in past tests, the results did not simply chart individual student ability; but rather they were seen as a way to "diagnose and monitor" schools and students (Peterson, 1983).

Testing also benefited from technology. Devices such as the opticalscoring machine made processing multiple-choice tests more efficient (Walsh, 2000). Such advancements made testing affordable and readily accessible for schools throughout the nation (OTA, 1992).

\section{0-1969}

Curriculum changes from the end of the 1940s well into the '50s were predominantly centered on life-adjustment education. Only about half of America's youth fell into either vocational or college preparatory tracts (Cremin, 1961). Dr. Charles Prosser, a lobbyist of the National Society for the Promotion of Industrial Education, raised the issue with the U.S. Commissioner of Education and the Assistant Commissioner for Vocational Education. "We do not believe that the remaining $60 \%$ of our youth of secondary school age will receive the life adjustment training they need and to which they are entitled as American citizens -- unless and until the 
administrators of public education with the assistance of the vocational education leaders formulate a similar program for this group" (U.S. Office of Education, nd: 15). Shortly thereafter the federal Commission on Life Adjustment Education for Youth was founded. Its goal was to set a curriculum to "equip all American youth to live democratically with satisfaction to themselves and profit to society as home members, workers, and citizens" (US Office of Education, 1951: 1).

Also through the 1950s, achievement testing continued to grow, aided by the ease and cost effectiveness of pencil and paper tests. Optical scanners replaced the older electro-mechanical scorers. In 1955, Lindquist developed the first "lowa Machine," a state-of-the-art scoring machine for its day. The reliance on such devices led to a subtle shift in teacher-student relationship.

[Before scoring machines] most standardized tests were handscored by teachers...under that system, tests corrected and scored by the teacher provided opportunity for careful pupil analysis by the teacher. In turn, that analysis, pupil by pupil and class by class, provided meaningful measures for individualizing pupil instruction, improving instruction, reassessing the curriculum, and making appropriate textbook decisions... as the machine-scoring movement grew, the activities related to testing changed. Certainly, the scoring activity left the classroom and often as not the school system itself. Test results moved increasingly into the hands of the administrative staff. Test specialists were employed who were interested in an ever broader array of derived scores to be used for many purposes ... the hands-on dimension for teachers receded and in due course 
disappeared almost entirely" (Communication with $\mathrm{H}$. Miller as sited in OTA, 1992:255).

Also in the early years of the 1950s, education was a bottom-up system. Local school boards were near autonomous. Local superintendents and administrators faced few constraints from federal or state governments. Most upper level school administrators were college trained in the field of education; they were handpicked by their local school boards. Their main roles were, "Keeping schools out of politics, especially resisting pressure groups, impartially administering the rules, preserving the integrity and dignity of the profession; and keeping the faith that 'what happens in and to the public schools of America happens to America' " (Tyack \& Hansot, 1982:219). It was a closed system, one run by local superintendents with their own, "professional culture, values, and interests...controlled the flow of information to school board members, by claiming impartial expertise, and by obfuscation when necessary, they have turned school boards into rubber stamps for their policies" (Tyack \& Hansot, 1982:222). By the late '50s, this situation prompted what was termed a "Crisis in Education" (Life Magazine, 1958:2). Protestors seeking social change turned their attention to public education. They addressed their message to the highest levels of government for leverage (Tyack \& Hansot, 1982).

In the late '50s and early '60s, public schools moved away from lifeadjustment education to an emphasis on academics. Enacted by Congress in 1958, the National Defense Education Act (NDEA) provided federal money to aid in sciences, mathematics, and modern languages. NDEA came as a response to the Soviet Union launching of Sputnik (OTA, 1992). Most Americans believed the United States lost the race to space because of 
academic inferiority. Factors identified as weaknesses included a curriculum that emphasized a wide variety of electives instead of core academic classes. Examples of electives included, "guidance and education in citizenship, home and family life, use of leisure, health, tools of learning, work experience, and occupational adjustment" (Manzo, 2000: 129). In order to catch the Soviets, Americans wanted to replace such classes with academic courses or more valuable electives such as foreign languages. It was a move recommended three decades earlier by the Committee of Ten in the Cardinal Principles report (1919). "All programs included, as an example, three years of mathematics and at least four years of a foreign language as well as heavy doses of science and literature...excluding such newly emerging subjects such as manual training and commercial courses." (Kliebard,1995; p. 199).

Testing for achievement became a primary partner of this more academic learning curriculum. Federal funds paid for test development and usage. "...A program for testing aptitudes and ability of students in public secondary schools, and...to identify students with outstanding aptitudes and abilities...to provide such information about the aptitudes and abilities of secondary school students as may be needed by secondary school guidance personnel in carrying out their duties; and to provide information to other educational institutions relative to the educational potential of students seeking admissions to such institutions..." (PL 85-864).

While the federal initiative was geared toward identifying talented students, public schools faced another challenge: namely, how to best educate children of the poor. Press reports from the time labeled the 1940s through the '60s as an era of "urban crisis" (Ravitch, 1983:147). Technology began to mechanize traditional agricultural practices. This fostered a 
migration from the south, particularly its black population, to American cities. In urban settings, blacks were segregated into poorer slums. At the same time, jobs for semi-skilled or unskilled workers dwindled, leaving many blacks and other poor immigrants in a state of poverty. "Blacks were concentrated in low-wage jobs...few had the education to become professionals...even those with credentials discovered...people with dark skin were not welcomed (Ravitch, 1983:147). The issue of racial equality helped spur a highly politicized school reform debate in the '60s. Many believed that states had failed in their public education mission, and that the current system did not meet the needs of social and economic realities. The federal government was asked to step in. Professor Philip Hauser, speaking at the $4^{\text {th }}$ Annual Conference of the National Committee for Support of the Public Schools, said the states had failed miserably, "The fact is should the states continue in their ways, I think state governments will wither and die, as probably they have earned the right to do" (1966:14).

Titles IV and VI of the Civil Rights Act of 1964 focused on ending school segregation and eliminating separate and unequal facilities, issues fought for in Brown v. Education of Topeka in 1954. Title IV provided technical assistance to prepare, adopt, and implement plans for desegregation within public schools. Title VI prohibited discrimination in any federal-funded program and withheld funding from institutions that did not comply (Spring, 1990). A year later, Congress passed the Elementary and Secondary Education Act (ESEA). Within the first four years of its enactment, this act provided $\$ 4$ billion in aid to disadvantaged children (Mondale \& Patton, 2001). Title I of ESEA (renamed Chapter 1 in 1981) provided federal dollars for program evaluation. 
The purpose of Chapter 1 was to:

1. Determine the effectiveness of the program in improving the education of disadvantaged children;

2. Instill local accountability for Federal funds; and

3. To provide information that State and local decision makers can use to assess and alter programs" (OTA, 1992).

Testing was used to evaluate the programs, prompting an increase in norm-referenced tests such as the Comprehensive Test of Basic Skills and the California Achievement Tests (Walsh, 2000). Tying federal funds to desegregation increased the involvement of the federal government in public schools. According to President Lyndon B. Johnson, "It represents a major new commitment of the federal government to quality and equality in the schooling that we offer our young people (Mondale \& Patton, 2001: 148). Testing was part of that equation.

Some opposed mandating tests to evaluate programs. By the late '60s, however, such tests were providing information to policy makers. As an unintended consequence, the collected data sparked a debate on national testing. At the 1966 meeting of the National Committee for Support of the Public Schools, a national testing protocol was proposed: "A national assessment to identify kinds of progress being made in education" was the proposal. Those against national testing believed differences in local curricula would make the results of these tests inaccurate as a measure of true student performance. They also believed national assessment put too much power in the hands of the federal government, allowing it to develop and set tested objectives (Proceedings, 1966: 85). Three years after the conference, the 
National Assessment of Educational Progress was created to survey student achievement in elementary, middle, and high schools.

Another teaching movement in the late '60s set up class structure to meet diverse student needs. According to Thomas and Thomas, the main school classifications were as follows: 1) ability grouping, 2) special classes for slow learners, 3) special classes for the gifted, 4) other special classes, 5) un-graded classes, 6) retention and acceleration classes, 7) frequent promotion plans, 8) contract and unit plans, 9) team teaching, 10) and paralleltract plans (1965:97).

The parallel tract further divided students based on aptitude and achievement tests. Some of the more popular tracts were college preparatory and vocational. The rationale behind tracking involved fitting subject matter to group needs based on the approach that learning would be more effective among a set of relatively homogenous students (Thomas \& Thomas, 1965). There were lots of critics. Critics felt that tracking discriminated against lowerincome and minority students. The tests, they argued, favored white middleclass students. Once in a tract, the students felt locked into a path without much opportunity for developmental changes. The lower, non-college prep tracts also were viewed as inferior and tended to attract rebellious students. Lastly, tracking limited contact between students with different backgrounds (Thomas \& Thomas, 1965). However, according to the Coleman Report, which reported the effects of tracking, there was no difference in the outcome of students in a tracked system (1966). Tracking drove curriculum in the early 1970 s and helped develop programs such as cooperative education and workbased learning. 


\section{Elementary and Secondary Education Act.}

In 1965, Congress passed the Elementary and Secondary Education Act (ESEA). Title I of ESEA (renamed Chapter I in 1981 and back to Title I in 1993) provided federal dollars for program evaluation. The purpose of Title I

of the ESEA was to, "ensure that all children have a fair, equal, and significant opportunity to obtain a high-quality education and reach, at a minimum, proficiency on challenging state academic achievement standards and state academic assessments." A large percentage of Title I funding is allocated for public schools with a high rate of low-income families and low-achieving students. It is used in providing the resources to help these disadvantaged students meet student academic achievement standards outlined by the states.

In recognition of the special education needs of low-income families and the impact that concentrations of low-income families have on the ability of local education agencies to support adequate educational programs, the Congress hereby declares it to be the policy of the United States to provide financial assistance...to local educational agencies serving areas with concentrations of children from low-income families to expand and improve their educational programs by various means (including preschool programs) which contribute to meeting the special educational needs of educationally deprived children. (Elementary and Secondary School Act, 1965, Section 201)

Schools were viewed as a democratic institution at the time of ESEA passage. Policy makers and education officials in states and localities set guidelines for school programs- including such areas as designing curriculum, 
distributing funds, and hiring of teachers. Leaders at state and local levels did not want to cede this control to the federal government. In order to protect local and state autonomy ESEA prohibited any "Federal agency or official from exercising direction, supervision, or control over the curriculum, program of instruction, administration, or personnel in any educational institution or school system" (1965, Section 604).

From 1965 to the present, ESEA has been reauthorized eight times, providing funds for more than just disadvantaged students. It now has expanded to serve other interests such as bilingual education, American Indian education, teacher training, technology, and school libraries. In regard to assessment, during the 1994 reauthorization of ESEA, at the time referred to as the Hawkins-Stafford Elementary and Secondary Schools Improvement Amendments, there was emphasis for each state to develop its own plan for curriculum standards and an assessment system to measure those standards. The legislation also called for local plans to be aligned to a corresponding state plan, which would be submitted for federal approval. The law emphasized outcomes-based and performance-based testing and the assessment of higher-order thinking skills. It required state standards to be valid and reliable, integrating technical and professional standards. The frequency of testing, as mandated by Title 1, was to be yearly in an array of subjects with adopted standards and a minimum of once for every students during grades $3-5,6-9$ and $10-12$ the subjects of mathematics and reading or language arts. In 2002, ESEA of 2001 was signed into law. It was subtitled the No Child Left Behind Act. 


\section{0-1989}

The 1970s became viewed as the "Decade of Accountability." Accountability has had many different definitions: 1) keeping track of federal and state aid, 2) action taken in response to the agendas of protest groups, e.g. Title IX coordinator to correct gender injustices, 3) compliance with legal mandates 4) offering students more choices such as electives (Tyack, 2005: 151). Many public interests groups advocated for equal educational opportunities. In 1972 President Richard M. Nixon signed an educational amendment known as Title IX of the ESEA. This legislation provided equal resources and opportunities to women. Shortly thereafter in 1975, Public Law 94-142 provided equal opportunity to students with disabilities. This legislation ended the exclusion of students with mental or physical disabilities from public schools (Fraser, 2001:294).

To ensure that federal aid was used for its intended purpose, programs were monitored with their own accounting systems, creating schools with loosely-coupled systems of separate but similar services across many federalaided programs (Tyack \& Hansot, 1982). The system monitored compliance with federal regulations, but it did not ensure that schools performed up to minimum standards. This fostered a minimum competency testing movement.

By the late 1970s into the 1980s, public concerns grew more strident regarding students graduating without knowledge in basic skills. This was addressed through minimum competency-based education and standards (Tyack, 2005: 151). The responsibility fell to individual students. If they did not pass they could be barred from extracurricular activities, not promoted to the next grade level, or restricted from graduation (Massell, 2001). The basic 
skills regimen was multiple-choice and known as minimum competency testing (MCT). Mandated by states or local agencies, MCT was described as:

1. All or almost all students in designated grades take a paperand-pencil tests designed to measure a set of skills deemed essential for future and life work

2. The state or locality has established a passing score or acceptable standard or performance on these tests

3. The state of locality may use test results to a) make decisions about grade-level promotion, high school graduation, or the awarding of diplomas; b) classify students for remedial or other special services; c) allocate certain funds to school districts; or d) evaluate or certify school districts, schools, or teachers (OTA, 1992:57).

There was public support for MCT. By 1980, 29 states had implemented MCT; by 1985 it had risen to 33 states with 11 requiring passing scores as a prerequisite for graduation (OTA, 1982). By the mid 1990s over 20 states required passable scores for graduation (Bishop, Mane, Bishop, \& Moriarty, 2001).

A second main national education reform came in the mid '80s when the Regan Administration issued a federal report termed A Nation at Risk (National Commission on Excellence in Education, 1983). The report, "urged U.S. schools to retain an international competitive edge, seeking a more rigorous, standardized curriculum" (Cooper, Fusareli, \& Randall, 2004:170). Implementing national standards would restructure public schools and target specific money for a specific curriculum. Developing standardized tests based on a standard curriculum meant policy makers could calculate if reform was 
working; it gave parents the choice of moving students elsewhere if schools were failing. This report helped launched school vouchers and supported the growth of charter schools. Reformers believed school accountability and school choice would result in competition and higher educational achievement (Moe \& Chubb, 1990). "The main barrier to more effective schools is the disorganization and lack of incentives and direction in the public school system. The remedy they favored is efficient, customer-oriented service such as that found in the private sector" (Walker, 2003:49). Systematic reform interested national organizations such as the National Science Foundation, which funded a Statewide Systematic Reform Initiative (Walker, 2003). By 1989, President George H.W. Bush was pushing for national goals that states could easily adopt. But it wasn't until the Clinton Administration that the U.S. established national standards.

\section{0-Present}

In 1994 the Goals 2000: Educate America Act (PL 103-227) was passed. It enacted eight broad goals for American schools to be reached by the year 2000. These goals served as a foundation for establishing national standards. Though voluntary, the Goals 2000 Act provided funding to states and localities that developed similar standards.

Through the early 1990s, education policy decisions were made mostly at the state level, holding schools accountable through the use of test scores (Tyack, 2005). There is much debate on how to hold educational practitioners -- primarily administrators and teachers -- responsible for student learning. According to Hess and McGuinn (2002), during the presidential elections of 2000 the public ranked education as the nation's most important issue. It was 
the first time education was thought of as the nation's No.1 problem in the past 40 years.

After winning election, President George W. Bush pushed for a national educational accountability system. Phrases prominent in the Children's Defense Fund like "Leave No Child Behind" became headlines (Marschall \& McKee, 2002). As the former governor of Texas, Bush fostered that state's education accountability system, known as Texas Assessment of Academic Skills (TAAS). It implemented a statewide curriculum with four end-of-course exams. Test results were used to generate school report cards, rating districts and individual school performance, rewarding high-performance schools and districts, and sanctioning low-performance ones (TEA website). Bush used Texas' educational accountability system, with its high-stakes testing, as a model to reauthorize the federal Elementary and Secondary Education Act (ESEA) and create the No Child Left Behind (NCLB) Act. In his State of the Union Address in 2001, Bush addressed issues of accountability and funding for schools. "We must tie funding to higher standards and accountability for results...when the Federal Government spends tax dollars, we must insist on results. Children should be tested on basic reading and math skills every year between grades three and eight. Measuring is the only way to know whether all our children are learning. And I want to know, because I refuse to leave any child behind in America" (2001).

Since the early ' 90 s content- and performance-based standards increased nationwide, essentially doubling, with almost every state establishing such standards and tests (Hurst, Tan, Meek, Sellers, 2003). By the start of the $21^{\text {st }}$ century, 48 states had such accountability systems in place (Goertz, 2001; Linn, 2000). In 2004, 30 states required students to pass 
assessment test to graduate. That was up from the 18 states that required graduation tests in 1996-1997 (Goerts, Duffy, Le Froch, 2001). Such highstakes testing is the centerpiece of NCLB, establishing consequences for poor performance. "High-stakes provide notable consequences for participants. Depending on the results, students may fail to graduate, teachers may lose salary bonuses, and schools may face reconstitution" (Lashway, 2001). According to Title I, Part A, Section 1116 of ESEA, schools are held accountable for student achievement. Schools and districts are given up to five years to meet annual yearly progress (AYP) goals. If they fail, they face drastic restructuring, relying on alternative school governance. AYP is determined at the state level and calculated based on reaching performance goals and standards.

Federal regulations focus on rewarding or sanctioning schools and teachers, not individual students. Student achievement standards are regulated by the state. For example, in 17 states students cannot be promoted to the fifth and ninth grades if they fail to pass the forth- and eightgrade statewide tests (Cortiella, 2004). Also, as referenced previously, a similar number of states require seniors to pass certain statewide tests or endof-course exams before graduating. Federal regulations, however, do reward and sanction teachers. According to NCLB, all teachers must be highly qualified. That means teacher must have: 1) a bachelor's degree, 2) a full state certification or licensure, and 3) proof that they know each subject they teach (US Department of Education, n.d. a). According to then U.S. Secretary of Education Rod Paige, failure to meet the requirements translates into a delay in federal funding until conditions are fully met (National School Boards Association [NSBA], 2004). 
Other aspects of high-stakes achievement are enforced at the local level. Examples include replacing career and technical programs when there is need for additional remediation of students in academic classes that are subject to statewide tests, such as has occurred in states like Virginia.

Though not explicitly spelled out in legislation, teachers face repercussions if a specified portion of their students fail high-stakes exams (Glatthorn \& Fontana, 2000), including shifting such teachers to non-testing classes. On the other side, teachers might get rewarded for high pass rates with incentives such as pay increases, as done in North Carolina. These represent examples, not definitions, of high-stakes accountability in practice. They are illustrative of repercussion and rewards.

Those strongly opposed to NCLB believed the high-stakes system did nothing to help disadvantaged students (Snell, 2001). Two studies looked at the effects of Title I spending: Sustaining Effects in 1984 and Prospects in 1997. Both found a lack of educational achievement in students targeted by Title I funding (Snell, 2001). According to education analyst Wayne Riddle, however, "Title I participants tend to increase their achievement at the same rate as non-disadvantaged pupils, so the gaps in achievement do not significantly change" (Snell, 2001:142). Schools are allowed five consecutive years of failing to meet AYP before they are restructured and reopened under a revised governing system. Some parents believed five years was too long a time to send children to poor-performing schools, and they should have the choice to send them elsewhere at an earlier time (Snell, 2001).

Goals 2000: Educate America Act.

In 1989, then Arkansas Governor William J. Clinton and the nation's governors agreed to set national education goals. At the time they set six 
goals for education by the year 2000. This led to the passage of Goals 2000: Educate America Act of 1994, which set eight broad goals for American schools. The goals, to be reached by the year 2000 , were as followed:

1. All students will start school ready to learn.

2. The high school graduation rate will increase to at least $90 \%$.

3. All students will become competent in challenging subject matter.

4. Teachers will have the knowledge and skills that they need.

5. U.S. students will be first in the world in mathematics and science achievement.

6. Every adult American will be literate.

7. Schools will be safe, disciplined, and free of guns, drugs, and alcohol.

8. Schools will promote parental involvement and participation. (Lashway, 2001, p. 49)

The real agenda of Goals 2000 was to help all Americans reach internationally educational competitive standards (Kean, 1995). The Act had four main components: (1) authorization of the National Education Goals Panel; (2) creation of the federal agency known as the National Education Standards and Improvement Council (NESIC)]; (3) establishment of a statutory grant program; and (4) authorization of award grants for the development of national opportunity-to-learn standards.

The mechanism set up to promote the outcomes planned for Goals 2000 was to require states to develop their own reform plans based on the national standards and then to distribute federal funds to aid in the implementation of those plans. Completed state plans were reviewed by the 
NESIC with comparison to national standards. The National Education Goals Panel then further reviewed the recommendation of the NESIC and either approved or dismissed it (Ravitch, 1995).

Goals 2000 created controversy after its enactment. Troublesome issues included the amount of control that the federal government had in the standards approval process; who was to be responsible for the standards development process; the use of test and other assessments; and school delivery standards, now renamed opportunity-to-learn (OTL) standards. The latter stirred the largest debate with this legislation. The definition of OTL standards was misunderstood; some thought OTL referred to standards that were to be assessed and others thought it referred to everything that a student had an opportunity to learn. The U.S. House of Representatives viewed the OTL standards as a way to force equalization in education and would have required states to document their OTL standards in their school reform plan for NESIC approval. The Senate asked for the same but proposed that states not to be required to submit their plans to the NESIC. The media interpreted OTL standards as the federal government's way to take control local programs. With much debate over the issue of OTL, the final version of Goals 2000 made OTL standards voluntary, in effect encouraging but not requiring state participation (McDonnell, 2004).

Tests and assessments were another issue debated in relation to Goals 2000. Was the adoption of national standards going to lead to a national assessment of these standards? If so, would it be the federal government's responsibility to design and implement a national testing program? After much debate legislators made it clear that Goals 2000 would not create a national examination system. Rather, testing was to be left to the respective states. 
Education policy makers in each state would be responsible for developing their own assessments based on their own individual standards. States were to be left with the option to seek approval from the NESIC to certify their tests, assuring their validity and reliability. Once certified, the tests were not to be used for high-stakes purposes, i.e. graduation retention, for five years. According to Goals 2000, the tests sole purpose were to measure the standards for what students should know and be able to do with no rewards or sanctions attached (Stevenson, 1995).

\section{No Child Left Behind.}

In 2001, Congress passed the reauthorization of ESEA, known as the No Child Left Behind Act (NCLB). The passage of NCLB has made a profound impact on the American education system, reinforcing the culture of accountability. Its goal is to strengthen Title I accountability by demanding student achievement in return for investments.

According to the federal government's Strategic Plan there are six main goals of NCLB legislation:

1. Create a Culture of Achievement.

2. Improve Student Achievement.

3. Develop Safe Schools and Strong Character.

4. Transform Education into an Evidence-based Field.

5. Enhance the Quality of and Access to Postsecondary and Adult Education.

6. Establish Management Excellence.

There are ten titles in NCLB. Title I is the largest, with a main goal of the NCLB act to strengthen Title I accountability (U.S. Department of Education, 2002). A 12-year plan was implemented to raise standards of all 
students through the use of testing in math, reading and science. There is a growth in the amount of federal involvement in individual schools as mandated by NCLB, challenging state and local control. The federal government withholds funds from states unwilling to participate in the national testing effort. The standards measured must have three levels of attainment: failure, proficient, and advanced. Attainment results based on these standards are then tied to a system of rewards and sanctions (PL 107-110: 1146).

As stated in NCLB, there are no federal regulations rewarding or sanctioning students based on student performance on testing. Typically, these are regulated by the states. A third of the 48 states with statewide testing will not let students graduate if they have not passed a certain number of statewide tests or their "end-of-course" exams. There are, however, federal regulations rewarding or sanctioning teachers. According to NCLB, all teachers must be highly qualified. To be highly qualified, a teacher must have: (1) a bachelor's degree, (2) full state certification or licensure, and (3) proof that they know each subject they teach (U.S. Department of Education, nd. a). According to U.S. Secretary of Education Rod Paige, states employing teachers that are not highly qualified will end up in a delay of federal funding until conditions are fully met (National School Boards Association [NSBA], 2004). In 2004, Title 1 authorized $\$ 11.7$ billion in aid earmarked to half of the nation's public schools. The expenditure represents a small percentage of the nation's overall education budget; but it is an amount that school districts serving the needs of the disadvantaged students cannot do without.

The century-old America tradition of having one "education reform movement" followed by yet another "education reform movement" has lead many educators to think that No Child Left Behind was just the first 
educational reform fad of the $21^{\text {st }}$ century. Even if the current emphasis on accountability promulgated by NCLB were to change after the next presidential election or some other major turn of events, it is fairly certain that a highstakes accountability system of standards and assessment will be a prominent part of the educational landscape in the United States for many years to come (Marschall \& McKee, 2001). National opinion polls reveal that Americans are in support of clear standards specifying what students are taught and how they are tested (Hochschild and Scott, 1998; Rose, Gallup, and Elam, 1997; Johnson and Immerwarh, 1994). The prospect of a national leader being seen as supporting "lowering education standards" or "reducing the accountability of schools" is incomprehensible in the current political climate.

\section{Beliefs about testing}

\section{Criticisms of Assessment}

Teachers, students, and parents have argued that there is simply too much testing; and that too much weight is given to such tests when it comes to evaluating student achievement and performance. Ebel (1979), however, noted that most criticism comes from three special interest groups:

1. Professional educators who are uneasy about the accountability with standardized tests and external testing in general.

2. Reformers who regard testing as part of an unsuccessful and outmoded instructional process.

3. Free-lance writers whose best sellers purport to expose scandals in important human institutions (p. 6).

Some basic assumptions that support achievement testing are being researched to make constructive arguments against testing and not just 
personal testimony. For example, Kornhaber and Orfield (2001) addressed beliefs that, "testing will enhance economic productivity, motivate students, and improve teaching and learning" (p. 5). Their studies found that only a weak connection existed between economic productivity and student performance; that tests used as motivational tools had variable results; and that testing did not improve teaching and learning (See Levin, 2001; Madaus \& Clark, 2001; McNeil \& Valenzuela, 2001 for a further read of studies influencing Kornhaber and Orfield).

Critics noted negative impacts related to testing, including: tests controlling the curriculum, false labeling of students as "masters" or "nonmasters", stress placed on students, and biased tests misrepresenting all levels of SES and minorities. Jones, Jones, and Hargrove (2003) noted that opponents believe testing: (a) does not inform the public about school quality; (b) does not provide an accurate measure of accountability; (c) does not provide information about student achievement; and (d) questions the integrity and accuracy of testing. Legitimate questions related to the integrity and accuracy of tests and results include: (a) Why do tests and results differ between the state and federal levels? (b) How valid are these tests? (c) Who sets the standard score of who passes and who fails? NCLB pushes American education more toward a free-market model -- schools either do better or get out of the business. A key concern that has been raised is whether policy makers have been too quick to rely simply on test results to make major decisions?

One impact of high-stakes testing relates to teachers adjusting typical instruction methods and adapting curriculum to focus on the fine points of what is expected to appear on the tests (Corbett \& Wilson, 1991; McNeil, 2000). 
This could lead to a lack of depth in specific subject matter and a failure to allot enough time to go over tested segments (Schmidt, McKnight, \& Raizen, 1996), with the principles found on tests reinforced to keep scores high (Perreault, 2000). Testing changed the make-up of classroom instruction, with more time spent on math, reading, and writing and less time on subjects that are not tested (Jones, Jones, Hardin, Chapman, Yarbrough, \& David 1999).

Testing also alters teaching practices, according to critics. There is a methodological shift from the constructivist student-centered approach to teacher-centered instruction, mainly due to time pressures (Wideen, O'Shea, Pye, \& Ivany, 1997). According to these researchers, this hinders teacher creativity by taking away the "art of teaching." That, in turn, hinders student creativity. Testing typically involves professional development for teachers, suggesting ways to integrate elements that appear on tests into the current curriculum. However, most of this development was found to be cosmetic only, not a deep change in teaching method (Schorr \& Firestone, 2001). Sustaining professional development also can prove costly for school systems and taxpayers.

Another complaint involves how test scores are determined and how are they used. This includes test score inflation. The 1987 "Lake Wobegon Report" (named after radio personality Garrison Keillor's fictional locale where "all children are above average") found that state test scores were regularly higher than the national average (Cannell, 1987). According to Linn (2000), this resulted from a situation where test scores continued to rise until a new test was introduced. Another problem with test scores is test score pollution. This results in a situation where different students, schools, districts, and states take different approaches to prepare for what can be essentially the 
same test, effecting score outcomes. Incorrect scores are also attributed to teacher stress of reaching AYP goals therefore providing inappropriate assistance to students during testing (Shepherd \& Doughtery, 1991).

Some of the negatives associated with testing are expected to have long-term effects. Researchers have found that dropout rates were linked to failing achievement tests (Grison and Shepard, 1989; Clark, Hanley, \& Madaus, 2000; Beatty, Neisser, Trent, \& Heubert, 2001). Retention in a grade level was not construed as a positive term, as in "extra help to ensure passing," but as a negative, as in "flunking." According to Byrnes (1989) and Holmes (1989), such a designation impacted a student's self-esteem. McCollum, Cortez, Maroney, and Montes (1999) also found that retained students did not do better the second time around in the same grade. DarlingHammond (1998) attributed this to repeating the same poor training a second time through a grade. Many school systems instituted promotional gates at specific grade levels, holding back students until they mastered skills tested at that check point. House (1989), however, indicated that this specific retention procedure had no appreciable relevance to overall achievement. This prompted some school systems, such as New York City public schools, to drop such checkpoints in the 1990s. Most school systems, however, reinstituted promotional gates after 2000.

\section{Support for Assessment}

On the other side of the spectrum, many believe testing is needed and is a positive tool providing valuable data on student achievement. According to Jones, Jones, and Hargrove (2003), most proponents say testing is necessary to (a) measure student achievement, (b) provide information about the quality of schools, and (c) hold students and educators accountable (p. 
10). Similar to the atmosphere of the early 1900 s, parents and taxpayers want to make sure public money is well spent and that public schools meet student needs. Standardized testing is viewed as a way to do this. Most states, about $85 \%$ in the year 2000 , test students through norm-referenced multiple-choice tests (Jones, Jones, \& Hargrove, 2003; p.16). This testing is a relatively inexpensive and quick way for legislators, school administrators, and parents to process statistical data about schools and students.

As referenced earlier, some educators believe testing negatively impacts the curriculum and alters instruction from a student-centered approach methodology to a teacher-centered approach. Other teachers, however, believe testing promotes just the opposite. The National Council of Teachers of Mathematics (NCTM) 2000 Standards recommended spending less time practicing skills to make room for conceptual learning. According to Borko and Elliott (1999), in a study conducted on the methodology of math teachers, it was found that teachers were aligning to the NCTM 2000 Standards, spending more time on student-centered conceptual learning.

Testing is viewed by some supporters as a way to enhance teaching. According to Popham (2003), standardized testing helps clarify the curriculum by basing it on content standards, objectives, or goals. It also helps teacher understand prior knowledge among students entering a new course or new unit of instruction. It can assist with designing a teaching calendar, planning out how much instructional time to spend on various units. Finally, it is a tool to measure the effectiveness of teacher instruction. Instead of relying on the often-referenced criticism that teachers are "teaching to the test," Popham (2003) introduced the observation of "teaching towards test-represented 
targets" (p. 27). Testing relates directly to measurable criterion, not the overall goal of instruction.

Testing proponents find fault with the contention that multiple-choice tests do not produce valid results, and that more authentic assessments are needed. They argue that portfolios, while a good way to evaluate student progress and ability over time, are expensive to score and less reliable due to greater subjectivity in grading procedures. Essays and writing rubrics, typically used to assess writing skills in English classes, are a violation of construct validity since they do not measure writing achievement but rather measure compliance to the rubrics themselves (Jones, Jones, \& Hargrove, 2003; p.52). Likewise, science investigations using laboratory exercise are expensive to conduct, expensive to evaluate, and, like portfolios, less reliable due to scoring subjectivity.

\section{Summary of Beliefs}

For every criticism against testing there is a counterpoint for the value of testing. Reasons to justify standardized testing changed over time; however, one underlying theme remains constant: the power testing has in forcing change within American education. Without this power, there would probably not be such controversy. Testing in the classroom has become the dominant measure of school and student accountability. It provides parents with a sense of trust that public schools are properly educating their children. Without testing, responsibility would fall to teacher opinion as to whether the student mastered a specific criterion. Still, this notion is subject to many reliability issues. Testing provides hard evidence that a student is able to perform at a certain level. Test design has evolved so that a specific criterion can be measured. Also, such tests strengthened the legitimacy of curriculum 
and instruction nationwide, providing information needed to move teaching methods forward.

The public is concerned about the use of test scores and decisions based on these scores. Very little was mentioned in the research on test construction methods. Further detailing of how standardized multiple-choice test are designed might allay such concerns. These tests are not sets of randomly written questions. Specific guidelines and procedures are followed in test design. Test companies produced various tests to meet the needs of different educational programs.

\section{Theories of Assessment}

\section{Criterion-Referenced Measurement}

During the 1960s, Glaser (1963) and Popham and Husek (1969) popularized the concept of criterion-reference measurement, later also referred to as objective-based or domain-based measurement. At that time the basic methodology for developing items on a criterion-reference test and a norm-reference test were the same (Glaser, 1963). However, there is a distinction between norm-reference measurement and criterion-reference measurement. Hambleton and Rogers (1991) noted four main differences: (1) test purpose, (2) content specificity, (3) test development, and (4) test score generalizability (p. 8). Norm-referenced testing (NRT) takes students' scores and places them along the normal distribution curve. It compares how students perform on a test relative to other students, commonly referred to as the norm group. While this is suitable for some settings, as students' scores become unequally distributed (i.e. many students score highly on the test), the reliability of the test itself becomes lower. The relative score of how students did compared to other students is the main outcome of NRT. 
Criterion-Referenced Tests (CRT) measure a student's absolute score on an assessment, not the relative score as done with norm-referenced testing, see Figure 2.1. While an ideal NRT frequency curve would be equally distributed among the test scores, see Figure 2.2, that is not common and the scores tend to range around the middle with a wide spread, producing a bellshaped curve. CRT's mastery curve, or j-shaped curve, does not compare examinees to one another but rather measures each examinee individually to determine if the examinee has mastered the specific ability set forth in the criterion. Since many test takers do well in CRT there are more scores clustered near the high end of the distribution curve.

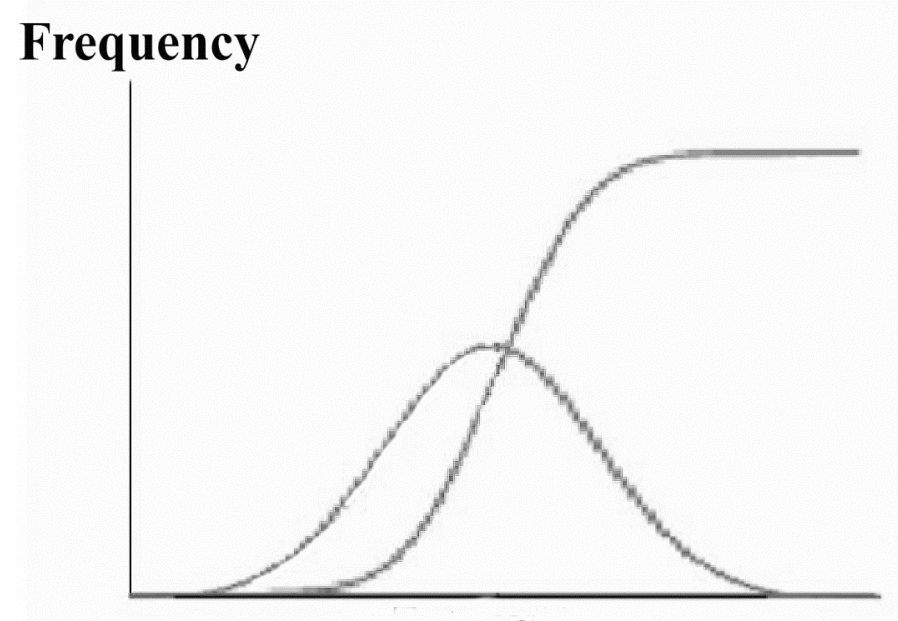

Test Scores

Figure 2.1. Norm-referenced distribution curve vs. criterion-referenced distribution curve 


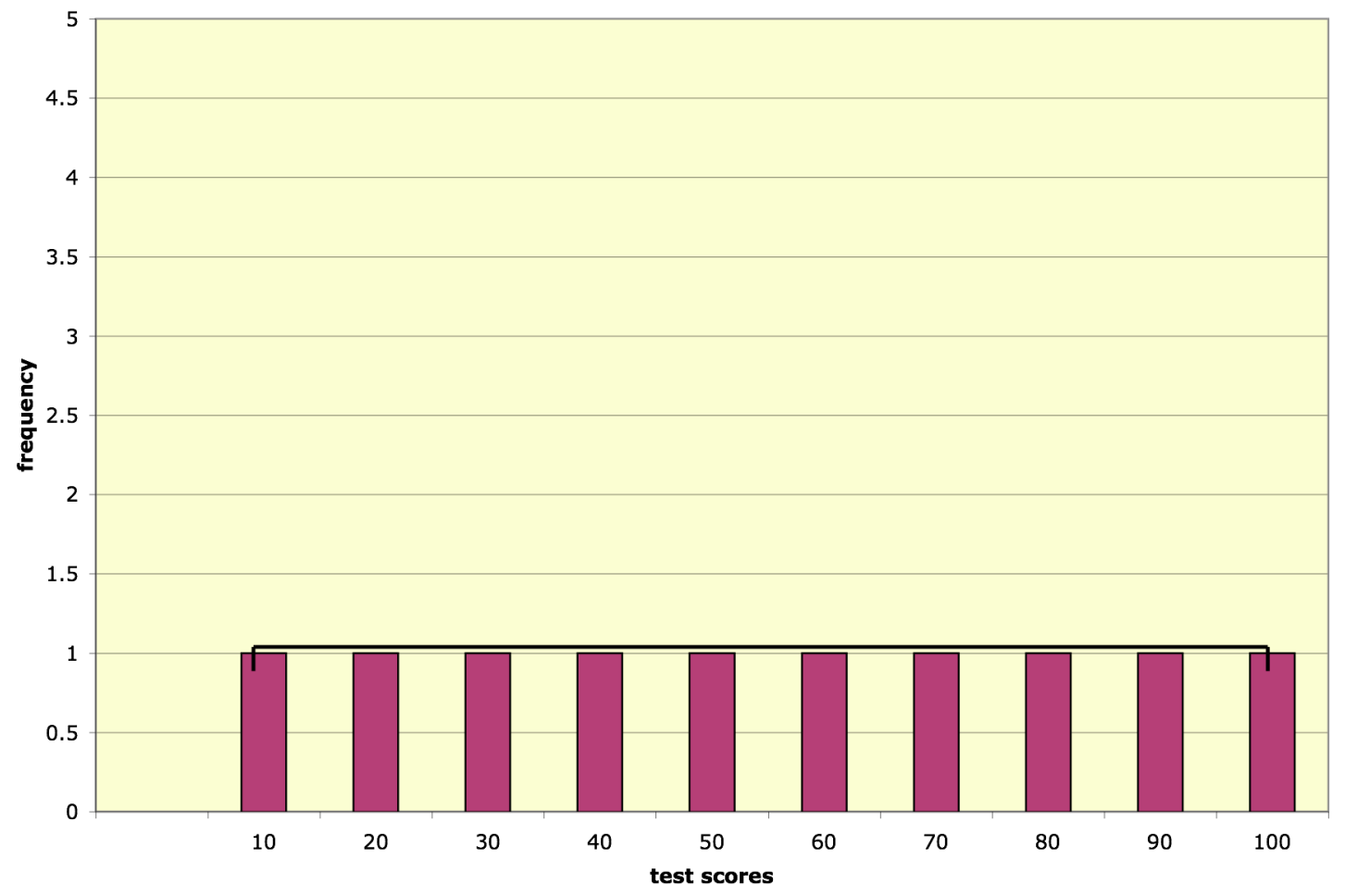

Figure 2.2. Ideal NRT Frequency Distribution

Adapted from Criterion-Referenced test development by S. Shrock and W.

Coscarelli, 2000, p. 24. () International Society for Performance Improvement. Reprinted with permission of the International Society for Performance Improvement, www.ispi.org.

There have been many interpretations of CRT since Glaser introduced the assessment theory in his 1963 article Instructional Technology and the Measurement of Learning Outcomes: Some Questions. Introduced in the era of behaviorist learning theory, a prominent interpretation of CRT was to develop tests closely articulated to relevant behaviors. Glaser (1994) summed up top psychometricians' interpretations of CRT in his 1994 review of the article. Linn (1994) highlighted the links to behaviorist learning theory to 
include the cognitive measure of higher-order thinking skills. "The goal in criterion-referenced measurement is to close the gap between the test and the criterion behaviors and understandings that correspond to the aims of instruction" (p. 14). He emphasized use of cutoff scores in CRT and the use of CRT to distinguish master learners from non-masters of the subject matter; however, he noted that while cutoff scores are beneficial, they are not necessary in CRT. He also stressed the fact that while CRT can provide norm-referenced data, NRT cannot provide criterion-referenced data.

Hambleton (1994) viewed CRT as a form of authentic measurement and performance assessment based on standards. He specified six CRT measurement advances developed from the work of Glaser (1963) and Popham and Husek (1969). Those measurement advances were:

1. Clarification in specifying objectives

2. Progress in item writing and increased emphasis on content validity

3. New approaches for reliability and validity assessment and proficiency estimation

4. Standard-setting methods

5. Increased emphasis on diagnosis, decision making, and criterion-referenced interpretations

6. Improved training of teachers in the area of assessment With these advances, CRT has been adapted and updated, making it a more valuable testing tool.

Hambleton and Rogers (1991) provided further findings on item validity. Unlike NRT, where items are selected at a moderate difficulty level ( $p$-values between .30 and .70), they highlighted calculating item validity through expert 
judgments or a measure of the item's difficulty and discrimination. Hambilton provided examples of test item review forms in Validating the Test Score $(1984,1990)$. These review forms can be altered to meet the needs of various item construction panels.

Millman linked the term criterion to domain, specifying each test item of a certain behavior to a specific domain. Within test design, he emphasized three domains in which test items can be divided: (1) curricular domain, (2) cognitive domain, and (3) criterion domain (Millman \& Greene, 1989). The curricular domain is defined as, "the skills and knowledge intended or developed as a result of deliberate instruction on identifiable curricular content" (p. 336). A test of this type administered after instruction would yield a measurement of the examinee's proficiency within that curriculum domain. The cognitive domain is defined as, "a circumscribed set of cognitive skills usually derived from theory...but not from specific curricula or instruction...test inferences in this domain emphasize examinee status vis-à-vis cognitive skills that underlie or cut across other domains" (p. 337). Tests constructed in the cognitive domain include certification licensing tests that are usually made up of minimum-competency skills essential for adult functioning. The last domain is the criterion domain and is defined as, "the knowledge, skills, and behaviors needed for successful performance in the criterion setting" (p. 337). These types of test could be used to predict the future behavior of the examinee.

According to Popham (1993), confusion surrounding the word criterion in CRT remained prevalent in the field with its association to the word level. Like Millman, he stressed the point that criterion refers to domain of criterion behaviors. This is more commonly referred to as a measurement of a student's ability in a specified criterion behavior. While not necessarily a 
characteristic of CRT, cutoff scores measuring proficiency can be determined from CRT.

There are advantages to using CRT, specifically the benefit that collected data can be compared to NRT. The data acquired through the use of $\mathrm{CRT}$ is more meaningful than that of the NRT cutoff score. According to Popham (1984), if a criterion-referenced examination has two main characteristics, (a) explicit test specifications and (b) congruent test items, then a more accurate interpretation of an examinee's performance can be determined. Other advantages of CRT include assessing competency on a certification exam, program evaluation, and monitoring progress and/or deficiencies of an individual in an objective-based instructional program (Hambleton, Swaminathan, Algina, \& Coulson, 1978).

\section{Developing Criterion-Referenced Tests}

Different psychonometricians specializing in the field of testing and assessment have developed multiple techniques or guidelines to develop criterion-referenced items. The underlying principle prominent in these theories is summed up by the work of Mehrens and Lehmann (1987). They noted three main characteristics of tests that should be identified when developing or choosing a criterion-referenced examination. They are:

1. Test items are free from irrelevant sources of difficulty

2. Content domains are specified and items generated from that domain are representative of the domain being sampled

3. Test is short enough so that it is not time-consuming, yet long enough so that a valid score can be obtained (p. 245)

Guidelines were established to conduct criterion-referenced testing. Glaser (1963) was among the first to discuss the use of CRT in systematic 
instruction. He tied the role of test scores to the adequacy of teacher performance and student performance. Popham (1993) highlighted the work of Glaser and provided a set of guidelines to follow when constructing criterion-referenced measurements. His procedure focuses on two main considerations: (1) test specification and (2) test-item specifications. Test specifications are described as, "rules to be followed in constituting the overall nature of the test." Test-item specifications are, "the rules to be followed in constructing the test items" (Popham, 1993; p. 138).

Similar to Popham, Roid and Haladyna (1982) described a five-step process as ideal for developing CRT. The five steps are: (1) instructional intent, (2) specifying the domain, (3) item development, (4) item review, and (5) test development.

Foley (1973) provided guidance on determining instructional intent based on task analysis procedures. Popham (1975) provided input on the utility of objectives and expanding objectives to include elements of the specified domain.

More recently, Shock and Coscarelli $(1998,2000)$ developed a 13-step systematic model to follow when designing CRT for certification or mastery purposes, as shown in Figure 2.3. While their work focuses on the technical and legal guidelines for corporate training and certification, the process is one that could crossover into developing certification tests in the educational field. By changing step one from analyze job content to analyze curriculum content, their version of the criterion-referenced process for corporate certification is adapted to meet the needs of educational certification. 

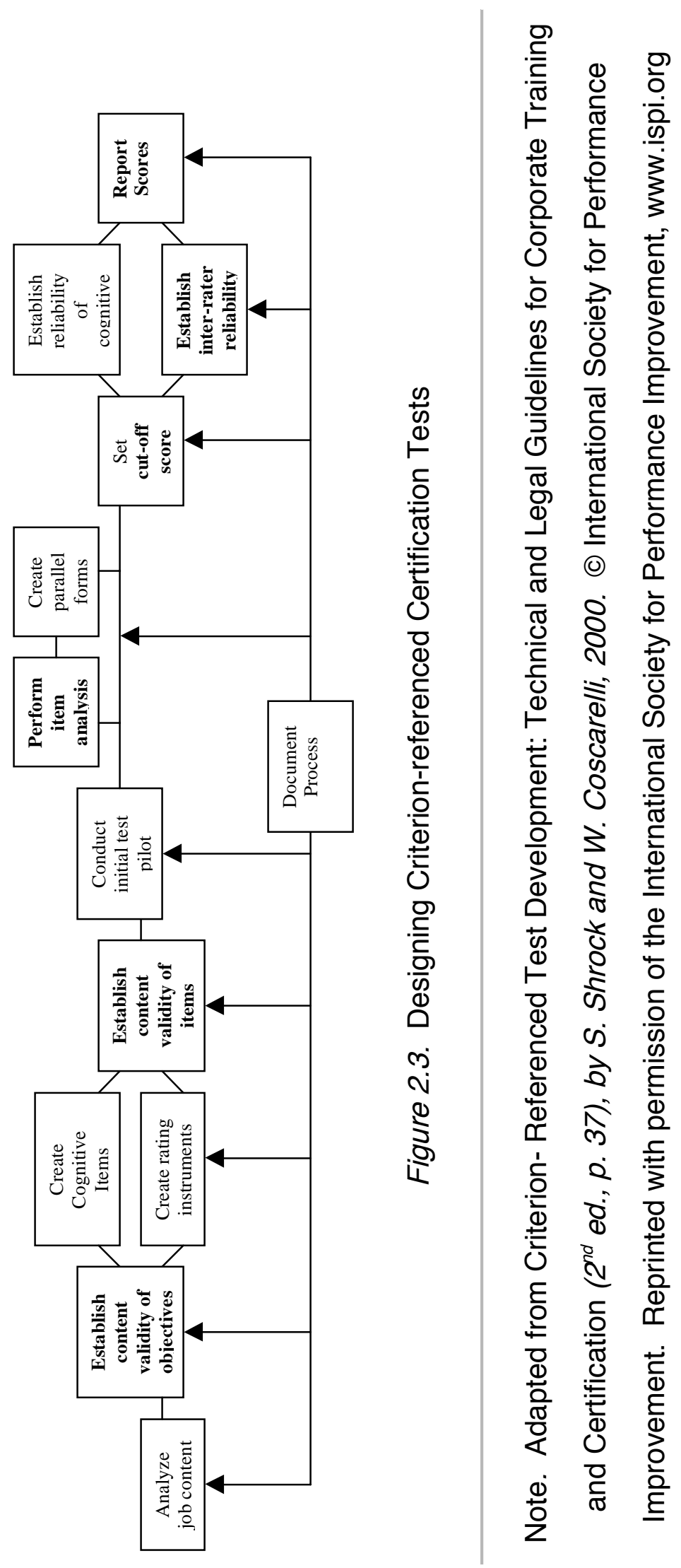


\section{Item Construction}

\section{Generating Criterion-Referenced Test Items}

When designing criterion-referenced measurements, emphasis is placed on the item construction procedure of the test design. When CRT began its popularity in the 1960s, the Instructional Objective Exchange (IOX) specialized in using the objectives-based approach to develop criterionreferenced measurements. They sought the help of two experts in CRT, Wells Hivey at the University of Minnesota and Jason Millman at Cornell University. Hivey had developed the use of item forms as the typical way to specify how to develop a test item (Hivey et al., 1968). These forms, however, were seen as too detailed and not enough item writers would employ the time to use them. Since item forms were too specific for CRT, IOX engaged in the use of amplified objectives. The amplified behavioral objectives were not precise in CRT design and they, too, were not widely used by item writers. IOX found success by delimiting the behavioral objectives and developing test specifications. According to Popham, there were four to five specifications:

1. General Description -- A brief overview of the attribute being measured. This can be anywhere from one sentence to a paragraph long.

2. Sample Items -- An illustrative test item for the test.

3. Stimulus Attributes -- The rules to be followed in constructing the stimulus segments of a test item.

4. Response Attributes -- The rules to be followed in (a) constructing the response segments of a selected-response test item or (b) scoring an examinee's response to a constructedresponse test item. 
5. Supplement (optional) -- Appendix, or supplement employed for tests in which substantial amounts of content need to be identified (p. 139).

These developed the most specific items to measure what a student can or cannot do, but they also proved to be lengthy and time consuming and were not used properly by item writers and teachers.

Aside from the procedural methods to develop test items, theoretical approaches were also explored to develop test items. Guttman (1959), Guttman \& Schlesinger (1967), Castro \& Jordan (1977), and Berk (1978) developed the theory of mapping sentences based on the Structural Facet Theory (Guttman, 1959; Foa, 1968). Mapping Sentences is similar to developing item forms: They are written with variable elements (facets) defining the variations in wording items to create parallel sentences. Unlike item forms that have a formal verification step by a team of experts, mapping sentences uses cluster analysis or small-space analysis to verify items. The mapping sentences technique is primarily used to generate items in the achievement domain. Engle and Martuza (1976) and Berk (1978) developed six steps in creating an item based on facet design using the instructional objective as the basis for mapping sentences. They are as follows: (1) Select an instructional objective, (2) list instructional materials, (3) develop an amplified objective, (4) generate a mapping sentence (See Table 2.1), (5) generate the item facet structure, and (6) write the item. 
With the aid of a soil textural triangle, students will be able to determine if the soil texture is classified as a Facet 1

\{loamy sand
sandy loam
loam
silt loam
silt
sandy clay loam
clay loam
silty clay loam
sandy clay
silty clay
clay\}

based on the percent by weight of Facet 2

\{sand and silt

sand and clay

silt and clay\}.

With the use of facet design to map sentences, an item writer can generate multiple questions systematically based on one instructional objective. In generating multiple-choice test items based on facet design, there is more contiguity among the distractors generated; and the relationship between the distractors and the stem is sounder. There are, however, some limitations in using facet design and sentence mapping to generate test items. One is that it is difficult for test writers to generate items in a certain content area when there is no prior knowledge in that specific area. Another is a lack of agreement among item writers as to their perception of what the facets should be (Roid \& Haladyna, 1982).

Another approach to develop items based on theories of teaching and learning is testing concepts, rules, and principles (Markle \& Tiemann, 1970; 
Tiemann \& Markle, 1983). Tiemann and Markle developed a training package based on three basic ideas:

1. Students must learn to discriminate between examples and non-examples of a concept.

2. Students must generalize from teaching examples to a broader set of examples.

3. Testing the understanding of concepts must include both examples and non-examples different from those used in teaching concepts (Roid and Haladyna, 1982; p. 58).

This technique could be applied to almost any discipline; and training workbooks provide rules and principles to develop proper questions.

The last well-known theory to developing criterion-referenced measurements is the factor-based construction method (Guliford, 1967; Meeker, Meeker \& Roid, 1985). Based of Guliford's (1967) Structure-ofIntellect (SOI) model, 90 cognitive abilities are identified. Items are generated from the subsets of the 90 abilities to measure student ability. Through the use of factor-analysis, criterion-referenced items can be generated. SOI Systems has continued to generate tests based on this method in general education, reading instruction, remedial education, gifted education, training and retraining, career counseling, and math (SOI Systems Structure of Intellect, n.d.).

Even though there have been advances in testing since the origin of $\mathrm{CRT}$, there is still no concrete "rule book" that instructs the item developer on how to generate criterion-referenced measurements. Hambleton and Rogers (1991) noted that there are no guidelines setting the (1) optimal number of items for each objective, (2) common cut-off scores, or (3) level of mastery vs. 
non-mastery. Given this, Hambleton and Rogers stressed specifying content domains for each objective by following the suggestions made by Popham (1984). Each objective should have (1) a description, (2) a sample test item, (3) a content description, and (4) a response description (Hambleton \& Rogers, $1991 ;$ p.8). In a review of the literature on CRT, Hambleton and Rogers (1991) offered the most detailed steps for preparing criterionreferenced tests (See Table 2.2).

Table 2.2 Steps for Preparing Criterion- Referenced Tests

\begin{tabular}{ll}
\hline \multicolumn{1}{c}{ Step } & \multicolumn{1}{c}{ Specific Detail } \\
\hline Considerations & a. Specify purpose of the test. \\
& b. Specify objectives to be measured \\
& by the test. \\
c. Specify groups to be measured, & special testing requirements. \\
d. Make initial decisions about item & formats. \\
e. & Determine time and financial \\
& resources available for test \\
& construction and production. \\
f. Identify and select qualified staff. & g. Specify an initial estimate of test \\
length.
\end{tabular}


Table 2.2 (Continued)

2 Review of Objectives

a. Review the descriptions of the objectives to determine their acceptability.

b. Select final group of objectives to be measured on the test.

c. Prepare item specifications for each objective and review them for completeness, accuracy, clarity, and practicality.

$3 \quad$ Item Writing

a. Draft a sufficient number of the objectives to be measured on the test.

b. Enter items into a computerized item bank.

c. Carry out item editing.

a. Identify a group of judges and validity measurement specialist.

b. Review the test items to determine their match to the objective, their representativeness, and their freedom from bias and stereotyping.

c. Review the test items to determine their technical adequacy. 
Table 2.2 (Continued)

5 Revision of test items

a. Based upon data from $4 \mathrm{~b}$ and $4 \mathrm{c}$, revise test items or delete them.

b. Write additional test items (if needed) and repeat step 4.

6 Field test administration

a. Organize the test items into forms for pilot testing.

b. Administer the test forms to appropriately chosen groups of examinees.

c. Conduct item analysis and item bias studies.

7 Test item revision

a. Using the results from $6 \mathrm{c}$, revise test items when necessary or delete.

$8 \quad$ Test assembly

a. Determine the test length, the number of forms needed, and the number of items per objective.

b. Select test items from available pool of valid test items.

c. Prepare test directions, practice questions, test booklet layout, scoring keys, and answer keys. 
Table 2.2 (Continued)

d. Specify modifications to instructions, medium of presentation or examinee response, and time requirements that may be necessary for special needs examinees.

$9 \quad$ Selection of a standard

a. Determine if description of examinee performance or determination of mastery status is appropriate for test purpose(s). (If descriptions are the primary use, go to step 10.)

b. Initiate a process to determine the standard to separate "masters" from "nonmasters". Alternatively, more than one standard can be set, if needed.

c. Specify considerations that may affect the standard(s) when applied to handicapped examinees.

d. Specify "alternative" test score interpretations for examinees requiring modified administration. 
Table 2.2 (Continued)

10 Pilot test administration

a. Design the test administration to collect score reliability and validity information.

b. Administer the test form(s) to appropriately chosen group of examinees.

c. Identify and evaluate administration modifications to meet individual special needs that may affect reliability and validity of tests.

d. Evaluate the test administration procedures, test items, and score reliability and validity.

e. Make final revisions based on the available technical data.

11 Preparation of Manuals

a. Prepare a test administrator's manual.

b. Prepare a technical manual.

12 Additional technical data

a. Conduct reliability and validity collection investigations. 
Note. Adapted from "Advances in criterion-referenced measurement," by R. Hambleton and H. Rogers, 1991, Advances in Educational and Psychological Testing, pp. 10-11.

\section{Generating the Multiple-choice Item \\ Characteristics of quality of multiple-choice tests.}

Multiple-choice (MC) items were introduced in the Army Alpha Test of 1917. In 1926, the first Scholastic Aptitudes Test (SAT) was administered consisting of MC questions. With the invention of the optical scanner, the use of $\mathrm{MC}$ testing increased due to the quick turnaround time between test administration and a final test score. This led to large-scale assessment programs primarily consisting of $\mathrm{MC}$ formats, which is seen in almost every state today (Rodriguez, 2002).

Multiple-choice testing is a form of selected-response used to measure knowledge. This type of format is regarded as more difficult to develop when compared to constructed-response testing, such as writing an essay question (Haladyna, 1994). However, the ease of test construction is aided with the use of computerized item banks and modern technology. Multiple-choice tests are simple to administer and easier to score with the help of answer overlays or optical scoring machines. There is little need to decipher student penmanship (Coffman, 1971). With the development of item analysis theories and software, results of MC exams are now easier to analyze. Such applications measure the probability of guessing and the reliability of items, among other things.

Validity of MC exams is determined through three main concepts: (1) content sampling, (2) higher level thinking, and (3) recognition versus production (Messick, 1989). In regard to content sampling, in a short period of 
time more test items can be administered, providing a larger sample. In regard to higher-order thinking, $\mathrm{MC}$ testing was once stereotyped as a test format measuring only lower-order thinking, such as recall or facts; however, $\mathrm{MC}$ tests have been proven to measure higher-order thinking if constructed properly (Bennett, Rock, \&Wang, 1990; Haladyna, 1997). Lastly, the issue of recognition versus production is still debated. Some test critics believe the process students go through during MC exams is different from constructedresponse exams (Fiske, 1990; Nickerson, 1989). They argue that picking the right answer is a different process than constructing the right answer. They question whether MC testing produces invalid results, or rather less conclusive results, than constructed-response exams. Bridgemann and Rock's (1992) study on college admittance testing, however, found otherwise; and other studies that compare essay exams and MC tests also show a high correlation between the two as student measurement tools (Bennet, Rock, \& Wang, 1990; Bracht \& Hopkins, 1970; Bridgeman \& Rock, 1993; Heim \& Watts, 1967; Joorabchi \& Chawhan, 1975; Patterson, 1926; Traub \& Fisher, 1977; Traub, 1993; Ward, 1982).

\section{Technology for generating multiple-choice test items.}

There is no one approach to generating $\mathrm{MC}$ items with theoretical underpinnings (Guttman, 1969). Rather, there are numerous guidelines, rules, and recommendations based on empirical studies (Bormuth, 1970). Roid and Haladyna (1982) addressed the need for item writing that connected teaching and testing. Traditionally, item writers heavily influenced characteristics of items (Bormuth, 1970). Roid and Haladyna (1982) provided guidance on methods that were based on the systematic relationship of instruction and evaluation that could be used by all. 
Haladyna and Downing (1989a) analyzed 46 references based on developing $M C$ items. They conducted a second study analyzing 90 research studies pertaining to the validity of item writing rules (Haladyna \& Downing, 1989b). Through their extensive investigation they provided guidance for developing and validating MC items (Haladyna, 1994). Halaydyna (1994, 2004) focused on four aspects of multiple-choice development: (1) foundations for multiple-choice testing, (2) development of multiple-choice items, (3) validity evidence arising from item development and item response validation, and (4) the future of item writing and item response validation (pp. v-vi).

Popham (1990) provided a set of guidelines for creating selectedresponse items related to a practitioner's perspective and focused on the obstacles to good item writing, MC dividends and deficits, and specific MC guidelines:

1. The stem should present a self-contained question or problem.

2. The stem should contain as much of the item's content as possible.

3. If possible, avoid negatively stated stems.

4. Be sure that only one alternative represents the correct or best answer.

5. Each alternative should be grammatically consistent with the item's stem.

6. Avoid creating alternatives whose relative length provides an unintended clue.

7. Make sure all alternatives are plausible. 
8. Randomly use each alternative position for correct answer in approximately equal numbers (pp. 238-243).

Popham (2003) also offered item-writing guidelines for MC items developed from the work of Haladyna (1999) and similar to his previous work. He focused on the advantages and disadvantages of MC items and basic rules of construction for all test writers, not just those whose profession is test writing.

\section{Test Validity}

Validity refers to, "the degree to which evidence and theory support the interpretations of test scores entailed by proposed uses of the test...it is the most fundamental consideration in developing and evaluating tests (AERA, APA, \& NCME, 1999; p. 9). Historically, validity has been approached as a tripartite scheme, categorizing validity evidence into construct, content, and criterion. This was not always the case; and it was updated in 1999. In the first edition of Standards (APA, 1954) there was no criterion validation. Instead, there were two other areas representing criterion validation: (1) predictive and (2) concurrent. This was changed in the second edition of Standards published in 1966 (APA), where validity was referred to as construct, content, and criterion. These three facets of validity were most representative in measurement texts from the 1960s to the 1990s (e.g., Aiken, 1994; Anastasis, 1988; Cronbach, 1990; Ebel \& Frisbie, 1991; Gronlund \& Linn, 1990; Hopkins, Stanley, \& Hopkins, 1990; Mehrens \& Lehmen, 1991; Popham, 1990; Sax, 1989).

Not all practitioners agreed with these three evidences of validity. As far back as 1957, Lovevinger (1957) argued that this scheme (then a four-part scheme) was not logically distinct and the evidences did not have equal 
importance. Based on her research, content, predicative and concurrent validity all support construct validity. For her, the only scientifically sound type of validity was construct validity. Her arguments were not reflected in the pedagogical literature of the time as they were based in the context of science rather than measurement.

Messick (1975) revisited the arguments of validity, emphasizing the centrality of construct validity. He expanded the concept of construct validity to include the social consequences of test use. He emphasized two questions that need to be addressed whenever decisions about testing are made:

First, is the test any good as a measure of the character it is interpreted to assess? Second, should the test be used for the proposed purpose? The first question is a technical and scientific one and may be answered by appraising evidence bearing on the test's psychometric properties, especially construct validity. The second question is an ethical one, and its answer requires an evaluation of the potential consequences of the testing in terms of social values (p. 962).

While the issue of validity gained attention in the educational and psychological measurement field (e.g. Cronbach, 1980; Guion, 1974) it was not reflected shortly thereafter in the 1985 version of Standards (AERA, APA, \& NCME, 1985). Continuing the use of the three-part framework for measurement fields meant the process could not move forward; steps to improve test validity were haltered (Messick, 1989). Cronbach agreed with the work of Messick, recommending similar approaches on the centrality of construct validity and the social consequences of testing. He focused on the functional, political, operational, economical, and exploratorical consequences 
of assessment (Cronbach, 1988). Cronbach $(1988,1989)$ offered advice for assessing the consequences of test uses and interpretations. In his most recent text (1990) he offered some techniques pertinent to construct validity:

1. Inspecting items...

2. Internal correlations...

3. Stability of scores...

4. Administering the test to individual who think aloud...

5. Varying test procedures experimentally...

6. Trying to improve scores...

7. Correlation with practical criteria...

8. Correlation with other tests...

9. Studies of group differences... (pp. 181-182)

In the later edition of Standards (1999) arguments against validity represented by a three-part scheme were partially addressed. That edition referred to types of validity evidence rather than the three distinct types of validity. The traditional nomenclature (i.e. content validity, predictive validity, etc.) was not utilized. Rather, the 1999 Standards focused on evidence based on: test content, response processes, internal structure, relations to other variables, and consequences of testing. It provided standards for integrating the types of validity evidence.

\section{Item Validation}

Writing the test item does not produce an item ready to be tested until it is validated. Hambleton and Rogers (1991) provided three features to focus on when reviewing a CRT item's content: (1) item validities, (2) technical quality, and (3) representativeness (p. 18). While these were for CRT tests, the same rules can be applied to a multiple-choice question, since these types 
of questions can generate a CRT test. These three guidelines were based on expert judgment to, "assess the degree to which the sample of items in the test is representative of some defined domain (Hambleton \& Rogers, 1991; p. 18). Haladyna (1994) offered three main characteristics that pertain to item validation: (1) a review of the test item from item development procedures, (2) an analysis of the statistical study of item responses, and (3) a summary of using item response patterns to study specific problems in testing.

\section{Reviewing Multiple-Choice Items}

It is important for items to go under review to check for flaws. Messick (1989) emphasized the importance of reviews. He noted that all items must be reviewed for factors that would impact the degree of difficulty of the test, or test biases. The importance of evidence gained through review of content is also supported by Standards (AERA, APA, NCME, 1999). Haladyna (1999) emphasized that all items must go under review for content, item writing violations, and grammatical errors. The Standards (AERA, APA, NCME, 1999) lists six standards applied to item development.

According to Haladyna, "the central issue in content review is relevance" (1994; p. 133). Reviewing for relevance is represented as a large number of expert judgments dominating validity studies (Popham, 1993).

Experts are used to ensure that items are relevant to the domain being tested and identifiable in terms of content. In the field, there is not much systematic information informing test developers on how to review items (Messick, 1989). Hambleton (1984b) provided a summary of methods used to validate items. When reviewing items he advised the consideration of three main features: (1) item-objective congruence, or how well the content reflects the domain from which it was derived, (2) technical quality, and (3) bias (p. 207). There have 
been multiple techniques established for reviewing item-objective congruence based on large-scale assessments to small classroom assessments.

Examples of techniques include the use of empirical techniques similar to norm-referenced testing, expert judgment used to calculate the index of itemobjective congruence, a rating of item-objective match on a five-point scale conducted by experts, and the use of a matching task (Hambleton, 1984). [See Rovinelli \& Hambleton, 1977 On the use of content specialist in the assessment of criterion-referenced test item validity for more information on the index of item-objective congruence]. A thorough technical review of each item should also reveal content bias. Hambleton (1994) provided technical review forms and a judges review forms. Berk (1984) provided an item review form used to detect bias when conducting as item analysis.

\section{Analyzing Item Responses}

Once items have been administered to a sample of students, the results of the testing can be analyzed using statistical methods. Traditionally classical test theory procedures have been used to analyze test results. More recently, item response theory (IRT) methods have gained popularity in the testing field, specifically in the use of large standardized testing programs like the SATs. When used properly, IRT methods can produce better statistical analysis of items, allowing more accurate results to be generated.

\section{Classical Test Theory}

Analyzing item response through the use of classical statistics requires various parameters of data to be collected as evidence for the validity of criterion-referenced examinations. Researchers (Crocker \& Algina, 1986) examined these characteristics and categorized them into the following: 
1. Indices that describe the distribution of responses to a single item (i.e. the mean and variance of the item responses),

2. Indices that describe the degree of relationship between responses to the item and some criterion of interest, and

3. Indices that are a function of both item variance and relationship to a criterion (Osterlind, 1989; pp. 273-274).

Common statistics used to describe these parameters include $p$-values, item discrimination, such as point-biserial correlation coefficient, alpha coefficient, and variance. With the use of this data, feedback can be provided to test designers on the validity and reliability of the test, allowing changes as needed.

Lord and Novick (1968) introduced classical theory approaches to the behavioral sciences, noting the differences from application to the physical sciences. They introduced the classical linear model and its application to estimating parameters of the latent trait variables. Some estimates of parameters of the classical model highlighted by Lord and Novick were true score and error variances. True score is a calculation of the measurement error subtracted from the observed score. Measurement error can be reduced during the item construction phase, producing better quality items (Osterlind, 1989).

The proportion correct index, or p-value for dichotomously scored items, is a proportion of the examinees that answered an item correctly. This index represents the level of difficulty based on the particular group of examinees to which the test was administered. The $p$-value is sample dependent and varies when groups of different ability levels are administered the same examination. This can be remedied by sampling from a large and diverse population to get 
representative ability levels. P-values for single items can be calculated and provide evidence of item performance relative to a group of examinees. They can reveal to the test writer the quality of the items and whether the items contain flaws that should be remedied. The $p$-value can also allow the test developer to administer a test with items of the same difficulty level. Item difficulty is determined by looking at the ability levels generated. Gulliksen (1945) concluded on the basis of a theoretical analysis that, "in order to maximize the reliability and variance of a test the items should have high intercorrelations, all items should be of the same difficulty level and the level should be as near 50 percent $[p$-value $=0.5]$ as possible" (p.80). Ebel (1979) determined levels and distribution of difficulty recommending that an ideal multiple-choice item for testing should be around $62.5 \%(p$-value $=0.625)$. Item discrimination is another parameter calculated using classical statistics methods that contributes to an item's reliability. Item discrimination is the relationship between the performance of an item and the ability of the examinee. It is based on the assumption that examinees with higher levels of ability will respond correctly to the items with a higher level of difficulty. This also leads to the assumption that examinees with lower levels of ability will not get the items with higher levels of difficulty correct. If all examinees get the item correct, then the item does not discriminate among examinees, offering no information about the level of discrimination.

Item discrimination can be calculated using three main methods: (1) point-biserial measurement of correlation, (2) biserial estimate of correlation, and (3) phi-coefficients. The point-biserial measurement is the association between a single item and a total test score. Using the point-biserial estimates along with the corresponding $p$-value of items sorted by difficulty allows test 
developers to choose items with a given range of difficulty and discrimination. Point-biserial measurements do have disadvantages when it comes to calculating discrimination indexes. The item being score contributes to the total test score, slightly skewing data. There are computations that can remedy these problems, which are typically used with small data sets needing precise calculations (Allen \& Yen, 2001; Henrysson, 1963; Nunnally \& Bernstein, 1994; Thorndike, 1982).

The biserial estimate of correlation is another statistic used to calculate item discrimination. It is similar to the point-biserial correlation; however, instead of one of the variables being dichotomous, both variables are assumed to be continuous. The biserial range of discrimination is -1 to +1 , better discriminating examinee ability. This method is preferred over pointbiserial correlations when considering items at high difficulty ranges.

The phi coefficient is similar to the biserial estimate ranging from -1 to +1. Its main use is to determine the degree of association between the item and another demographic characteristic of the population (i.e. gender, race). Aside from using the phi coefficient to look at associations between demographics and items, it also can be used with pre- and post-instructed groups. This technique has its flaws based on the fact that it is derived from the Pearson coefficient of correlation and is expressed in a standard score. If $p$-values for two groups are equal, the phi-coefficient will always be +1 .

Classical test theory statistics can also be used to determine values of reliability. Through the use of internal consistency methods such as split halves and item co-variance, estimates of item and test reliability can be determined. When using split-half procedures, items on a single test are split into two parts. Each half is scored separately with examinee and correlation 
coefficients calculated. Since the value underestimates the reliability of the full test, procedures such as the Spearman Brown prophecy formula are used to correct that estimate. Similarly, other split-half methods developed by Rulon (1939) and Guttman (1945) can also be used to estimate reliability of the full test. Cronbach (1951) noted that all these split-half methods produce the same results. However, Brownwell (1933) cautioned users of such methods due to the multiple ways tests could be split into two subsections, resulting in different reliability estimates.

Problems were found with split-half methods to estimate an internal consistency score based on a single sample. Various methods were developed in the 1930s and ' 40 s to surmount the problems associated with previous methods. The three most popular were the Kuder Richardson 20, Cronbach's alpha, and Hoyt's analysis of variance. All three can be used to calculate the coefficient alpha.

The Kuder Richardson- 20 (KR 20) was developed by Kuder and Richardson (1937). It is used solely with dichotomously scored items. The KR 20 formula calculates the variance of each item and then takes the sum of all the variances. This value is then divided by the total variance of the test and subtracted from 1, as seen in Equation 2.1.

$$
K R_{20}=\frac{K}{K-1}\left(1-\frac{\sum p q}{\hat{\sigma}_{x}^{2}}\right)
$$

where: $k=$ the number of items on a test

$$
\begin{aligned}
& \hat{\sigma}_{x}^{2}=\text { total test variance } \\
& p q=\text { variance of item i }
\end{aligned}
$$


Derived from this formula is a simpler formula known as the KR 21. This formula is used under the assumption that all items are of the same level of difficulty. The variances for individual items do not need to be calculated, see Equation 2.2.

$$
K R_{21}=\frac{k}{k-1}\left[1-\frac{\hat{\mu}(k-\widehat{\mu})}{k \hat{\sigma}_{x}^{2}}\right]
$$

where: $k=$ the number of items on a test

$\hat{\sigma}_{x}^{2}=$ total score variance

$\hat{\mu}=$ the mean total score

When using either the KR 20 or the KR 21, when items are not of the same difficulty, it is beneficial to report both results. This is due to the fact that the KR 21 results will produce lower estimates of the coefficient alpha than the KR 20 formula.

The next method to calculate alpha based on item covariance is the formula known as Cronbach's alpha (1951), see Equations 2.3 and 2.4. Equations 2.3 and 2.4 are the same with 2.4 taking the procedure one step further. Unlike the KR 20 and KR 21, Cronbach's alpha formula does not need to be based solely on dichotomously scored items. 


$$
\alpha=\left(\frac{k}{k-1}\right)\left(1-\frac{\sum s_{i}^{2}}{s_{t}^{2}}\right)
$$

where: $k=$ number of items on the test

$$
\begin{aligned}
& s_{i}^{2}=\text { variance of item } \mathrm{i} \\
& s_{t}^{2}=\text { total test variance }
\end{aligned}
$$

As the number of items on a test increases so does the alpha coefficient. If the inter-item correlation is high, Cronbach's alpha will be high. The items are better at measuring the same underlying construct. If the interitem correlation is low, or if running this formula on multi-dimensional data, Cronbach's alpha will be low. To adjust for problems associated with multidimensional data, a factor analysis can be conducted to determine which of the items load highest on the dimension.

$$
\alpha=\frac{k * \bar{r}}{1+(k-1) * \bar{r}}
$$

where: $\mathrm{k}=$ number of items

$$
\bar{r}=\text { inter-item correlation }
$$

The last of the three methods is Hoyt's method (1941). Hoyt developed a method to estimate reliability that provided results identical to calculating the coefficient alpha. Based on the analysis of variance, Hoyt's coefficient is 
displayed in Equation 2.5. Hoyt's coefficient is easily calculated with the aid of statistical software.

$$
\hat{\rho}_{x x^{\prime}}=\frac{M S_{\text {persons }}-M S_{\text {residual }}}{M S_{\text {persons }}}
$$

where: $\mathrm{MS}_{\text {person }}=$ mean square taken from the analysis of variance table $\mathrm{MS}_{\text {residual }}=$ mean square for the residual variance taken from the same table

\section{Item Response Theory}

Multiple-choice item development is a process involving more than just writing test items to measure a certain level of cognition. As part of the process items also must be validated through a review process, checking characteristics such as content, bias, and distracters. Far too often emphasis is given to the developmental stage of item construction and not the validation stage. With the use of statistical calculations, we can measure psychometric principles such as item quality and how it impacts test score reliability. Item performance patterns such as item difficulty, item discrimination, and distractor evaluation can be addressed with both classical test theory (CTT) and item response theory (IRT) models.

Under CTT, item difficulty can be measured through the calculation of $p$-values, the proportion of examinees that answered the item correctly. This measure is highly influenced by the performance level of the sample of test takers. Item discrimination is the product-moment relationship between item and test performance. Guessing does not influence test scores if the test is 
long enough. Evaluating distractors and their relationship to test scores with the use of CTT is rarely done (Wesman, 1971; Millman \& Greene, 1989). The use of CTT has its downfalls in evaluating item performance that can be addressed through the use of IRT.

\section{Advantages of item response theory.}

IRT affords several advantages over CTT when analyzing items to contribute to the reliability of tests:

1. Under IRT, item difficulty, "describes where an item functions along the ability scale" (Baker, 2001: p. 7). When determining the item's difficulty, IRT estimates difficulty without referring to the sample of students responding to the items. With CTT, p-values are calculated based on the sample. Samples including students who are highly trained might produce a test with easy test items ( $p$-value $>.90$ ) and samples with under trained students might produce a very hard test ( $p$-value <.40). IRT allows item difficulty to be estimated in an unbiased way.

2. Item discrimination is the correlation between the item and test performance $(-1.00$ to +1.00$)$. When determining item discrimination IRT employs dichotomous and polytomous scoring models. Discrimination is proportional with the slope of the curve. With item response models test constructors can better differentiate between samples of students with low abilities (below the curve) and high abilities (above the curve). CTT restricts the range of scores underestimating the discrimination index. 
3. Distractor quality can alter the performance on a test item. IRT response models for multiple-choice items allow test writers to identify poor performing items and revise and/or omit them. This provides more statistics summaries then one could obtain by solely using traditional frequency tables (Baker, 2001).

\section{Item response theory basics.}

The aim of IRT is to understand and improve reliability of tests (Wainer, 1989). Reliability is the precision of measurement using the ratio of true and observed score variance, equaling the test's average ability. However, there is fault in this definition due to the fact that reliability is not uniform across the entire range of test scores. For example, students scoring at the high end of the upper level of ability and students scoring at the low end of ability have more variance in their standard error of ability. The scores centered near the mean have less error. Error in this case is not equally distributed among the distribution of scores.

In measuring latent traits, such as ability, item characteristic curves can be modeled for each individual item, showing the item's difficulty and discrimination. While measuring this trait it is necessary to chart a student's ability, this scale can go anywhere from negative infinity to positive infinity with a midpoint of zero and a unit measurement of 1 . For practicality in scale construction, the examples in this paper are limited to a range of -3 to +3 (Baker, 2001).

Examinees in a sample are given a numerical value based on their ability in response to the item. This score is noted by the Greek letter theta, $\theta$, with a corresponding probability that the examinee has the ability to give a 
correct answer, noted $P(\theta)$. Using the logistic function is an equation for the two-parameter model, equation 2.6.

$$
P(\theta)=\frac{1}{1+e^{-L}}=\frac{1}{1+e^{-a(\theta-b)}}
$$

where: $e$ is the constant 2.718

$$
\begin{aligned}
& b=\text { difficulty parameter, }(-3<b<3) \\
& a=\text { discrimination parameter, }(-2.80<a<2.80) \\
& \mathrm{L}=\mathrm{a}(\theta-\mathrm{b}), \text { is the logistic deviate (logit), and } \\
& \theta=\text { ability level }
\end{aligned}
$$

This value is typically small for those with low abilities and large for those with high abilities. A three-parameter model takes into consideration the contribution of guessing. Addition of the guessing parameter improves the fit between item data and the model. Birnbaum (1968) modified this model to take that factor into account. The equation for a three-parameter model is seen in equation 2.7 .

With this information an item characteristic curve (ICC) can be constructed by plotting $P(\theta)$ as a function of ability. As the probability of correct response rests near zero, then that denotes those of low ability. This moves up as a smooth S-shaped curve as you approach those with high ability. Two main characteristics can be determined by using the ICC: (1) the difficulty of an item, and (2) item discrimination. Difficulty can be noted as a location index of the curve, "an easy item functions among the low-ability examinees and a hard item functions among the high-ability examinees" (Baker, 2001:7) (see Figure 2.4). 


$$
P(\theta)=c+(1-c) \frac{1}{1+e^{-a(\theta-b)}}
$$

where: $e$ is the constant 2.718

$$
\begin{aligned}
& b=\text { difficulty parameter, }(-3<b<3) \\
& a=\text { discrimination parameter, }(-2.80<a<2.80) \\
& c=\text { guessing parameter, and } \\
& \theta=\text { ability level }
\end{aligned}
$$

Figure 2.4 shows an item with the same level of discrimination but with three different levels of difficulty. The curve labeled difficulty 1 shows that the probability of a correct response is at a high-level for those with low abilities; therefore, it is an easy test item. The difficulty 2 curve is an item with medium difficulty, evenly distributed along the S-shape line. The line furthest to the right, difficulty 3 , is a hard item, with a low probability of a correct response among high achievers (Baker, 2001).

Discrimination is noted by the slope of the curve around its middle (average ability) and is a description of how well items differentiate between ability levels. It answers the basic question, "To what extent does an item discriminate between those who know the material and those who don't" (Ward, Stoker, Murray-Ward, 1996:58). The steeper the curve is around the average level of ability, the higher level of discrimination. For example, see the curve labeled high level displayed in Figure 2.5. 


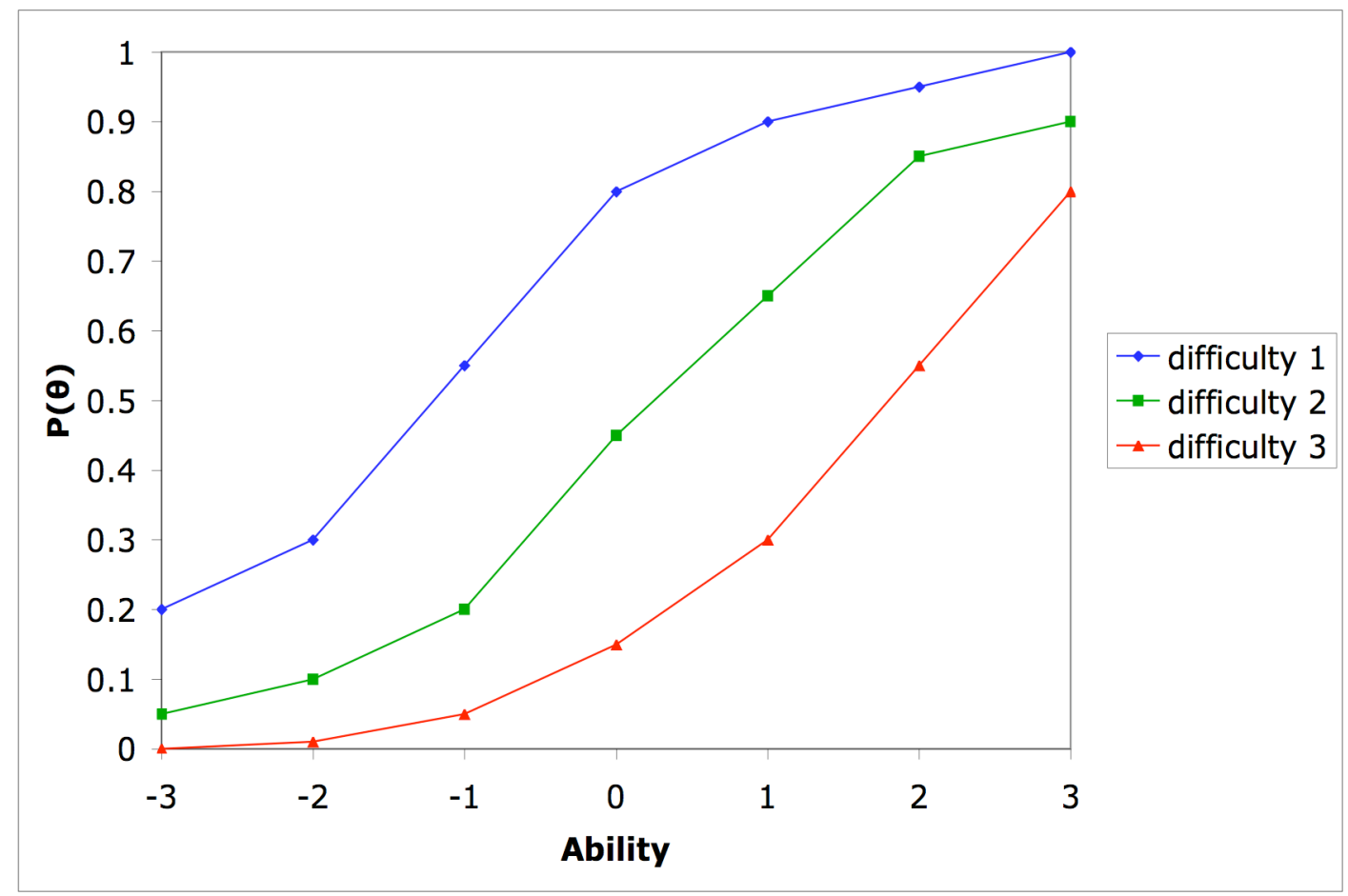

Figure 2.4. Item characteristic curve with three different levels of difficulty and the same discrimination

The flatter curve around the average ability denotes a low level of discrimination. This is the curve labeled low level in Figure 2.5. Therefore, curves that increase more rapidly than others have a higher discrimination level. If negative discrimination occurs, then there is discrepancy among the test item. This shows that it was either a poorly written item or that high-ability students were misinformed about the material generating the item. Item difficulty and item discrimination are independent of one another. 


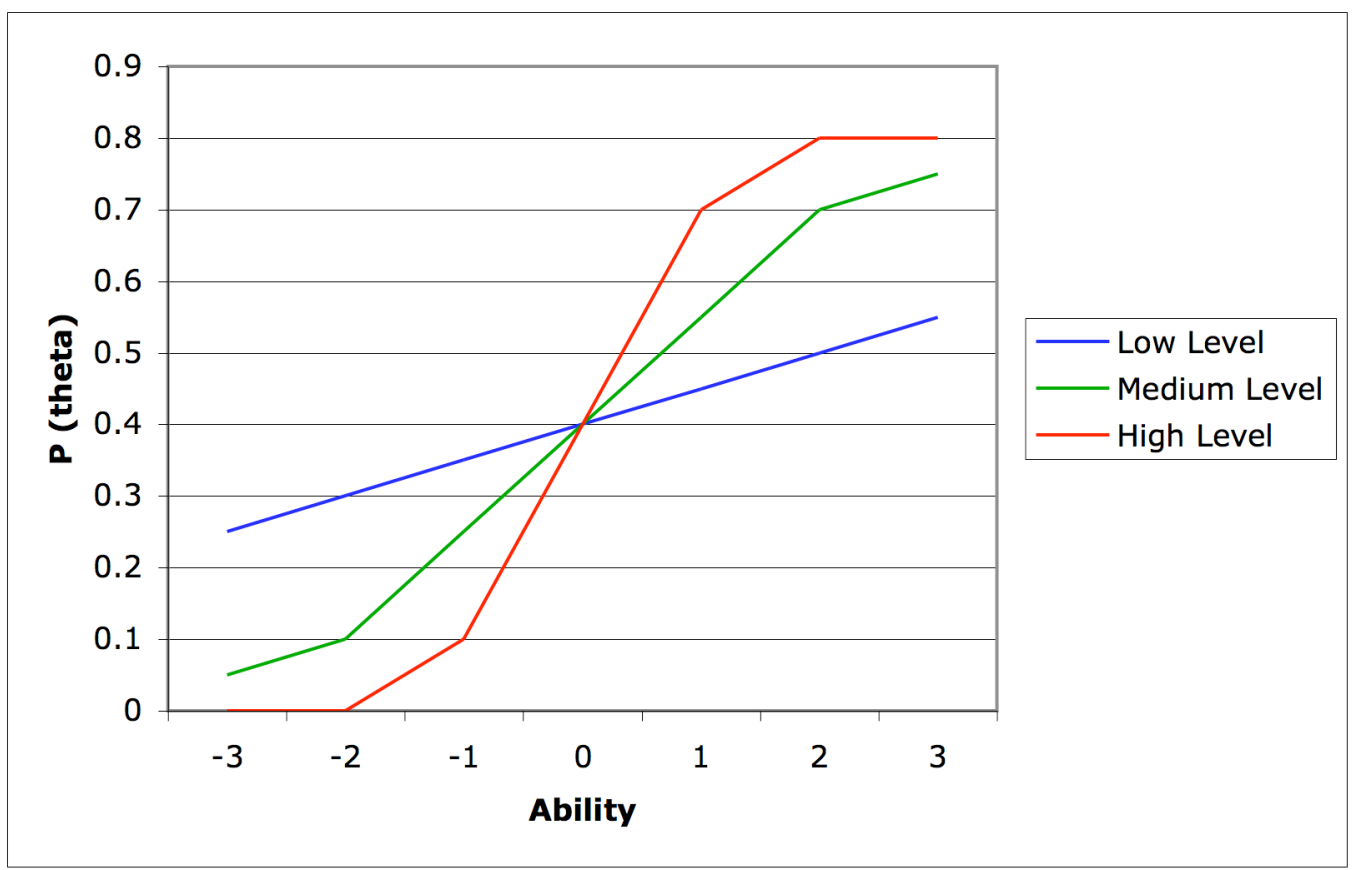

Figure 2.5. Three item characteristic curves with the same difficulty but with different levels of discrimination

When calculating ability scores, Hambleton and Swaminathan (1985) listed four main steps to follow. They are as follows:

1. Data collection -- score examinee responses dichotomously in a table for each examinee on each item.

2. Model selection -- Compare the fit of several models to the test data. Select one of the models for use.

Consideration of model selection is as followed:

a. Should the model be chosen so that it fits the data well or should the data be edited so that the data fit the modeled desired? 
b. Availability of the sample. Over 200 examinees, 2or 3-paramteter model; Less than 200 examinees use 1-parameter model

c. Quality of the data

d. Available resources- cost of the different models, availability of software

3. Parameter estimation -- Obtain item and ability parameter estimates, using one of the common computer programs (e.g. BICAL. LOGIST)

4. Scaling- Transform ability scores to a convenient scale.

With the generation of item response curves, estimation of item parameters can be calculated by a curve-fitting procedure. Calculating maximum-likelihood estimations and/or the chi-square goodness-of-fit of each item characteristic curve model informs the test developer if the model chosen was a good model to fit the data. When calculating a test characteristic curve, information derived from the item characteristic curve model, the number of items, and the value of item parameters are all factors used to calculate examinees' true scores. The formula for a true score is noted in equation 2.8 (Baker, 2001).

The use of item response theory principles can be applied to many different types of models to help increase the reliability of items and tests. Some of the more common models include the normal-ogive model (Lawley, 1943; Ferguson, 1942; Moiser, 1940, 1941), the Rasch or one-parameter logistic model (Rasch, 1960), and Birnbaum's two- and three-parameter 


$$
T S_{j}=\sum_{i=1}^{n} P_{i}\left(\theta_{j}\right)
$$

where: $\mathrm{TS}_{\mathrm{j}}$ is the true score for examinees with ability level $\theta_{\mathrm{j}}$. i denotes an item, and $P_{i}\left(\theta_{j}\right)$ depends upon a particular item characteristic curve model employed

logistic model (Lord \& Novick, 1968). These models have been further developed to include models such as the rating scale model (Rasch, 1961), the graded response model (Samejima, 1969), the partial credit model (Masters, 1988), and multiple-choice models (Thissen \& Steinberg, 1984).

\section{The response model for multiple-choice items.}

When constructing a multiple-choice test, data about item construction and validation is beneficial to make the test more reliable. As part of the test item validation process, reviewing the alternatives or distractors provides test developers information in their analysis of test items. This analysis can help describe the relationship between alternatives and the cognitive proficiency being measured. The use of IRT is helpful in item analysis as it describes this relationship. The original multiple-choice model was derived by Bock (1972), which takes the multivariate logistic transformation of the nominal model to analyze item parameters. This model was further developed by Samejima (1979), which added a latent response category referred to as don't know (DK). Thissen and Steinberg (1984) extended the model further to include trace lines for the incorrect alternatives on the item response model, see 
equation 2.9. The multiple-choice model provides a graphical representation of the performance of each item alternative. This analysis can be used to review distractors, providing information to test constructors when analyzing items.

$$
T_{(u=h)}=\frac{\exp \left[a_{h} \theta+c_{h}\right]}{\sum_{k=h}^{m_{j}} \exp \left[a_{k} \theta+c_{k}\right]}
$$

where: $\mathrm{T}=$ Trace Lines; $\mathrm{T}(\mathrm{u}=\mathrm{h})$ is a hypothetical type of probability $h=1,2, \ldots, m$, where $m$ is the number of $m c$ responses $\mathrm{k}=$ the most correct response $\mathrm{a}=$ slope parameter $\mathrm{C}=$ intercept, relative frequency of the selection of each alternative

\section{Postscript}

Three main topics related to assessment were reviewed in this chapter: theories of assessment, policy issues related to assessment, and legislation impacting assessment practices. A relationship -- sometimes casual, sometimes direct -- exists among these topic areas. Taken together they provide insight as to how high-stakes accountability testing gained its strong foothold on the American educational landscape, and why political and educational leaders consistently turn to such broad-based testing methods to address real and perceived problems in public schools. The rationale for such testing is driven by the American democratic ideal of an equal education for 
all. Such an ideal requires proofs along the way, and accountability testing gives statistical, as opposed to anecdotal, evidences that students are achieving required learning goals. This accountability system is dependent on technological advances in distilling information, and research into test development and test evaluation aimed at ensuring that testing methods provide a true barometer of student and school performance. The cumulative impact of this review indicates that accountability testing is a teaching tool that when applied appropriately generates valuable information, useful in evaluating individual students and broader educational groupings like classes, schools, and districts. The challenge, as it applies to agricultural sciences instruction, is to understand fully the strengths and limitations of accountability testing as such a test protocol is considered for this field. 


\section{CHAPTER 3}

\section{RESEARCH METHODS}

Under New York State Education Department (NYSED) guidelines, a technical assessment system for student achievement, including an objective test, is required for New York State (NYS) Agricultural Science Education. As the state's leading agricultural science teacher education program, Cornell's Department of Education was asked to develop the assessment system. Since NYS's agricultural science education programs are based on local needs, the curriculum offered in local programs varies widely across the state. However, even with such variability, the broad content areas outlined in the Agricultural and Natural Resources (ANR) portion of the Career Pathways model (see Figure 1.1) with the addition of an agricultural safety and an agricultural foundations pathway appear to accurately reflect much of the content of NYS agricultural education programs. Thus, the modified Career Pathways ANR model was selected as the conceptual framework for the objective test portion of the assessment system.

In the spring semester of 2004, the Agricultural Education Assessment Project (AEAP) was initiated to construct that technical assessment system. This study focused on one portion of the AEAP: to construct and validate multiple-choice test items for two of the nine pathways -- plant systems and animal systems. The results of this study are to be incorporated into the larger AEAP project outcomes and the techniques developed in the current study will be used to develop the remaining test item banks for the other career pathways. Developing a complete item pool for all nine content areas was well beyond the scope of this study. 


\section{Purpose and Objectives}

The purpose of this study was to develop, validate, and field test separate banks of test items for the Animal Systems and Plant Systems content areas. The specific objectives of this study were to:

1. Develop an item construction protocol.

2. Organize technical teams of item writers.

3. Write draft items.

4. Validate items through expert judgment.

5. Pilot test items.

6. Analyze items based on statistical measures to provide further evidences of validity and reliability.

\section{Research Design}

\section{Item construction protocol}

To achieve the goal of item construction contributing to evidences of test validity a study involving the nature of criterion-referenced item construction was needed. After extensive literature research, Haladyna's (1994) procedures and suggestions for developing multiple- choice items were selected as the procedural protocols for item development.

\section{Item Writing Panels}

A team of item-writers was assembled consisting of eight content experts for each team. The target representation for each team consisted of three secondary agricultural science educators and one extension agent. Nominations were solicited from Agricultural Education Outreach (AEO) staff, LEAD NY staff, administrators from Cornell Cooperative Extension, and science teacher educators from the Cornell teacher Education (CTE) program. 
Nominees were invited to participate in a two-day tem construction and validation workshop.

\section{Instruction}

The first day began with instruction on identifying the objective or criterion for each domain of the core curriculum outlines, (see appendicies $A$ and B). Once domains for each area were thoroughly identified, participants received instruction on the anatomy of a multiple-choice item and on basic criterion-reference item construction techniques, (see appendix C), based on the work of Haladyna, 1997, 1994; Halaydyna and Downing, 1989a; Roid and Haladyna, 1982; Shrock and Coscarelli, 2000. These researchers provided a set of guidelines to follow when writing multiple-choice items. Four main areas were addressed in the instructions provided: (1) content guidelines, (2) style and format concerns, (3) writing the stem, and (4) writing the options or alternatives. The instructional phase was followed by the item construction phase that went into the second day. The remainder of the second day was used for item validation.

\section{Item Construction}

Participants were advised to bring with them any curriculum material and resources that might assist them in writing items. During the initial item construction phase, the expert panelists were instructed to specify the type of student outcome per item tested: (a) knowledge, (b) mental skill, or (c) mental ability. They were also asked to specify the type of content measured: (a) fact, (b) concept, (c) principle, or (d) procedure. Finally, they were asked to specify what type of behavior the questions were attempting to develop: (a) recall, (b) understanding, (c) critical thinking, or (d) problem solving. An item set 
template, (derived by Haladyna, 1994; p. 69), contained descriptions of these three criteria and the panelist completed a template for each item, (see Appendix C).

\section{Validation}

The remaining section of the workshop focused on item validation. To measure the results of criterion validity and construct validity of these items, mixed methods were used to elicit expert judgment and feedback from the panelists themselves. A Likert-type scale was used to judge each item on the degree to which the item matched the domain it was intended to measure, the type of content and behavior measured, and whether the item needed revision. Each item was reviewed by two panel members, neither of whom was involved in the initial draft of the item. Each item was scored on a Likert-type 5-point scale, with 1 being of poor quality and 5 being of high quality. If a judge rated an item less a 5 , he or she was instructed to indicate the deficiencies of the item and what could be done to revise the item. A copy of the evaluation sheet can be found in Appendix D. After each item was judged twice, each group reconvened and reviewed the items based on the judges' comments. As a group they had the power to alter any items as needed before the items went to an editorial review. Upon completion of the group task the workshop ended and the participants were free to leave.

Once all items were collected, they were sent to a professional test specialist for an editorial review and a final item revision. Items were reviewed based on the following criteria established by Haladyna and Downing (1989b), updated by Haladyna (1994), (see Appendix E). 
Aside from expert judgment, quantitative methods were also used to analyze the validity of items after the items have been piloted. By using classical test theory procedures, evidence was provided about the difficulty of the item and the item discrimination. The frequency of alternatives of each item was calculated and that information was considered in determining whether the questionable items should be revised or omitted based on the evidence derived from the data. The data were also analyzed using item response theory (IRT) models.

\section{Item Pilot}

Once all items were reviewed, the item pools were piloted at different agricultural science programs throughout the state based on their individual curricula- plant systems or animal systems. Examinees consisted of students enrolled in agriculture grades 9-12. Pilot testing took one month with nine different programs participating. The identity of all students participating remained confidential. The only demographics collected were gender and grade level. The scores were not reported back to the teacher and were used only for the purpose of item analysis. The test booklets were collected at the end of each test pilot and the teachers were not allowed to keep or make copies.

\section{Item Analysis}

Analysis and revision of items took approximately two months. Item analysis consists of seven main steps using classical test theory procedures. Item response theory methods were also used to calculate item difficulty, discrimination and guessing parameters. The steps are as follows: Step 1- Code data dichotomously and enter into SPSS and MultiLog 7. 
- Data was coded two ways for analysis- dichotomously with a missing answer being coded independently from the correct and incorrect options and forced dichotomously with a missing response being coded as an incorrect response. All data was entered into SPSS, the application used to calculate descriptive statistics based on CTT.

- $\quad$ IRT- Data was also entered into MultiLog 7 (Thissen, Chen, \& Bock, 1993), an application used to calculate descriptive statistics and graphical representation of the items based on IRT models.

Step 2- Calculate Item Difficulty Index

- $\quad$ CTT- $p$-values calculated using SPSS descriptive statistics option. The $p$-value for each item was calculated by the number of correct response divided by the total number of responses. It was calculated including all the data and then recalculated leaving the missing data out of the equation.

- $\quad$ IRT- fit data to a one-, two-, or three- parameter model depending on which model best fit the data. Used maximum likelihood procedures of test calibration ran on MultiLog 7. Steps 2-4 were done simultaneously.

Step 3- Calculate Item Discrimination Index

- $\quad$ CTT- $r_{p b}$ point-biserial correlation relationship between item and test performance was calculated. This was calculated using the dichotomously scored data for each item and the total test scores of each student. Calculations were done twice-- once 
including all the data and then recalculated leaving the missing data out of the equation

- $\quad$ IRT- Discrimination index was the second parameter calculated based on the two-, or three- parameter model. Used maximum likelihood procedures of test calibration.

Step 4- Calculate Guessing Index

- $\quad$ CTT- guessing was not calculated since the number of test items was large enough.

- IRT- From Step 2, guessing index is the third parameter calculated based on the three- parameter model. Used maximum likelihood procedures of test calibration.

Step 5- Distractor Evaluation

- $\quad$ CTT- Using SPSS frequency tables were generated. Options A, $\mathrm{B}, \mathrm{C}$, and $\mathrm{D}$ were broken down by score groups determining the percent frequency.

- $\quad$ IRT- this step was not done.

Step 6- Item Evaluation

- Using the information derived for each item in the previous steps, items with a low discrimination index were flagged for further review. The $r_{p b}$ for each flagged item was compared to its corresponding $p$-value to see if the two parameters conflicted. This was also done to both sets of data for further comparison.

Step 7- Item Revision

- Based on information determined in the previous steps items were revised or omitted, increasing the quality of items to be included in the item bank. 


\section{CHAPTER 4}

\section{RESULTS}

This chapter presents the outcomes resulting from the study. It begins with a précis of the situation that produced the need for the study. The remainder of this chapter is organized to present the results of each step in that process and the section headings directly correspond to the specific objectives of the study, see Chapter 1 .

\section{Background}

This study makes up one part of a larger project that is being conducted by staff members of the Agricultural Education Outreach program and faculty of the Agricultural Science Education program of the Department of Education at Cornell University. The purpose of the larger project is to develop a content core for the Agricultural Science Education program for New York State (NYS), then to use that core as the basis for development of a statewide assessment system for student achievement. The content core developed prior to the initiation of the current study was based primarily on the Agriculture and Natural Resources Career Clusters Pathways model (Career Clusters, 2006) developed under the auspices of the US Department of Education and promulgated by the National Consortium of Directors of Career and Technical Education. The NYS core content project resulted in a matrix of curriculum content and student competencies organized into nine broad content domains.

The purpose of this study was to develop, validate, and field test separate banks of test items for two of those core content domains: animal systems and plant systems. It is anticipated that the procedures developed for use in the current study will provide the basis for the item pool construction process for the remaining seven content domains. 


\section{Objective 1. Develop an Item Construction Protocol}

After a review of the literature supporting test construction and evaluation, it was determined that criterion referenced test (CRT) methods would be employed rather than norm-reference testing (NRT) procedures. CRT was selected based on the fact that each questions derived from this method is associated with a specific element of content, in our case each test item would be connected to an element of the core curriculum. Tests based on the CRT model are intended to measure student mastery of instructional objectives; students are not compared along a normative curve. Aligning item construction to test use made CRT the ideal choice.

After examining the literature to determine applicable research regarding CRT, it was found that Shock and Coscarelli $(1998,2000)$ provided a viable model with specific protocols to follow when developing CRT items. Five steps of their thirteen-step model were selected to make-up the specific protocol for this study:

1. Create cognitive items.

2. Create rating instruments.

3. Establish content validity of items.

4. Conduct initial pilot tests.

5. Perform item analysis

Additional guidelines for criterion-referenced item construction were adapted from Hambleton and Rogers (1991) and Halaydyna (1994, 2004), and we infused those procedures into the directions provided to test item developers and validators. 


\section{Objective 2. Organize a Technical Team of Item Writers}

The technical team for each content area was designed to include secondary teachers of agricultural education whose programs emphasis the respective content area. It was also decided to include content experts in the respective disciplines from Cornell Cooperative Extension (CCE).

Nominations for secondary teachers and were sought from Agricultural Education Outreach state staff members and nominations for the Extension representatives were sought from the Director and Associate Director of CCE. The target size for each technical writing team was four secondary teachers and two extension educators.

A group of six writers for each area - four agricultural educators and two extension agents - indicated beforehand that they would participate in the two-day item writing workshop. However, at that workshop the two extension agents specializing in animal systems and two of the agricultural educators in the plant systems were not present. To alleviate this problem, one agricultural educator participated in both animal and plant systems since his expertise spanned both disciplines. Two additional members facilitating the workshop participated in the plant systems group as additional item writers and item validators because the group was short agricultural educators. Both had prior experience in plant systems. During the second day of the workshop one extension agent in the plant systems group was not present.

\section{Objective 3. Construct draft items based on core curriculum framework domains.}

Participants spent the first day of the workshop constructing items independently and the second day as a group. For the area of animal 
systems, 110 items were constructed individually, and 92 were constructed as a group. For the area of plant systems, 76 were constructed individually, and 44 were constructed as a group. All items were multiple-choice and each was based on a single content item of the agricultural education core curriculum that had been developed in an earlier phase of the overall project.

\section{Objective 4. Validate items through expert judgment.}

Each item was validated by the item writing team (Appendix E), and a professional test developer (Appendix F). The item writing team validated items for content, quality, and relation to the specific content domain. The test developer corrected all grammatical problems and flagged problematic items for further content review. The test specialist returned15 items in animal systems and 5 items in plant systems for having content issues. Further review was done by agricultural educators at Cornell University. After a thorough review for content, bias, and grammar, and after the pilot test, 192 animal systems questions and 115 plant systems questions remained in the item banks. The other items were omitted due to content problems and low correlations with the total test score.

\section{Objective 5. Pilot Test Items}

Using Atrixware, a test generator software program, two versions of at test for each of the two curriculum areas were generated. Each of the four tests consisted of all the questions remaining in the respective item bank. The animal systems exam consisted of 192 questions and the plant systems consisted of 115 (due to the security of the test, a copy of the exams cannot be included in this text). 
The pilot test student population was chosen based on two criteria: the primary curriculum offered in the agricultural education program included an emphasis in the respective content area and the availability and willingness of the teachers to participate. There was a need to get a diverse representation of students to omit cultural bias. The pilot test group consisted of seven agriculture programs throughout the state with emphasis in animal systems, and a total of 226 students. Four programs with emphasis on plant systems programs participated, consisting of 155 students.

The pilot tests were strictly voluntary. Class schedules ranged from school to school and program to program with some schools on block scheduling and others on a regular schedule. The pilot exams were not timed but in some cases the students were unable to complete them because of class length restrictions. For students with shorter periods, some of the students were directed to start at the end and work backwards on the test. In all cases the exams were proctored by an outside test administrator. Classroom teachers were all present and assisted in assuring discipline within the classroom.

Instructions provided to the students emphasized that they would not receive grades for the examination and that there was no penalty for guessing or for incomplete answers. The participants reported levels of education in agriculture and gender for further analysis. All materials for the test were provided by the test administrator, and the tests were taken without the aid of any external devices, such as calculators or rulers. 
Objective 6. Analyze items for reliability and validity using CTT methods.

The multiple-choice exams were analyzed using both a nominal scale $(A=1, \ldots, D=4)$ for distractor analysis and coded into a dichotomomous scale (with a non-response as an incorrect response) to determine descriptive statistics. Students in the sample for both areas were grouped into advanced (2) -- two or more years in a plant/animal specific agriculture program, or three of more years in a regular agriculture program -- or novice (1) -- first or second year in the specific discipline in a regular agriculture program. Gender was coded as female, 1 , or male, 2 . No information identifying individual students was collected. No other demographical information was collected.

\section{Animal systems}

For detailed student response data for items in the animal systems content area, refer to Figure 4.1, which displays a frequency distribution of the scores. Identification for each student was entered as nominal-level data identifying school and assigning students $(1, \ldots, \infty)$. The score of each student was entered as interval level data with 100 representing a perfect score. Scores ranged from a minimum of 0 to a maximum of 73 with a mean score $(x=28.8)$ and a standard deviation $(\sigma=15.8)$. Data shows that most students scored low on the tests since most students were unable to complete the test in the time allotted.

Three parameters needed in CTT analysis are item reliability, item difficulty, and item discrimination. Cronbach's alpha was calculated using SPSS and the reliability of the 192 items in the animal systems pilot test was 0.971. The proportion correct index, or p-value for dichotomously scored items, is a proportion of the examinees that answered an item correctly. For 
the animal systems pilot item difficulty refer to Table 4.1. The values under the heading $p$-value were calculated including missing values as incorrect values in the computations. The $p$-values ranged from 0.05 to 0.81 . The adjusted $p$-value was calculated to make further comparisons. They exclude the missing values from the computation. They range from 0.05 to 0.85 .

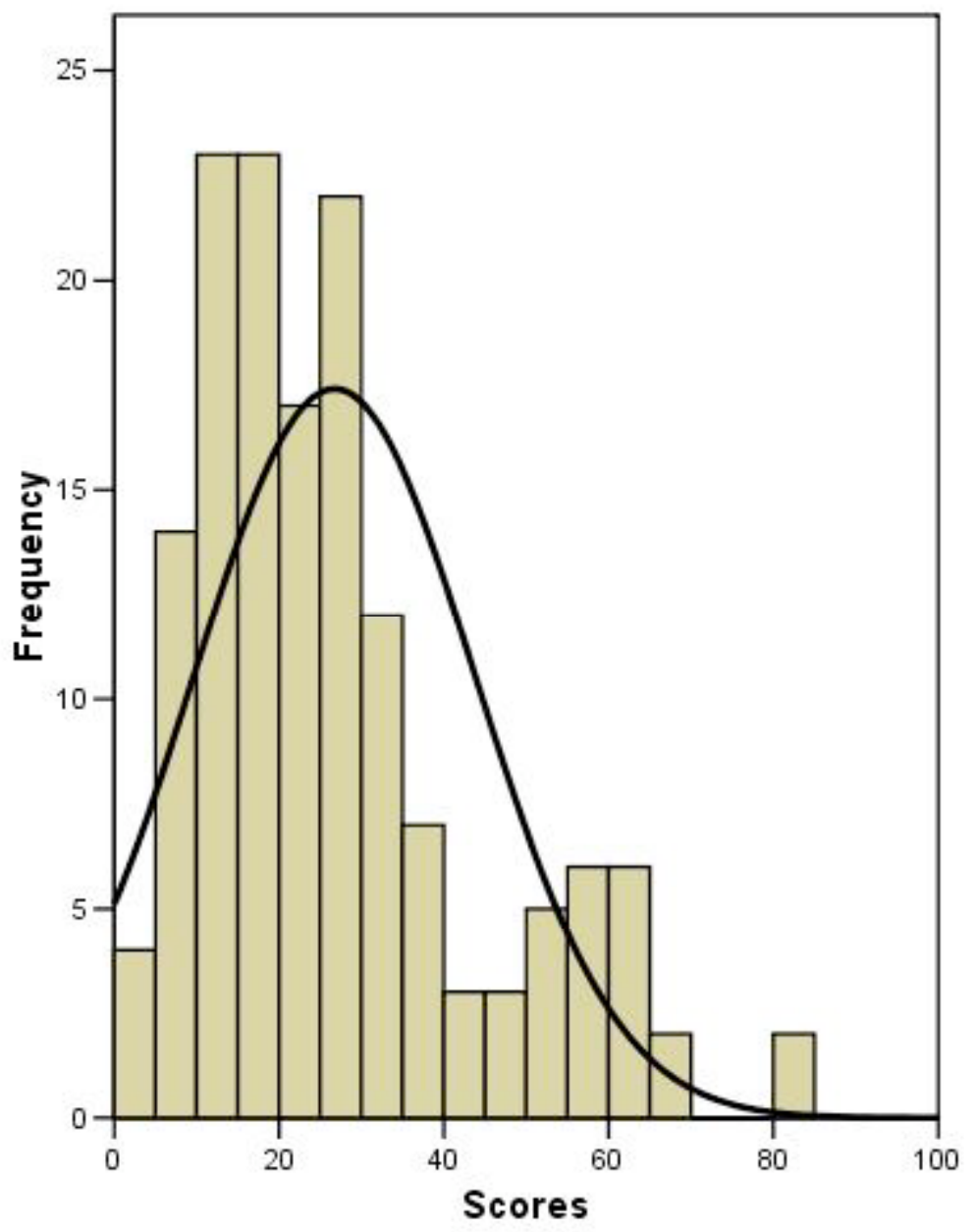

Figure 4.1 Frequency distribution of test scores on animal systems pilot

The item discrimination coefficient for each animal systems item was determined by calculating in SPSS the point-biserial correlation coefficient, see Table 4.1. The point-biserial correlation coefficients were corrected by 
excluding the item score from the total score before computation. Adjusted point-biserial coefficients were also calculated excluding missing data in the calculations. A point-biserial coefficient of 0.15 was the minimum threshold value for retaining an item. Items below this value are highlighted in yellow as items to reevaluate. Twenty-five items were flagged and twenty-two items from the adjusted calculations were flagged. The responses flagged for both the regular calculations and the adjusted calculations varied with items. One method did not prove to be better then other; however, it is valuable to have data calculated both ways to make sure all items that need revision based on a low discrimination index get revised. Further analysis of their difficulty and frequency of their alternatives was done.

Table 4.1: Animal Systems Item Difficulty and Discrimination

\begin{tabular}{cccccc}
\hline Item Number & $p$-value & Discrimination $^{1}$ & $\begin{array}{c}\text { Number of } \\
\text { Responses }\end{array}$ & $\begin{array}{c}\text { Adjusted } p \text { - } \\
\text { value }^{2}\end{array}$ & $\begin{array}{c}\text { Adjusted } \\
\text { Discrimination }^{2}\end{array}$ \\
\hline 1 & 0.218 & .136 & 222 & 0.225 & .090 \\
3 & 0.240 & .082 & 221 & 0.249 & .101 \\
4 & 0.409 & .297 & 221 & 0.421 & .459 \\
5 & 0.551 & .224 & 147 & 0.850 & .591 \\
6 & 0.196 & -.094 & 133 & 0.338 & .271 \\
7 & 0.329 & .170 & 155 & 0.484 & .341 \\
8 & 0.222 & .001 & 188 & 0.271 & .208 \\
9 & 0.222 & .126 & 227 & -0.233 & .043 \\
10 & 0.542 & .230 & 220 & 0.559 & .541 \\
11 & 0.262 & .144 & 132 & 0.455 & .433 \\
12 & 0.107 & -.166 & 180 & 0.139 & .055 \\
\hline${ }^{1}$ Including non-responses in the calculations as incorrect responses. & .608 \\
${ }_{2}^{2}$ Non-responses were assumed to be missing data and excluded from the calculations
\end{tabular}


Table 4.1 (Continued)

\begin{tabular}{|c|c|c|c|c|c|}
\hline 13 & 0.404 & .353 & 224 & 0.411 & .456 \\
\hline 14 & 0.516 & .273 & 150 & 0.780 & .353 \\
\hline 15 & 0.471 & .241 & 141 & 0.759 & .354 \\
\hline 16 & 0.218 & .251 & 129 & 0.388 & .316 \\
\hline 17 & 0.142 & .071 & 143 & 0.231 & .071 \\
\hline 18 & 0.409 & .218 & 131 & 0.710 & .200 \\
\hline 19 & 0.813 & .372 & 222 & 0.829 & .040 \\
\hline 20 & 0.467 & .369 & 135 & 0.785 & .420 \\
\hline 21 & 0.200 & -.015 & 179 & 0.257 & .380 \\
\hline 22 & 0.276 & .240 & 179 & 0.352 & .557 \\
\hline 23 & 0.133 & -.062 & 148 & 0.209 & -.017 \\
\hline 24 & 0.644 & .451 & 202 & 0.723 & .000 \\
\hline 25 & 0.622 & .245 & 217 & 0.650 & .486 \\
\hline 26 & 0.631 & .296 & 220 & 0.650 & -.051 \\
\hline 27 & 0.111 & .041 & 153 & 0.170 & .558 \\
\hline 28 & 0.480 & .210 & 207 & 0.527 & .239 \\
\hline 29 & 0.244 & .213 & 194 & 0.289 & .606 \\
\hline 30 & 0.769 & .330 & 225 & 0.773 & .656 \\
\hline 31 & 0.151 & .136 & 147 & 0.238 & .025 \\
\hline 32 & 0.507 & .484 & 151 & 0.762 & .591 \\
\hline 33 & 0.671 & .307 & 191 & 0.796 & .591 \\
\hline 34 & 0.236 & .030 & 178 & 0.303 & .181 \\
\hline 35 & 0.458 & .325 & 185 & 0.562 & .498 \\
\hline 36 & 0.369 & .338 & 130 & 0.646 & .652 \\
\hline 37 & 0.164 & -.011 & 154 & 0.247 & .353 \\
\hline 38 & 0.413 & .333 & 140 & 0.671 & .032 \\
\hline 39 & 0.258 & .232 & 135 & 0.437 & .549 \\
\hline 40 & 0.591 & .302 & 214 & 0.626 & .503 \\
\hline
\end{tabular}


Table 4.1 (Continued)

\begin{tabular}{|c|c|c|c|c|c|}
\hline 41 & 0.444 & .118 & 196 & 0.515 & -.060 \\
\hline 42 & 0.649 & .419 & 218 & 0.674 & .525 \\
\hline 43 & 0.400 & .150 & 223 & 0.408 & .393 \\
\hline 44 & 0.284 & .126 & 220 & 0.295 & .288 \\
\hline 45 & 0.107 & .153 & 150 & 0.167 & .671 \\
\hline 46 & 0.231 & -.066 & 160 & 0.331 & .279 \\
\hline 47 & 0.711 & .357 & 218 & 0.739 & .374 \\
\hline 48 & 0.547 & .325 & 185 & 0.670 & .184 \\
\hline 49 & 0.320 & .318 & 137 & 0.533 & .395 \\
\hline 50 & 0.298 & .343 & 142 & 0.479 & .569 \\
\hline 51 & 0.218 & .309 & 130 & 0.385 & .089 \\
\hline 52 & 0.520 & .334 & 227 & 0.167 & .146 \\
\hline 53 & 0.431 & .505 & 227 & 0.057 & .582 \\
\hline 54 & 0.222 & .044 & 183 & 0.279 & .190 \\
\hline 55 & 0.644 & .464 & 222 & 0.658 & .203 \\
\hline 56 & 0.280 & .513 & 129 & 0.496 & .492 \\
\hline 57 & 0.147 & .120 & 209 & 0.163 & .549 \\
\hline 58 & 0.787 & .367 & 217 & 0.820 & .193 \\
\hline 59 & 0.364 & .003 & 211 & 0.393 & .016 \\
\hline 60 & 0.133 & .200 & 141 & 0.220 & .016 \\
\hline 61 & 0.289 & .416 & 121 & 0.545 & .290 \\
\hline 62 & 0.142 & -.063 & 122 & 0.270 & .342 \\
\hline 63 & 0.480 & .259 & 200 & 0.545 & .293 \\
\hline 64 & 0.356 & .248 & 202 & 0.401 & .251 \\
\hline 65 & 0.582 & .624 & 213 & 0.620 & .345 \\
\hline 66 & 0.427 & .365 & 187 & 0.519 & .477 \\
\hline 67 & 0.724 & .583 & 209 & 0.785 & .656 \\
\hline 68 & 0.338 & .416 & 133 & 0.579 & .368 \\
\hline
\end{tabular}


Table 4.1 (Continued)

\begin{tabular}{|c|c|c|c|c|c|}
\hline 69 & 0.138 & .313 & 133 & 0.241 & .623 \\
\hline 70 & 0.520 & .522 & 197 & 0.599 & .537 \\
\hline 71 & 0.551 & .466 & 201 & 0.622 & .539 \\
\hline 72 & 0.449 & .313 & 201 & 0.507 & .378 \\
\hline 73 & 0.627 & .545 & 199 & 0.714 & .365 \\
\hline 74 & 0.351 & .294 & 171 & 0.468 & .273 \\
\hline 75 & 0.280 & .297 & 195 & 0.328 & .181 \\
\hline 76 & 0.396 & .544 & 120 & 0.750 & .206 \\
\hline 77 & 0.636 & .601 & 197 & 0.731 & .437 \\
\hline 78 & 0.373 & .706 & 126 & 0.675 & .443 \\
\hline 79 & 0.342 & .602 & 106 & 0.736 & .244 \\
\hline 80 & 0.280 & .159 & 192 & 0.333 & .518 \\
\hline 81 & 0.320 & .514 & 160 & 0.456 & .470 \\
\hline 82 & 0.191 & .099 & 183 & 0.240 & .351 \\
\hline 83 & 0.658 & .652 & 185 & 0.805 & .365 \\
\hline 84 & 0.173 & .304 & 113 & 0.354 & .201 \\
\hline 85 & 0.342 & .510 & 146 & 0.534 & .305 \\
\hline 86 & 0.142 & .170 & 133 & 0.248 & -.001 \\
\hline 87 & 0.351 & .394 & 166 & 0.482 & -.042 \\
\hline 88 & 0.396 & .361 & 189 & 0.476 & .328 \\
\hline 89 & 0.609 & .608 & 191 & 0.723 & .422 \\
\hline 90 & 0.293 & .684 & 99 & 0.677 & .697 \\
\hline 91 & 0.236 & .387 & 108 & 0.500 & .347 \\
\hline 92 & 0.133 & .357 & 109 & 0.284 & .289 \\
\hline 93 & 0.204 & .395 & 100 & 0.470 & .599 \\
\hline 94 & 0.542 & .560 & 182 & 0.676 & .274 \\
\hline 95 & 0.293 & .638 & 94 & 0.713 & .472 \\
\hline 96 & 0.058 & .140 & 93 & 0.151 & .106 \\
\hline
\end{tabular}


Table 4.1 (Continued)

$\begin{array}{cccccc}97 & 0.253 & .324 & 174 & 0.333 & .439 \\ 98 & 0.347 & .622 & 139 & 0.568 & .631 \\ 99 & 0.627 & .657 & 185 & 0.768 & .450 \\ 100 & 0.213 & .506 & 100 & 0.490 & .440 \\ 101 & 0.129 & .430 & 99 & 0.303 & .453 \\ 102 & 0.182 & .253 & 150 & 0.280 & .324 \\ 103 & 0.222 & .601 & 98 & 0.520 & .477 \\ 104 & 0.373 & .549 & 142 & 0.599 & .364 \\ 105 & 0.249 & .579 & 97 & 0.588 & .326 \\ 106 & 0.173 & .600 & 79 & 0.506 & .514 \\ 107 & 0.067 & .000 & 152 & 0.105 & .170 \\ 108 & 0.120 & .403 & 92 & 0.304 & .442 \\ 109 & 0.307 & .587 & 164 & 0.427 & .447 \\ 110 & 0.164 & .550 & 85 & 0.447 & .571 \\ 111 & 0.093 & .422 & 81 & 0.272 & .531 \\ 112 & 0.258 & .541 & 96 & 0.615 & .373 \\ 113 & 0.329 & .599 & 157 & 0.478 & .588 \\ 114 & 0.222 & .329 & 116 & 0.440 & .171 \\ 115 & 0.204 & .260 & 166 & 0.283 & .298 \\ 116 & 0.391 & .561 & 163 & 0.546 & .300 \\ 117 & 0.209 & .363 & 166 & 0.289 & .612 \\ 118 & 0.169 & .533 & 72 & 0.542 & .508 \\ 119 & 0.449 & .516 & 161 & 0.634 & .106 \\ 120 & 0.284 & .488 & 148 & 0.439 & .333 \\ 121 & 0.080 & .243 & 71 & 0.268 & .387 \\ 122 & 0.182 & .432 & 123 & 0.341 & .422 \\ 123 & 0.204 & .322 & 154 & 0.305 & -.058 \\ 124 & 0.173 & .599 & 68 & 0.588 & .484\end{array}$


Table 4.1 (Continued)

$\begin{array}{llllll}125 & 0.293 & .494 & 129 & 0.519 & .282 \\ 126 & 0.107 & .543 & 85 & 0.294 & .193 \\ 127 & 0.147 & .465 & 77 & 0.442 & .532 \\ 128 & 0.387 & .556 & 151 & 0.583 & .693 \\ 129 & 0.311 & .439 & 156 & 0.455 & .138 \\ 130 & 0.160 & .658 & 73 & 0.507 & .629 \\ 131 & 0.129 & .274 & 133 & 0.226 & .329 \\ 132 & 0.138 & .607 & 63 & 0.508 & .416 \\ 133 & 0.053 & .507 & 36 & 0.361 & .378 \\ 134 & 0.129 & .366 & 61 & 0.492 & .294 \\ 135 & 0.191 & .544 & 84 & 0.524 & .521 \\ 136 & 0.138 & .533 & 62 & 0.516 & .354 \\ 137 & 0.178 & .341 & 146 & 0.281 & .404 \\ 138 & 0.062 & .155 & 111 & 0.135 & .373 \\ 139 & 0.120 & .344 & 143 & 0.196 & .128 \\ 140 & 0.120 & .524 & 58 & 0.483 & .583 \\ 141 & 0.116 & .145 & 150 & 0.180 & .548 \\ 142 & 0.347 & .690 & 126 & 0.627 & .768 \\ 143 & 0.200 & .707 & 74 & 0.622 & .671 \\ 144 & 0.111 & .361 & 84 & 0.310 & .234 \\ 145 & 0.111 & .368 & 113 & 0.230 & .593 \\ 146 & 0.187 & .538 & 127 & 0.339 & .482 \\ 147 & 0.311 & .253 & 142 & 0.500 & .025 \\ 148 & 0.209 & .641 & 88 & 0.545 & .666 \\ 149 & 0.209 & .615 & 77 & 0.623 & .415 \\ 150 & 0.160 & .484 & 76 & 0.487 & .467 \\ 151 & 0.418 & .611 & 146 & 0.651 & .582 \\ 152 & 0.298 & .631 & 119 & 0.571 & .482\end{array}$


Table 4.1 (Continued)

$\begin{array}{llllll}153 & 0.160 & .606 & 63 & 0.587 & .503 \\ 154 & 0.298 & .705 & 100 & 0.680 & .651 \\ 155 & 0.409 & .627 & 138 & 0.674 & .715 \\ 156 & 0.156 & .545 & 72 & 0.500 & .509 \\ 157 & 0.533 & .636 & 143 & 0.846 & .498 \\ 158 & 0.093 & .479 & 65 & 0.338 & .677 \\ 159 & 0.302 & .507 & 116 & 0.595 & .456 \\ 160 & 0.236 & .604 & 80 & 0.675 & .561 \\ 161 & 0.213 & .670 & 96 & 0.510 & .680 \\ 162 & 0.173 & .710 & 69 & 0.580 & .711 \\ 163 & 0.187 & .354 & 141 & 0.305 & .557 \\ 164 & 0.258 & .406 & 139 & 0.424 & .390 \\ 165 & 0.351 & .561 & 142 & 0.563 & .489 \\ 166 & 0.178 & .727 & 61 & 0.672 & .768 \\ 167 & 0.156 & .417 & 132 & 0.273 & .234 \\ 168 & 0.111 & .492 & 50 & 0.520 & .419 \\ 169 & 0.191 & .638 & 75 & 0.587 & .380 \\ 170 & 0.080 & .504 & 50 & 0.380 & .580 \\ 171 & 0.076 & .290 & 77 & 0.234 & .090 \\ 172 & 0.289 & .468 & 139 & 0.475 & .334 \\ 173 & 0.076 & .378 & 52 & 0.346 & .231 \\ 174 & 0.116 & .613 & 48 & 0.563 & .482 \\ 175 & 0.196 & .403 & 109 & 0.413 & .502 \\ 176 & 0.062 & .322 & 48 & 0.313 & .187 \\ 177 & 0.191 & .349 & 123 & 0.358 & .484 \\ 178 & 0.102 & .484 & 68 & 0.353 & .616 \\ 179 & 0.098 & .478 & 55 & 0.418 & .508 \\ 180 & 0.129 & .525 & 63 & 0.476 & .436\end{array}$


Table 4.1 (Continued)

$\begin{array}{llllll}181 & 0.200 & .560 & 87 & 0.529 & .572 \\ 182 & 0.160 & .691 & 58 & 0.638 & .768 \\ 183 & 0.187 & .601 & 64 & 0.672 & .562 \\ 184 & 0.191 & .624 & 62 & 0.710 & .508 \\ 185 & 0.356 & .522 & 135 & 0.600 & .345 \\ 186 & 0.089 & .413 & 67 & 0.313 & .605 \\ 187 & 0.284 & .597 & 115 & 0.565 & .517 \\ 188 & 0.360 & .657 & 102 & 0.804 & .521 \\ 189 & 0.164 & .567 & 78 & 0.487 & .244 \\ 190 & 0.071 & .187 & 122 & 0.139 & .208 \\ 191 & 0.089 & .479 & 50 & 0.420 & .395 \\ 192 & 0.262 & .570 & 140 & 0.429 & .554\end{array}$

There were fewer items flagged in the adjusted calculations; however not many and there were some similarities between the two. For the items that were flagged in the regular calculations and were not flagged in the adjusted, there was a high amount of missing data taken into consideration. The items in the adjusted calculations that were flagged either displayed similarities to the regular calculations or contained a high amount of incorrect responses.

For the purposes of this study, it is important to view how each question fared by reviewing the frequency of alternatives. The frequency of the alternatives of each individual question was calculated; see Table 4.2 as an example. 


\section{Table 4.2 Animal Systems- Frequency of Alternatives}

\begin{tabular}{lccccc}
\hline Question 3 & & Frequency & Percent & Valid Percent & $\begin{array}{c}\text { Cumulative } \\
\text { Percent }\end{array}$ \\
\hline Valid & A & 89 & 39.4 & 40.5 & 40.5 \\
& B & 11 & 4.9 & 5.0 & 45.5 \\
& C & 26 & 11.5 & 11.8 & 57.3 \\
& D & 92 & 40.7 & 41.8 & 99.1 \\
& E & 2 & .9 & .9 & 100.0 \\
& Total & 220 & 97.3 & 100.0 & \\
Missing & -1 & 6 & 2.7 & & \\
Total & & 226 & 100.0 & &
\end{tabular}

The highlighted portion displays the correct alternative. The frequency is the number of students who chose that alternative. The percent is the percentage of students who chose that alternative. The valid percent are those who chose an alternative omitting those who left the choice blank. This was taken into consideration when analyzing results of the corrected data because there was no negative repercussion given to students who were unable to complete the exam or to those who skipped questions of difficulty to answer the questions of which they were sure within the time frame allotted.

Of the 25 items that were flagged due to low point-biserial coefficients, 22 contained extremely low $(p<0.25) p$-values indicating the items were of high difficulty. When analyzing the frequency of distractors for these 25 items the correct alternative for 21 of the items was not the choice most frequently chosen by the test takers. All 25 items were flagged for further review of content and wording with specific attention to those with the high p-values and low point-biserial coefficients. 
Of the 22 items from the corrected point-biserial calculations that were flagged due to low point-biserial coefficients, 10 contained extremely low pvalues indicating the items were of high difficulty. When analyzing the frequency of distractors for these 22 items the correct alternative for 12 of the items was not the choice most frequently chosen by the test takers. All 22 items were flagged for further review of content and wording with specific attention to those with the high p-values and low point-biserial coefficients.

When comparing data between the calculations done including all the missing responses and the calculations done excluding missing responses, there were 8 items that were similar. All items were kept in the review since time was a limiting factor in the results and it is uncertain how much of the variation to attribute to this factor.

\section{Plant systems}

For detailed student response data for items in the plant systems content area refer to Figure 4.2, which displays a frequency distribution of the scores. Identification for each student was entered as nominal-level data identifying school and assigning students $(1, \ldots, \infty)$. The score of each student was entered as interval level data with 100 representing a perfect score. Scores ranged from a minimum of 3.5 to a maximum of 83.5 with a mean score $(x=26.7)$ and a standard deviation $(\sigma=17.1)$. Most students scored low on the plant systems test because they were unable to complete the test in the time available based on class schedules. 


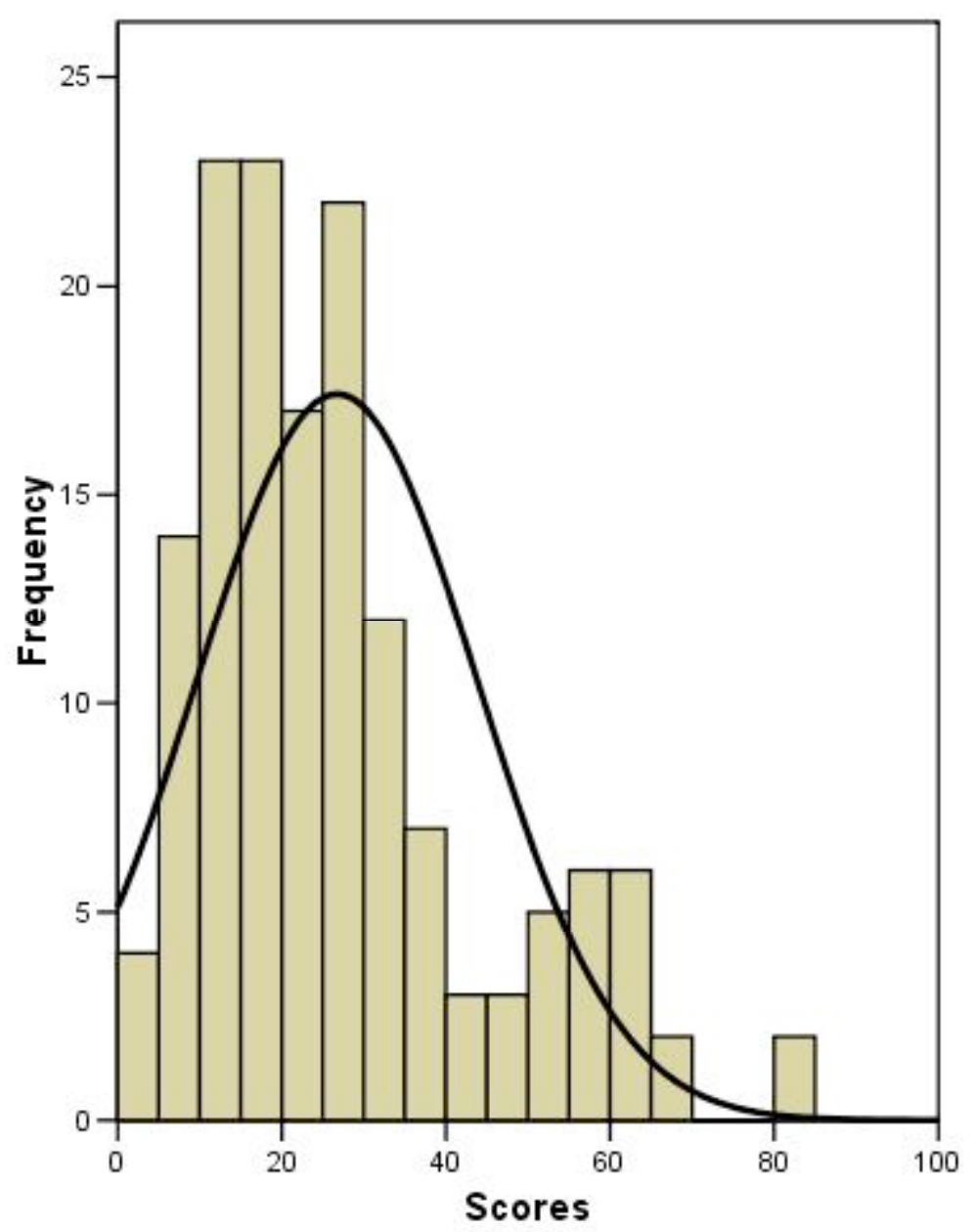

Figure 4.2 Frequency distribution of test scores on plant systems pilot

Three parameters needed in CTT item analysis are item reliability, item difficulty, and item discrimination. Cronbach's alpha was calculated using SPSS 12 and the reliability of the 115 items in the plant systems pilot test was 0.952. The proportion correct index, or p-value for dichotomously scored items, is a proportion of the examinees that answered an item correctly. For the plant systems pilot item difficulty refer to Table 4.3. The values under the heading $p$-value were calculated including missing values as incorrect values in the computations. The $p$-values ranged from 0.06 to 0.62 . The $p$-values do not reflect those students who did not finish due to lack of time. They include 
missing values as incorrect values in the computations. The adjusted $p$-value was calculated to make further comparisons. They exclude the missing values from the computation. They range from 0.09 to 0.74 .

Item discrimination coefficients for the plant systems items were determined by calculating in SPSS the point-biserial correlation coefficient, see Table 4.3. The point-biserial correlation coefficients were corrected to exclude the respective item scores from the total score before computation. Adjusted point-biserial coefficients were also calculated excluding missing data in the calculations. A point-biserial coefficient of 0.15 was the minimum threshold value to retain the items. These items are highlighted in yellow as items to reevaluate. One method did not prove to be better then other; however, it is valuable to have data calculated both ways to make sure all items that need revision based on a low discrimination index get revised. Nine items from the regular calculations and twenty-five items from the adjusted calculations were flagged. Further analysis of their difficulty and frequency of their alternatives was indicated.

Table 4.3 Plant Systems Item Difficulty and Discrimination

\begin{tabular}{|c|c|c|c|c|c|}
\hline $\begin{array}{c}\text { Item } \\
\text { Number }\end{array}$ & $p$-value ${ }^{3}$ & Discrimination $^{3}$ & $\begin{array}{l}\text { Number of } \\
\text { responses }\end{array}$ & $\begin{array}{c}\text { Adjusted } p- \\
\text { value }^{4}\end{array}$ & $\begin{array}{c}\text { Adjusted } \\
\text { Discrimination }^{4} \\
\end{array}$ \\
\hline 1 & 0.27 & .229 & 127 & 0.323 & .288 \\
\hline 2 & 0.33 & .370 & 98 & 0.500 & .346 \\
\hline 3 & 0.36 & .372 & 101 & 0.535 & .231 \\
\hline 4 & 0.29 & .329 & 111 & 0.387 & .164 \\
\hline 5 & 0.60 & .335 & 122 & 0.738 & .269 \\
\hline
\end{tabular}


Table 4.3 (Continued)

\begin{tabular}{|c|c|c|c|c|c|}
\hline 6 & 0.43 & .461 & 124 & 0.524 & .543 \\
\hline 7 & 0.26 & .280 & 126 & 0.310 & .212 \\
\hline 8 & 0.15 & .097 & 110 & 0.209 & .104 \\
\hline 9 & 0.20 & .168 & 125 & 0.240 & .137 \\
\hline 10 & 0.26 & .338 & 124 & 0.315 & .460 \\
\hline 11 & 0.25 & .518 & 115 & 0.330 & .540 \\
\hline 12 & 0.40 & .274 & 122 & 0.492 & .380 \\
\hline 13 & 0.41 & .236 & 126 & 0.492 & .381 \\
\hline 14 & 0.31 & .408 & 108 & 0.426 & .172 \\
\hline 15 & 0.47 & .471 & 102 & 0.686 & .486 \\
\hline 16 & 0.32 & .439 & 101 & 0.475 & .218 \\
\hline 17 & 0.31 & .369 & 124 & 0.379 & .208 \\
\hline 18 & 0.47 & .419 & 131 & 0.542 & .568 \\
\hline 19 & 0.19 & .264 & 124 & 0.226 & .156 \\
\hline 20 & 0.20 & .109 & 127 & 0.236 & .040 \\
\hline 21 & 0.24 & -.006 & 121 & 0.298 & -.255 \\
\hline 22 & 0.29 & .489 & 120 & 0.358 & .468 \\
\hline 23 & 0.23 & .039 & 117 & 0.291 & -.317 \\
\hline 24 & 0.31 & .443 & 98 & 0.480 & .137 \\
\hline 25 & 0.23 & .410 & 121 & 0.281 & .325 \\
\hline 26 & 0.43 & .481 & 119 & 0.546 & .463 \\
\hline 27 & 0.41 & .344 & 121 & 0.512 & .300 \\
\hline 28 & 0.21 & .363 & 109 & 0.294 & .462 \\
\hline 29 & 0.23 & .082 & 127 & 0.268 & .120 \\
\hline 30 & 0.23 & .491 & 105 & 0.324 & .345 \\
\hline
\end{tabular}


Table 4.3 (Continued)

\begin{tabular}{|c|c|c|c|c|c|}
\hline 31 & 0.16 & .271 & 106 & 0.226 & .070 \\
\hline 32 & 0.41 & .517 & 114 & 0.544 & .557 \\
\hline 33 & 0.19 & .170 & 132 & 0.212 & .426 \\
\hline 34 & 0.36 & .178 & 115 & 0.470 & .136 \\
\hline 35 & 0.43 & .302 & 137 & 0.474 & .526 \\
\hline 36 & 0.31 & .350 & 105 & 0.438 & .356 \\
\hline 37 & 0.35 & .246 & 136 & 0.382 & .316 \\
\hline 38 & 0.30 & .597 & 102 & 0.441 & .538 \\
\hline 39 & 0.21 & .413 & 102 & 0.304 & .483 \\
\hline 40 & 0.22 & .146 & 119 & 0.277 & -.021 \\
\hline 41 & 0.20 & .276 & 107 & 0.280 & .311 \\
\hline 42 & 0.07 & .332 & 124 & 0.282 & .168 \\
\hline 43 & 0.21 & .322 & 109 & 0.284 & .209 \\
\hline 44 & 0.62 & .260 & 132 & 0.705 & .342 \\
\hline 45 & 0.29 & .360 & 102 & 0.431 & .417 \\
\hline 46 & 0.13 & .029 & 102 & 0.186 & -.428 \\
\hline 47 & 0.26 & .301 & 129 & 0.302 & .339 \\
\hline 48 & 0.31 & .171 & 132 & 0.356 & .055 \\
\hline 49 & 0.27 & .374 & 117 & 0.350 & .357 \\
\hline 50 & 0.28 & .508 & 103 & 0.408 & .210 \\
\hline 51 & 0.50 & .440 & 124 & 0.605 & .487 \\
\hline 52 & 0.41 & .576 & 100 & 0.620 & .723 \\
\hline 53 & 0.21 & .279 & 93 & 0.333 & .141 \\
\hline 54 & 0.27 & .504 & 106 & 0.377 & .510 \\
\hline 55 & 0.27 & .401 & 93 & 0.430 & .308 \\
\hline
\end{tabular}


Table 4.3 (Continued)

\begin{tabular}{|c|c|c|c|c|c|}
\hline 56 & 0.38 & .571 & 93 & 0.613 & .541 \\
\hline 57 & 0.17 & .210 & 116 & 0.224 & .052 \\
\hline 58 & 0.33 & .394 & 102 & 0.490 & .295 \\
\hline 59 & 0.21 & .413 & 112 & 0.277 & .356 \\
\hline 60 & 0.21 & .388 & 95 & 0.326 & .218 \\
\hline 61 & 0.35 & .471 & 108 & 0.481 & .335 \\
\hline 62 & 0.23 & .467 & 90 & 0.389 & .274 \\
\hline 63 & 0.24 & .482 & 89 & 0.146 & -.349 \\
\hline 64 & 0.19 & .155 & 93 & 0.301 & -.203 \\
\hline 65 & 0.26 & .465 & 109 & 0.358 & .353 \\
\hline 66 & 0.33 & .457 & 99 & 0.505 & .436 \\
\hline 67 & 0.31 & .669 & 86 & 0.535 & .677 \\
\hline 68 & 0.18 & .288 & 87 & 0.310 & .056 \\
\hline 69 & 0.19 & .371 & 106 & 0.264 & .357 \\
\hline 70 & 0.31 & .550 & 91 & 0.516 & .458 \\
\hline 71 & 0.09 & .114 & 83 & 0.157 & -.153 \\
\hline 72 & 0.23 & .432 & 110 & 0.309 & .452 \\
\hline 73 & 0.34 & .356 & 108 & 0.472 & .175 \\
\hline 74 & 0.24 & .469 & 105 & 0.343 & .335 \\
\hline 75 & 0.26 & .463 & 99 & 0.394 & .508 \\
\hline 76 & 0.29 & .624 & 85 & 0.518 & .548 \\
\hline 77 & 0.25 & .575 & 101 & 0.376 & .593 \\
\hline 78 & 0.15 & .380 & 85 & 0.259 & .219 \\
\hline 79 & 0.15 & .443 & 90 & 0.256 & .306 \\
\hline 80 & 0.13 & .091 & 100 & 0.200 & .098 \\
\hline
\end{tabular}


Table 4.3 (Continued)

\begin{tabular}{|c|c|c|c|c|c|}
\hline 81 & 0.23 & .622 & 70 & 0.500 & .514 \\
\hline 82 & 0.25 & .355 & 100 & 0.370 & .199 \\
\hline 83 & 0.15 & .350 & 70 & 0.314 & -.076 \\
\hline 84 & 0.17 & .342 & 90 & 0.289 & .368 \\
\hline 85 & 0.21 & .235 & 92 & 0.348 & .005 \\
\hline 86 & 0.17 & .158 & 95 & 0.274 & -.074 \\
\hline 87 & 0.13 & .161 & 67 & 0.284 & -.189 \\
\hline 88 & 0.32 & .442 & 92 & 0.522 & .319 \\
\hline 89 & 0.21 & .384 & 90 & 0.356 & .389 \\
\hline 90 & 0.18 & .287 & 96 & 0.281 & 240 \\
\hline 91 & 0.06 & -.049 & 93 & 0.097 & -.290 \\
\hline 92 & 0.24 & .502 & 87 & 0.414 & .296 \\
\hline 93 & 0.15 & .396 & 65 & 0.338 & .138 \\
\hline 94 & 0.25 & .499 & 75 & 0.507 & .514 \\
\hline 95 & 0.35 & .518 & 87 & 0.609 & .468 \\
\hline 96 & 0.36 & .478 & 89 & 0.607 & .347 \\
\hline 97 & 0.38 & .482 & 92 & 0.620 & .525 \\
\hline 98 & 0.27 & .701 & 65 & 0.615 & .384 \\
\hline 99 & 0.31 & .416 & 92 & 0.500 & .471 \\
\hline 100 & 0.19 & .220 & 96 & 0.302 & .348 \\
\hline 101 & 0.31 & .533 & 91 & 0.505 & .567 \\
\hline 102 & 0.25 & .451 & 89 & 0.416 & .463 \\
\hline 103 & 0.17 & .498 & 80 & 0.313 & .266 \\
\hline 104 & 0.09 & .332 & 63 & 0.222 & .127 \\
\hline 105 & 0.23 & .623 & 73 & 0.479 & .512 \\
\hline
\end{tabular}


Table 4.3 (Continued)

\begin{tabular}{llllll}
\hline 106 & 0.23 & .576 & 90 & 0.378 & .444 \\
107 & 0.19 & .596 & 66 & 0.439 & .513 \\
108 & 0.42 & .365 & 90 & 0.700 & .216 \\
109 & 0.16 & .344 & 78 & 0.308 & .096 \\
110 & 0.16 & .416 & 79 & 0.304 & .413 \\
111 & 0.35 & .572 & 94 & 0.564 & .460 \\
112 & 0.15 & .145 & 77 & 0.286 & -.166 \\
113 & 0.30 & .417 & 90 & 0.500 & .502 \\
114 & 0.24 & .625 & 85 & 0.424 & .491 \\
115 & 0.15 & .407 & 93 & 0.237 & .517
\end{tabular}

Similar to the animal systems results, there were fewer items flagged in the adjusted calculations; however not many and there were some similarities between the two. For the items that were flagged in the regular calculations and were not flagged in the adjusted, there was a high amount of missing data taken into consideration. The items in the adjusted calculations that were flagged either displayed similarities to the regular calculations or contained a high amount of incorrect responses.

For the purposes of this study, it is important to view how each question fared by reviewing the frequency of alternatives. The frequency of student responses to each of the alternatives of each individual question were calculated, see Table 4.4 as an example.

The highlighted portion displays the correct alternative. The frequency is the number of students who chose that alternative. The percent is the percentage of students who chose that alternative. The valid percent are 
those who chose an alternative omitting those who left the choice blank. This was used in the adjusted point-biserial calculations. This was taken into consideration when analyzing results because there was no negative repercussion given to students who were unable to complete the exam or to those who skipped questions of difficulty to answer the questions of which they were sure within the time frame allotted.

Table 4.4 Plant Systems - Frequency of Alternatives

\begin{tabular}{lcc|c|c|c}
\hline \multicolumn{2}{c}{ Question 2 } & Frequency & Percent & $\begin{array}{c}\text { Valid } \\
\text { Percent }\end{array}$ & Cumulative Percent \\
\hline Valid & A & 15 & 10.0 & 15.2 & 15.2 \\
& B & 19 & 12.7 & 19.2 & 34.3 \\
& C & 50 & 33.3 & 50.5 & 84.8 \\
& D & 15 & 10.0 & 15.2 & 100.0 \\
& Total & 99 & 66.0 & 100.0 & \\
Missing & -1 & 51 & 34.0 & & \\
Total & & 150 & 100.0 & &
\end{tabular}

Of the nine items that were flagged due to low point-biserial coefficients, all contained extremely low $(p<0.25) p$-values indicating the items were of high difficulty. When analyzing the frequency of distractors for these nine items the correct alternative for all the items was not the choice most frequently chosen by the test takers. Of the twenty-five items that were flagged from the adjusted calculations, nine contained extremely low $(p<0.25) p$-values indicating the items were of high difficulty. When analyzing the frequency of distractors for these twenty-five items the correct alternative eighteen of the items was not the choice most frequently chosen by the test takers. These nine items plus the twenty-five adjusted items were flagged for further review. 
Objective 7. Analyze items for reliability and validity using IRT methods.

All data was coded and entered into MULTILOG 7 . It was determined a priori that the multiple-choice model to analyze item distractors would be employed for further analysis of data. Upon further analysis of the data, it was determined that the sample size was too small. This further caused the run of the data to respond in error and the IRT results were found inconclusive. 


\section{CHAPTER 5}

\section{SUMMARY AND DISCUSSION}

This chapter restates the research process and reviews the major methods used in the study. The major sections offer summaries of the results and discussions on their implications. Also provided are recommendations along with suggestions for further research related to the study as it applies to the field of agricultural education.

\section{Review of Problem and Objectives}

\section{Problem}

NYS agricultural science education programs are based on local needs. Therefore, no single approved statewide curriculum exists for agricultural science. The result of that situation is that local programs differ widely from one school to another. The seven pathways outlined in the Agriculture, Food, and Natural Resources portion of the Career Clusters Pathways model (2006) with the addition of agricultural foundations and agricultural safety pathways was determined to represent the range of content being delivered in NYS agricultural science education programs. Complicating the lack of a statewide curriculum in agricultural science is the situation that no national standards or competency assessment systems currently exist which are appropriate for that range of content.

New York State Education Department policies promote the use of a technical assessment system for student achievement. Yet developing a valid and reliable technical assessment system is beyond the resources and ability of most local teachers. Therefore, there is a need for a useable technical assessment system appropriate for NYS agricultural science education students. It should include both performance and content components. The 
content component should provide objective measurements of the core content domains and should include item banks reflective of the wide range of content offered in NYS agricultural science education programs.

\section{Purpose and Objectives}

An objective content test requires a bank of test items, but no test item bank exists to measure student achievement in the content areas specific to New York State agricultural science education. Developing a complete item pool for all nine content areas was beyond the scope of this study. Therefore, the purpose of this study was to develop, validate, and field test separate banks of test items for both the Animal Systems and Plant Systems content areas. The specific objectives of this study included:

1. Develop an item construction protocol based on criterionreferenced testing.

2. Organize technical teams of item writers.

3. Write draft items based on core curriculum framework domains.

4. Validate items through expert judgment.

5. Pilot test items.

6. Use classical test theory to analyze items based on statistical measures to provide further evidences of validity and reliability.

7. Use item response theory to analyze items based on statistical measures to provide further evidences of validity and reliability.

\section{Review of the Research Design}

The research design for this study followed the seven main objectives indicated in the Purpose and Objectives portion of this chapter. The procedure protocol for item development follows Shock and Coscarelli (1998, 2000) for developing criterion-referenced items and Haladyna's (2004) 
procedures and suggestions for developing multiple-choice items. Teams of experts were assembled for each of the two content areas- 4 panelists for animal systems and 4 for plant systems. The items were constructed and validated by the panels and edited by a test item specialist. Agricultural science education students throughout New York State piloted the item pools. Classical test theory methods were used to establish item difficulty, item discrimination, and frequency analysis and results were used to revise items.

\section{Item Analysis Summary}

Of the 192 animal systems items that were piloted, 25 items were flagged for having low point-biserial (discrimination) coefficients $(<0.15)$.

Of the 25 items that were flagged due to low point-biserial coefficients, 22 contained extremely low $(p<0.25) p$-values, indicating that fewer than $25 \%$ of the test takers indicated correct responses. When analyzing the frequency of distractors for these 25 items the correct alternative for 21 of them was not the most frequent choice of the test takers. All 25 items were flagged for further review of content and wording, with specific attention to those with the high $p$ values and low point-biserial coefficients.

Of the 115 plant systems items that were piloted, nine items were flagged for having low point-biserial coefficients $(<0.15)$. Of the nine items that were flagged due to low point-biserial coefficients, all contained extremely low $(p<0.25) p$-values, indicating that fewer than $25 \%$ of the test takers indicated correct responses. When analyzing the frequency of distractors for these nine items, the correct alternative for all the items was not the choice most frequently chosen by the test takers. These nine items were flagged for further review. 
The further review of the items allowed the test developers to revise items rather than just omitting the items from the test bank. In some cases the frequency of the distractors indicated that there were similarities between the correct alternative and one or more of the incorrect alternatives. As test developers looked back at these items, there was ambiguity between the correct and the incorrect alternative(s) most frequented by the pilot sample. These distractors were altered allowing the same question to be addressed with a clear distinction between correct and incorrect alternatives. In other cases a revision of the stem was needed to clarify exactly what the question was written to address. Once all the items were revised they were entered into a test bank and will be piloted again in a later study.

\section{Item response theory.}

All data were coded and entered into MULTILOG 7. It was determined a priori that the IRT multiple-choice model to analyze item distractors would be employed. Upon further analysis of the data, it was determined that the sample size was too small. Additionally, this caused the run of the data to respond in error and the data report was found inconclusive.

\section{Discussion of Results}

\section{Item Construction}

The item construction workshop took place during a two-day conference set in a central location in NYS scheduled in the early spring. Full participation from the selected panelists was anticipated, but some members who had agreed to participate failed to attend as inclement weather likely made travel difficult. 
During the workshop it became apparent that most of the participating teachers had little experience in designing multiple-choice tests. They seemed to prefer more open-ended examinations which are easier to construct. Extension agents attending reported that they had never designed a test nor written a test question. This challenge demanded detailed instruction on how to properly construct a criterion-referenced, multiple-choice test item. Therefore, the instructional period took longer than expected and included many questions from the participants.

Once participants began writing items individually, the process ran smoothly. However, when participants began sharing items with one another, some became frustrated at the quality of their items. Some deleted items and started over, even though they had spent much of the day on the items. This situation slowed the process and meant that fewer questions were completed. Most participants chose to type items on the laptop computers provided; however, some wrote items out in longhand. Deciphering penmanship became another factor limiting the number of items completed.

Once all individuals were finished constructing items, the panels began to work as a group. This portion of the process moved at a faster pace, with many ideas and discussions about the best ways to measure content domains. Once all the items were constructed the group discussed the difficulty members had with the item construction process; specifically generating multiple-choice items for higher levels of cognition. It was an area in which the panelists felt that they needed further instruction, specifically recommending a three-day workshop instead of a two-day one. 


\section{Item Validation}

The validation process was done quickly by the animal systems panel, making recommendations related to editing content and some grammar. However, in the plant systems group, this task resulted in forceful disagreements among some members. There were arguments related to the difficulty level of about half the items put forward. Another argument centered on the fact the not all schools have horticulture in their plant science program, raising the question of whether horticulture-related questions should appear on a statewide assessment. Similar questions about the scope and difficulty of individual items were raised numerous times. Each time, the panel was reminded that the items should be representative of all plant systems programs in the state; and even if one individual item focused on a specified area of plant science, it should not be completely eliminated from the item bank.

Once all the items were validated the panels adjourned. The animal group worked well together, and that panel completed validating items hours ahead of the plant systems group. This caused a feeling of anxiety within the plant systems group and resulted in the panel rushing through the validation process for about one-quarter of the items, not providing a thorough review of them.

The item reviewer spent about one month editing the items for grammar and bias. This reviewer's background was in biology so he also flagged some questions for poor or confusing content. He made adjustment to questions as needed and worked with an undergraduate research assistant in animal 
systems and a former plant science educator to help re-work some of the items.

\section{Test Item Pilot}

The test item pilot was a time consuming process due to the fact that New York is a large state and agricultural education programs are spread out. Trying to get a representative sample of students from different regions took many hours of travel. None of the exams were mailed due to security reasons; all exams were administered by an AEAP team member. Most programs solicited to participate in the pilot testing declined. They indicated that there was not an available day to administer outside projects into their classroom time. Other school officials noted that approval from administrators was needed, and that likely would be a lengthy process. Another reason cited for nonparticipation in the test was that some teachers felt the process was a waste of instruction time since they never planned to utilize a statewide assessment of their curriculum.

Four of the programs participating in the pilot were led by the same agricultural educators who had participated in the item writing workshop. They indicated at the workshop that they would like to continue to contribute to the development of the statewide examination and help pilot various areas of the exam. The other participating programs were led by agricultural educators who indicated that they planned on utilizing such an exam once it was completed. Only one participating program leader indicated that she was not going to utilize the exam but wanted to see how it compared to NOCTI.

Since the pilot tests were voluntary and there was no grade or student identity attached to the tests, some students' intrinsic motivational levels were 
low. With no outside rewards for scoring high on the test, they did not take the process seriously and marked incorrect answers to finish quickly and take the remainder of the class period to relax. Some teachers stated that they would offer extra credit for participating, which may have given more students a desire to finish the exam.

The animal systems pilot exam consisted of 192 questions; the plant systems had 115. A lengthy period of time (about two hours) was needed to finish each exam. That was a large amount of time to devote, and only programs on block scheduling could accommodate it. Students that were not on either a block schedule or in a double period found it difficult to finish the exam. Since the items were coded with a forced dichotomy, with no answer being coded as an incorrect answer, the students that did not finish ended up with poor scores.

\section{Item Analysis}

\section{Reliability.}

The reliability index calculated for both animal systems and plant systems was high ( $p>0.95$, adjusted $p>0.97$ ). When analysis was conducted on how each item contributed to the overall test reliability, the alpha coefficient still remained high. The standard error of measurement was low (plant $S E_{m}=1.399$, animal $S E_{m}=1.048$ ), probably due to the fact that reliability and standard error of the mean have a negative relationship, and the greater the reliability coefficient the lower the standard error of measurement. 


\section{Item difficulty.}

The Item difficulty coefficients ( $p$-values) for most of the items on both animal systems and plant systems and the adjusted p-values were a little less than ideal ( $p$-value<0.625) for multiple-choice test items (Ebel, 1979). This indicates that most of the items were difficult, and most students answered incorrectly. However, time restraints may have attributed to these low results since most of the exams were not completed. The adjusted $p$-values may have been more accurate since most of the students did not finish due to lack of time. A comparison of the regular $p$-value and the adjusted $p$-values show that there were some similarities between the two values.

\section{Item discrimination.}

Items that had low item discrimination (point biserial coefficient<0.15) were flagged for further review (Varma, nd). These low values implied that students who got the item incorrect also scored high on the test overall, while student who got the item incorrect scored low on the test overall. There is a relationship between point biserial statistics and $p$-values. They are found to be conflicting when one is high and the other is low. When the items that were flagged in both animal and plant systems for low point biserial coefficients were checked for the p-value statistics, no conflicting items were found. When the items that were flagged in both animal and plant systems for low adjusted point biserial coefficients were checked for the adjusted p-value statistics, no conflicting items were found. Similar to the adjusted $p$-values the adjusted point-biserial coeffients may have been more accurate since most of the students did not finish due to lack of time. All items from the regular 
calculations and the adjusted calculations were flagged for further review of content and review of a possible incorrect score key.

\section{Alternative frequencies.}

A review of the frequencies of the alternatives for all the questions was conducted. It allowed comparison of the four choices which helped in revision of the test item. For example, in most cases the correct choice was not the choice most frequented. The choice most frequented in most cases was very similar to the correct choice, indicating that the alternatives need to be revised so that there is less ambiguity in the alternatives. The further inspection of the frequencies for each item provided extra feedback, contributing to the construct validity of the tests.

\section{Item Response Theory}

This study has aimed to compare the results of classical test theory and item response theory. By comparing the two, it was hoped to make a further recommendation of which theoretical methods better analyzed the data. Data collected through IRT methods were found inconclusive. The first major cause of error was the sample size- it was found to be too small for the data collected. An underlying assumption of IRT is unidimensionality. Unidimensionality could not be determined when the IRT models were being generated. Therefore, it was not known if the 1-paramter, 2-paramter, or 3parameter model should be taken into consideration. Item parameters such as difficulty and discrimination could not be calculated and goodness of fit to determine how well the models could predict test results was also found inconclusive. 


\section{Conclusions}

A broader evaluation of this study points out areas from which constructive conclusions can be drawn-- specifically test construction, item writing, pilot testing, and item analysis. These conclusions are not only supported by the data collected, but also rely on first-hand observations made during the process. The main goal of this study was to develop a test item bank for two areas for a statewide agricultural exam. As such, this study offers the opportunity to explore one approach to developing such exams. The process detailed here relied on workshops, revisions, and field tests. Below are the key conclusions from these phases.

The first of these relates to the item construction protocol. Through the use of criterion-referenced test item design, items developed were directly linked to specific content domains or objectives. Utilizing this method over more traditional methods, such as norm-referenced test design, allowed direct alignment between the agriculture and natural resources core curriculum and the items developed. Furthermore, CRT allowed for specific domains within the agriculture curriculum to be tested- a valuable characteristic for a statewide assessment designed to cater to the specifics of individual agricultural science programs.

Item writing is a skill that with practice one can learn to master, but it was very difficult to find agriculture teachers with the skills to write good items, and it is equally difficult to find test specialists with expertise of the specific content. The team of item writers made up of teachers and extension agents might not have been the best group to design and write questions. They were knowledgeable in content, but lacked the skills in generating well constructed 
items. This meant there were multiple revisions from the initial item draft stage to the final validation. Such a process poses the danger of content being altered through revisions. To alleviate this, a more direct link between the content area specialist (teachers) and test specialist (professional item writers) needs to occur earlier on in the item construction process.

The third conclusion relates to students taking the pilot tests. These pilot tests included all of the questions developed, in animal systems 192 and plant systems 115 . These tests proved to be too long and not specific enough. There was insufficient data collected from students who were not knowledgeable in certain areas covered by the test. Many of the students did not finish the test which skewed the results related to specific test items. More valuable data could have been collected if the pilot test targeted students had been more thoroughly instructed in the individual curriculum domains. CRT allows items to be categorized based on such domains, meaning the test could have been broken down into fewer questions for more content-specific tests.

The last conclusion is based on the IRT item analysis. According to the findings of this study, the results calculated through the use of IRT were found inconclusive primarily due to low sample size. A recommendation to all who plan on using IRT methods is to make sure to have data collected from a large sample size $(>1000)$ or access to data with a large sample size. For this particular study, I recommend collecting more data from the students in plant systems and animal systems programs in NYS and then running the IRT models for further comparison to CTT models. If it is determined that IRT models are better to predict item characteristics, then that is the model that 
should be used to evaluate the remaining seven areas from the core curriculum that are going to be piloted in the future.

\section{Suggestions for Further Research}

Additional research is needed on the construction of exams to measure specific domains set forth in career and technical education (CTE) programs. As previously noted, criterion-referenced exams are more useful in determining if a student has mastered a certain domain of instruction. However, the hands-on nature of CTE programs is difficult to measure in a multiple-choice exam. Many states are beginning to develop ways to assess CTE programs. There is a need for research to investigate theoretical models of test design and test validation. In the case of this study, investigation of test construction was conducted outside of agricultural science education, and then further outside of CTE, because there has been no research conducted in test construction for such programs. While guidance was provided from academic courses, which use examinations as a way to assess programs, academic programs typically are not as hands-on in instruction and do not associate well with the nature of CTE.

A contributing factor to well constructed assessments is the alignment among standards, curriculum, and assessment (Solomon, 2002). This study was based on criterion-referenced guidelines to ensure that the items being developed were aligned to a certain domain from the core outline. However, there remains a large gap when there are no standards and curriculum available on which to base such an examination. Further research needs to be conducted reviewing the alignment of bridging assessments to standards in CTE. In NYS, consideration is recommended on the need to develop 
standards and curriculum since it is becoming a national issue impacting all areas of instruction.

There is a need for further research in improving assessment design (Janesick, 2001). Too often educational programs continue to use normreferenced, multiple-choice exams as a way to evaluate student progress. Studies evaluating more authentic measures, such as rubrics, portfolios, and essays should be investigated, especially in the CTE field. Within agricultural education, there are many resources available to assist in student evaluation. There are Supervised Agricultural Experiences and leadership opportunities provided by the FFA, such as Career Development Events; and there is the nature of the agriculture classroom and curriculum, which incorporate many hands-on experiences, such as greenhouse management, small animal care, and investigations in biotechnology, to name a few. Such factors unique to agricultural science education need further research as to how they can contribute to an overall assessment and evaluation of student performance.

In states that are beginning to use CTE programs to offer alternative venues for students to get academic credit, issues of evaluation of this model need to be addressed. While helping students find an alternative pathway to fulfill graduation requirements and helping CTE programs maintain enrollment, further attention needs to be given on the outcome of student learning. Investigation into whether students are mastering the academic content needs to be conducted. 


\section{APPENDIX}

Appendix A- Plant Systems Core Content Outline

Appendix B- Animal Systems Core Content Outline

Appendix C- Writing Multiple-Choice Test Items PPT

Appendix D- Item Template

Appendix E- Evaluation Sheet

Appendix F- Multiple-Choice Item Criteria 
Appendix A

\section{Plant Systems Core Content Outline}

I. Apply principles of anatomy and physiology to produce and manage plants in both a domesticated and a natural environment.

a. Analyze and evaluate nutritional requirements and environmental conditions

i. Describe nutrient sources.

ii. Determine plant nutrient requirements for optimum growth.

iii. Identify function of plant nutrients in plants.

iv. Determine the environmental factors that influence and optimize plant growth.

b. Examine data to evaluate and manage soil/media nutrients.

i. Collect and test soil/media and/or plant tissue.

ii. Interpret tests of soil/media and/or plant tissue.

iii. Identify soil slope, structure and type.

iv. Evaluate soil/media permeability and water-holding capacity.

v. Evaluate soil/media permeability and water-holding capacity.

vi. Determine the biological functions of microorganisms of soil/media.

c. Explain and use basic methods for reproducing and propagating plants.

i. Determine the role of genetics in plants.

ii. Describe the components and functions of plant reproductive parts.

iii. Identify and practice methods of asexual/sexual plant propagation.

d. Develop a plan for integrated pest management.

i. Identify plant pests (e.g., insects, diseases, weeds, rodents).

ii. Determine pest management safety practices.

iii. Determine pest management methods.

iv. Develop pest management plans based on pest life cycles.

v. Evaluate pest control plans. 
II. Address taxonomic or other classifications to explain basic plant anatomy and physiology.

a. Examine unique plant properties to identify/describe functional differences in plant structures including roots, stems, flowers, leaves and fruit.

i. Identify plant structures (e.g., seeds).

ii. Describe physiological functions of plants.

iii. Describe germination process and conditions.

b. Classify plants based on physiology for taxonomic or other classifications.

i. Classify plants as monocots or dicots.

ii. Classify plants as annuals, biennials or perennials.

iii. Classify plants according to growth habit.

iv. Classify plants by type.

v. Classify plants by economic value.

III. Apply fundamentals of production and harvesting to produce plants.

a. Apply fundamentals of plant management to develop a production plan.

i. Identify and select seeds and plants.

ii. Manipulate and evaluate environmental conditions (e.g., irrigation, mulch, shading) to foster plant germination, growth and development.

iii. Evaluate and demonstrate planting practices (e.g., population rate, germination/seed vigor, inoculation, seed and plant treatments).

iv. Evaluate and demonstrate transplanting practices.

v. Prepare soil/media for planting.

vi. Control plant growth (e.g., pruning, pinching, disbudding, topping, detasseling, staking, cabling, shearing, shaping).

vii. Prepare plants and plant products for distribution.

b. Apply fundamentals of plant management to harvest, handle and store crops.

i. Determine crop maturity.

ii. Identify harvesting practices and equipment.

iii. Calculate yield and loss.

iv. Identify options for crop storage. 
IV. Analyze the importance of plants with relation to governmental policy and the Global Food Systems.

a. Define global food systems.

b. Discuss policies, laws, and the administration of plant sciences.

c. Discuss the advancements in biotechnology in relation to plant sciences. 
Appendix B

\section{Animal Systems Core Content Outline}

I. Apply knowledge of anatomy and physiology to produce and/or manage animals in a domesticated or natural environment.

a. Use classification systems to explain basic functions of anatomy and physiology.

i. Identify how animals are scientifically classified ( kingdom, phylum, class, order, family, genus, species)

ii. Describe functional differences in animal structures and body systems.

1. Differentiate between herbivores, omnivores and carnivores and give examples of each

2. Compare an animal cell to a plant cell.

a. Explain the parts and functions of the animal cell.

3. Provide an overview of all major systems of the body including circulatory, skeletal, nervous, digestive, reproductive, respiratory, etc.

iii. Classify animals according to anatomy and physiology.

1. Livestock

a. Identify the basic characteristics of livestock.

b. Define and identify the major bones of various livestock skeletons.

c. Identify different breeds of livestock.

d. Judge livestock.

2. Companion animals

a. Identify basic characteristics of companion animals.

b. Identify breeds of dogs according to AKC classifications.

C. Identify cat groups and breeds according to CFA.

3. Laboratory and exotic species

a. Identify basic characteristics of laboratory and exotic species.

b. Analyze a subject animal to determine the nature of its health status.

i. Perform simple procedures in evaluating an animal's health status. 
ii. Identify symptoms of diseases, illnesses, parasites, and other health-related problems.

1. Define parasitism, endoparasites, ectoparasites

2. Identify infectious diseases

3. Identify non-infectious diseases

4. Identify common internal parasites of livestock and companion animals.

5. Identify common external parasites of livestock and companion animals

iii. Diagnose animal ailments

iv. Identify and implement (i.e., treat) treatment options

1. Demonstrate basic first-aid for animals (bandages, wraps, shots, restraints, etc

2. Describe types of vaccines.

II. Recognize animal behaviors to facilitate working with animals safely a. Develop a safety plan for working with a specific animal

i. Explain factors that serve to stimulate or discourage given types of animal behavior.

ii. Perform safe handling procedures when working with animals.

iii. Describe situations that could cause physical harm when working with animals.

III. Provide proper nutrition to maintain animal performance.

a. Examine animal developmental stages to comprehend why nutrient requirements are different throughout an animal's life cycle.

i. Recognize the different phases of an animal's life cycle.

ii. Select diets that provide the appropriate quantity of nutrients for each animal developmental stage.

1. Classify the major nutrient groups and identify foods that are associated with each group.

iii. Analyze a feed ration to determine whether or not it fulfills a given animal's nutrient requirement.

1. Explain how to read a feed/pet label

2. Read and utilize MSDS sheets

3. Calculate nutrient requirements for various animals given feed labels

4. Create a balance ration for a given animal.

IV. Know the factors that influence an animal's reproductive cycle to explain species response. 
a. Analyze elements in the reproductive cycle to explain differences between male and female reproductive systems.

i. Identify the parts of male and female reproductive tracts on major commercial livestock and companion animals.

ii. Analyze the reproductive cycle of a given animal.

iii. Evaluate animal readiness for breeding.

b. Discuss reproductive cycles to show how they differ from species to species.

i. Discuss the pros and cons of breeding through natural cover and artificial insemination.

ii. Discuss the implications of genetic insemination.

iii. Describe the techniques of artificial insemination

iv. Understand the history and development of cloning and its impact on society.

v. Identify reproduction management practices (e.g. male to female ratios, age and weight for breeding, fertility and soundness for breeding, heat synchronization, flushing)

vi. Explain how biotechnology is impacting animal production.

c. Evaluate an animal to determine its breeding soundness.

i. Describe the procedure for determining an animal's breeding readiness.

ii. Identify and prevent problems associated with reproduction.

iii. Select animals based on breeding soundness.

1. Analyze performance data on male and female animals to determine the best crosses for a given trait.

2. Identify the differences between purebred and cross bread animals.

V. Identify environmental factors that affect an animal's performance.

a. Recognize optimum performance for a given animal.

i. Identify good performance for a given animal species.

ii. Identify reasons why some animals perform better than others.

iii. Identify factors that can be manipulated to control a given animal's performance

iv. Use appropriate tools in manipulating animal performance. 
1. Identify proper equipment needed for livestock care and maintenance.

b. Assess an animal to determine if it has reached its optimum performance level.

i. Make appropriate changes in an animal's environment in order to achieve optimum performance

1. Describe and explain the environmental concerns associated with raising animals in confinement.

ii. Develop efficient procedures to produce insistently highquality animals, well suited for their intended purpose.

1. Identify a given species' desirable production numbers (e.g. birth weight, rate of gain, age of maturity, age of sexual maturity)

2. Evaluate desired traits (e.g. production) of animals.

3. Evaluate the role that economics plays in animal production.

a. Identify products derived from major commercial livestock.

b. Identify uses for manures and other wastes from cattle, sheep, hogs, poultry, etc.

4. Make a decision of using new techniques and methods in the production facility so that both profit and animal safety are maximized.

VI. Animal Issues

a. Identify and discuss major issues impacting the animal production industry today.

b. Compare and contrast animal rights v. animal welfare.

VII. Careers in animal systems

a. Identify careers associated with animals and animal systems. 
Appendix C

\section{Writing Multiple-Choice Test Items PPT Outline}

Slide 1: Writing Multiple-Choice Test Items

Agricultural Science Education Assessment Project

Slide 2: Overview

- What we measure with test items?

- Writing multiple-choice items

- Specific guidelines for test item writing

Slide 3: Knowledge \& Skills

To achieve at the knowledge and skill level = Student ability

- Knowledge: Lowest level of cognition

- Skills: Complex acts that require knowledge and involves performance

- Mental Ability: Resembles skills but more complex

Slide 4: Content

- Facts: Basic knowledge that is not disputed

- Concepts: Classes of objects or events that share a common set of traits

- Principle: Cause and Effect, Relationship between two concepts, law of probability, axiom

- Procedure: Sequence of mental and/or physical acts leading to a result

Slide 5: Types of Mental Behavior

- Recall

- Understanding

- Critical Thinking

- Problem Solving 


\section{Slide 6: Recall}

Any item may really test recall if teaching is aimed at having student memorize responses to questions that may otherwise appear to test something other than recall. This is the difference between teaching to the test and teaching so that test performance is good. The latter is what we want to emphasize.

Slide 7: Understanding

- Similar to comprehension on Bloom's Taxonomy

- Applies to facts, concepts, principles, and procedures

- Key Verbs in Items: Define, demonstrate, find, exemplify, illustrate, list, listen, provide, show, and tell

Slide 8: Critical Thinking

- Reflect, Compare, Evaluate, Make Judgment

- Key Verbs: Anticipate, appraise, attack, analyze, classify, compare, contrast, critique, defend, distinguish, expect, evaluate, hypothosize, infer, judge, predict, relate, value

Slide 9: Problem Solving

A set of mental steps leading to the realization of a goal.

Process:

1. Problem identification

2. Problem definition

3. Analysis

4. Proposed Solution

5. Experiment

6. Conclusion

Slide 10: Test Item Considerations

Reliability \& Validity 
Slide 11: Reliability

- Wording is clear

- Use appropriate vocabulary

- No tricky answers

- No double negatives

- Moderate difficultly level (not too easy or not too hard)

- Avoid complex or multiple sentences

Slide 11: Validity

- Matches instructional objectives/criterion

- Measures the type of student outcome

- Measures the content taught

- Measure performance at cognitive level taught

Slide 12: Multiple-Choice Items

- Stem

- Alternative: Correct response \& Distractors (incorrect responses)

Slide 13: Consistent format

Stems:

- Stated as briefly and concisely as possible

- Use direct questions or statements

- Use words known to the students- Avoid window dressing

- One central problem or question

- Include as much of the item as possible so that students need not reread the same material in each alternative 
Slide 14: Stem Examples

Poor Example:

If a gas is compressed
A. its temperature increases.
B. its temperature decreases.
C. its temperature remains the same.
D. its temperature fluctuates up and down.

This is a poor example because it rereads the same material in each alternative

Slide 15: Stem Examples

Good Example of the same question:

Compressing a gas causes its temperature to
A. increase.
B. decrease.
C. remain the same.
D. fluctuate up and down.

Slide 16: Alternatives

- Consistent format

- Correct response

- Clearly correct

- Grammatically correct with the stem

- Logical or numerical order.

Slide 17: Distractors

- Plausible

- Grammatically correct with stem

- Should NOT include "none of the above" or "all or the above" or " $a, b, \&$ not c"

- $\quad+$ - equal in length with correct response 
Appendix D

\section{A Template for Developing a Multiple-Choice Test Item}

Choose the type of student outcome:

\begin{tabular}{|l|l|l|}
\hline Knowledge & Mental Skill & Mental Ability \\
\hline
\end{tabular}

What content are you measuring?

\begin{tabular}{|l|l|l|l|}
\hline Fact & Concept & Principle & Procedure \\
\hline
\end{tabular}

What type of mental behavior are you developing?

\begin{tabular}{|l|l|l|l|}
\hline Recall & Understanding & Critical Thinking & Problem Solving \\
\hline
\end{tabular}

Stem:

Correct Answer:

Distractor 1:

Distractor 2:

Distractor 3: 
Appendix E

\section{Test Content Validation Form}

Judge:

Title:

Location: Cobleskill, NY

Pathway: Plant Systems

Date: March 14, 2006

Please read each objective and it's corresponding items. For each test item, please make two judgments.

1. Do you feel the item assesses its intended objective? Circle "Y" for "yes" of "N" for "no" to indicate your opinion. If you are uncertain, circle "N" and explain your concern in the comments section.

2. Do you see any technical problem with the item? For example, is there more than one corret answer among the alternatives? Is there a cue to the correct answer within the item? Is the indicated correct answer indeed correct? Circle O.K. if you see no problems; circle the "?" if you do see technical problems, and explain your concern in the comments section.

Please feel free to add any additional comments (on back) you think would be helpful to the designers of this test. 


\section{Appendix F}

\section{Multiple-Choice Item Criteria}

\section{Item Number}

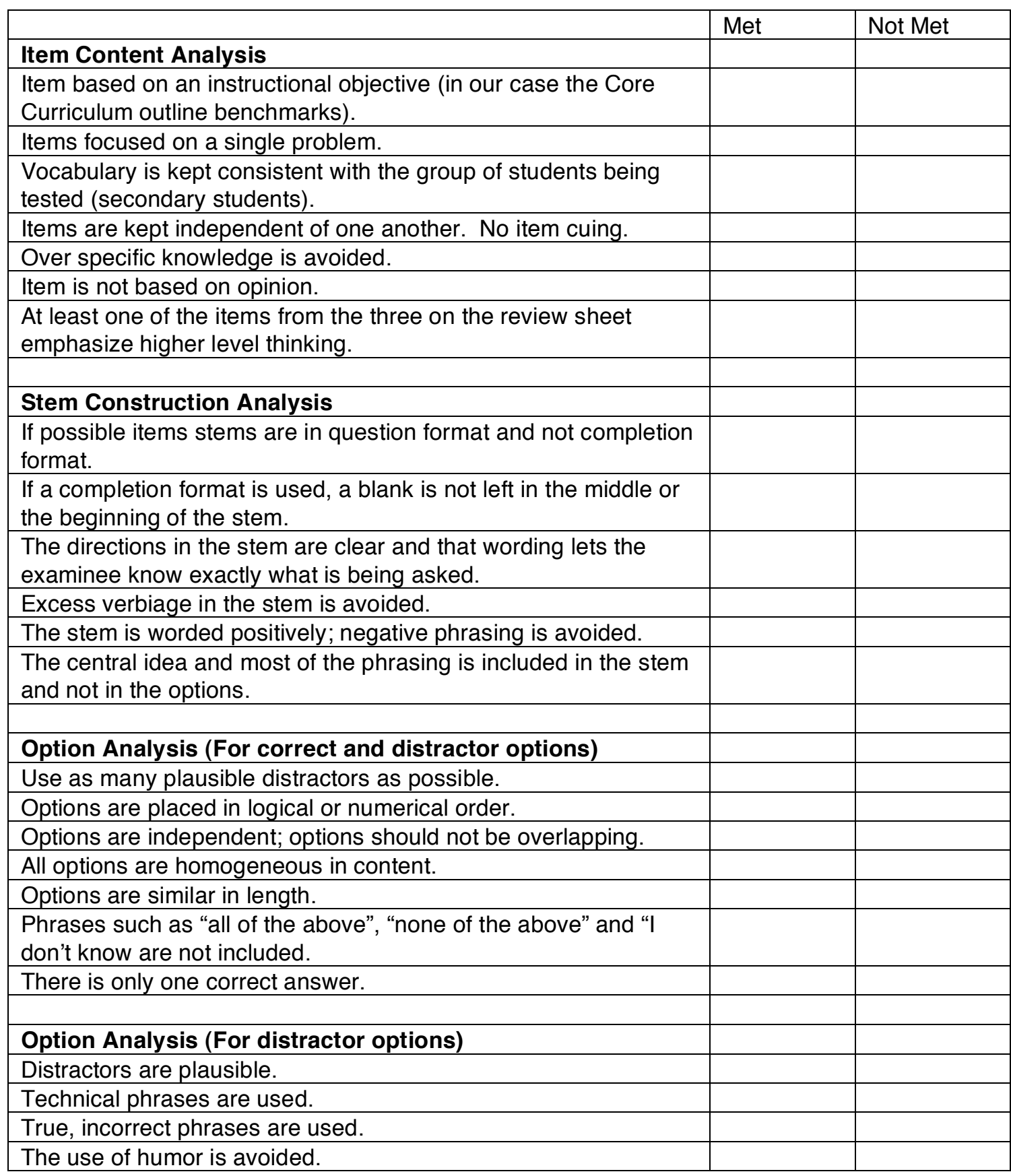




\section{REFERENCES}

Aiken, L.R. (1994). Psychological testing and assessment ( $8^{\text {th }}$ ed.). Needham Heights, MA: Allyn and Bacon.

Allen, M.J, \& Yen, W.M. (2001). Introduction to measurement theory. Longrove, IL: Waveland Press.

American Psychological Association, American Educational Research Association, National Council on Measurement and Education. (1999). Standards for educational and psychological testing. Washington, DC: American Psychological Association.

American Psychological Association (1985). Standards for educational and psychological testing. Washington, DC. American Psychological Association.

American Psychological Association (1966). Standards for educational and psychological testing. Washington, DC. American Psychological Association.

American Psychological Association (1954). Standards for educational and psychological testing. Washington, DC. American Psychological Association.

Anastasi, A. (1988). Psychological testing (6 $6^{\text {th }}$ ed.). New York: Macmillan. Baker, Frank (2001). The Basics of Item Response Theory. ERIC Clearinghouse on Assessment and Evaluation, University of Maryland, College Park, MD. 
Beatty, A., Neisser, U., Trent, W.T., \& Heubert, J.P. (2001). Understanding dropouts: Statistics, strategies, and high-stakes testing. Retrieved August 28, 2006 from http://darwin.nap.edu/books/0309076021/html/R1.html.

Bennet, R.E., Rock, D.A., \& Wang, M. (1990). Equivalence of free-responses and multiple-choice items. Journal of Educational Measurement, 28, 77-92.

Berk, R.A. (1978). The application to structural facet theory to achievement test construction. Educational Research Quarterly, 42, 145-170.

Bishop, J.H., Mane, F., Bishop, M., \& Moriarty, J. (2001). The role of end-ofcourse exams and minimum competency exams in standards-based reforms. Brookings Papers on Education Policy, 2001, 267-345

Bock, R.D. (1972). Estimating item parameters and latent ability when responses are scored in two or more nominal categories. Psychometrika, 37, 29-51.

Bolon, C. (2000). School-based standard testing. Education Policy Analysis 8, (23) Retrieved August 28, 2006 from http://epaa.asu.edu/epaa/v8n23/.

Borko, H., \& Elliot, R.(1999). Hands-on pedagogy versus hands-off accountability: Tension between competing commitments for exemplary math teachers in Kentucky. Phi Delta Kappan, 80, 394-400.

Bormuth, J.R. (1970). On the theory of achievement test items. Psychometrika, 35, 509-511.

Bracht, G.H., \& Hopkins, K.D. (1970). On a theory of achievement tests. Chicago: University of Chicago Press. 
Bridgeman, B., \& Rock, D.A. (1993). Relationship among multiple-choice and open-ended analytical questions. Journal of Educational Measurement, 30, 313-329.

Brownell, W. A. (1933). On the accuracy with which reliability may be measured by correlating test halves. Journal of Experimental Education, 1, 204-215.

Bush, G.W. (1991). America 2000: An educational strategy. Washington, DC: US Department of Education.

Butts, R.F. \& Cremin, L.A. (1953). A History of Education in American Culture. New York: Holt, Rinehart \& Winston.

Byrnes, D.A. (1989). Attitudes of student and educators towards repeating a grade in L.A. Shepard and M.L. Smith (Eds.), Flunking Grades: Research and policies on retention (pp. 108-131). Philadelphia, PA: Falmer Press.

Capen, S.P. (1921). Review of Recent Federal Legislation on Education. In Proceedings of a Conference on The Relation of the Federal Government to Education (pp. 77-88). Urbana, IL: University of Illinois.

Cannell, J.J. (1987). Nationally normed elementary achievement testing in America's public schools: How all fifty states are above the national average ( $\left.2^{\text {nd }} \mathrm{ed}.\right)$. Daniels, WV: Friends of Education.

Castellano, M., Stringfield, S. \& Stone III, J.R. (2003). Secondary career and technical education and comprehensive school reform: Implications for research and practice. Review of Educational Research, 73 (2), pp. 231-272.

Castro, J.G. \& Jordan, J.E. (1977). Facet theory attitude research. Educational Researcher, 11, 7-11. 
Clark, M., Haney, W., \& Madaus, G. (2000). High stakes testing and high school completion. Retrieved August 28, 2006 from http://www.bc.edu/research/nbetpp/publications/v1n3.html.

Coffman, W.E. (1971). Essay examinations. In R.L. Thorndike (Ed.), Educational Measurement ( $2^{\text {nd }}$ ed., pp. 271-302). Washington, DC: American Council of Education.

Cooper, B.S, Fusareli, L.D. \& Randall, E.V. (2004). Better Policies, Better Schools: theories and Applications. Boston, MA: Pearson.

Cortiella, C. (2004). Implications of high-stakes testing for students with learning disabilities. Retrieved May 2, 2005 from http://www.schwablearning.org/articles.asp? $r=846 \& g=2$.

Corbett, H.D., \& Wilson, B.L. (1991). Testing, reform, and rebellion. Norwood, NJ: Ablex.

Cremin, L.A. (1961). The Transformation of The School: Progressivism in American Education 1876-1957. New York, NY: Alfred A. Knopf, Inc. Crocker, L, \& Algina, J. (1986). Introduction to classical and modern test theory. New York: Hold, Rinehart, and Wilson.

Cronbach, L.J. (1990). Essentials of psychological testing (5 $5^{\text {th }}$ ed.). New York: Harper \& Row.

Cronbach, L. J.1(1980). Toward reform of program evaluation: Aims, methods, and institutional arrangements. San Francisco: Jossey-Bass.

Cronbach, L.J. (1989). Construct validation after thirty years. In R.E. Linn (Ed.), Intelligence: Measurement, theory and public policy (pp. 147171). Urbana: University of Illinois Press.

Cronbach, L.J. (1988). Fiver perspectives on validity argument. In H. Wainer \& H.I. Braun (Eds.), Test validity (pp. 3-17). Hillsdale, NJ: Erlbaum. 
Cronbach, L. J. (1951). Coefficient alpha and the internal structure of tests. Psychometrika, 16, 297-334.

Darling-Hammond, L. (1998). Alternatives to grade retention. The School Administrator Web Edition.

http://www.aasa.org/publications/saarticledetail.cfm?ltemNumber=4466 (accessed February 14, 2006).

Dillon, S (2006). Schools Cut Back Subjects To Push Reading and Math. The New York Time Select. The New York Times Company, March 26, 2006.

Ebel, R.L. (1979). Essentials of educational measurement (3 ${ }^{\text {rd }}$ ed.). Englewood Cliffs, NJ: Prentice-Hall Inc.

Ebel, R.L., \& Frisbie, D.A. (1991). Essentials of educational measurement ( $5^{\text {th }}$ ed.). Englewood Cliffs, NJ: Prentice Hall.

Elementary and Secondary School Act. Public Law 89-10 (Aprill 11, 1965).

Elemore, R.F. \& Rothman, R. (Eds.) (1999). Testing, teaching, \& learning: A guide for states and school districts. A report of the National Research Council's Committee on Title I Testing and Assessment. Washington, DC: National Academy Press.

Engle, J.D. \& Martuza, V.R. (1976). A systematic approach to the construction of domain referenced multiple-choice test items. Paper presented at the meeting of the American Psychological Association. Washington, DC.

Ferguson, G.A. (1942). Item selection by the constant process. Psychometrika 7, 19-29. 
Fiske, E.B. (1990). Smart schools, smart kids: Why do some schools work? New York: Simon and Schuster.

Foa, U.G. (1968). Three kinds of behavioral objectives. Psychological Bulletin, 70, 460-473

Foley, A. (1973). A bolton childhood. Manchester: Manchester Extra Mural Department of the WEA.

Fraser, J.W. (2001). The School in the United States: A Documented History. Boston, MA: McGraw- Hill.

Glaser, R. (1984). Criterion-referenced tests: Part I. origins. Educational Measurement: Issues and Practice, 13(4). 9-11; 27-30.

Glaser, R. (1963). Instructional technology and the measurement of learning outcomes: Some questions. American Psychologist, 18, 519-521.

Glatthorn, A \& Fontana, J. (2000). Coping with standards, tests, and accountability: Voices from the classroom. Alphareta, GA: NEA Professional Library.

Goertz , M.E. (2001, September). The federal role in defining "adequate yearly progress:" The flexibility/accountability trade-off. Consortium for Policy Research in Education. Retrieved May 25, 2006 , from http://www.cpre.org/Publications/cep01.pdf.

Goertz, M.E. (2001). Standards-based Accountability: Horse Trade or Horse Whip? In S. Fuhrman (Ed.), From the Capitol to the Classroom: Standards-based Reform in the States (pp. 39-59). Chicago: The University of Chicago Press.

Goertz, M.E., Duffy, M.C., \& Le Froch, K.C. (2001). Assessment and Accountability Systems in the 50 States: 1999-2000. CPRE Research Report Series. RR-046- March 2001. 
Grissom, K.B, \& Sheperd, L.A. (1989). Attitudes of student and educators towards repeating a grade in L.A. Shepard and M.L. Smith (Eds.), Flunking Grades: Research and policies on retention (pp. 108-131). Philadelphia, PA: Falmer Press.

Gronlund, N.E., \& Linn, R.L. (1990). Measurement and evaluation in teaching (6 $6^{\text {th }}$ ed.). New York: Macmillan.

Guion, R. M. (1974) Open a new window: Validities and values in psychological measurement. American Psychologist, 29, 287-296.

Guliford, J.P. (1967). The nature of human intelligence. New York: McGrawHill.

Guttman, L. (1945). A basis for analyzing test-retest reliability. Psychometrika, $10,255-282$.

Guttman, L.A. (1959). A structural theory for intergroup beliefs and actions. American Sociological Review, 24, 318-328.

Guttman, L.A. \& Schlesinger, I.M. (1967). Systematic construcion of distractors for ability and achievement testing. Educational and Psychological Measurement, 27, 569-580.

Guttman, L.A. (1969). Integration of test design and analysis. In Proceedings of the 1969 invitational conference of testing problems. Princton, NJ: Educational Testing Service.

Haladyna, T.M. (2004) Developing and validating multiple-choice test items, $3^{\text {rd }}$ ed. Hillsdale, NJ: Lawrence Erlbaum Associates Haladyna, T.M. (1994). Developing and validating multiple-choice test items. Hillsdale, NJ: Lawrence Erlbaum Associates. Haladyna, T.M. (1999). Developing and validating multiple-choice test items ( $2^{\text {nd }}$ ed.). Hillsdale, $\mathrm{NJ}$ : Lawrence Erlbaum Associates. 
Haladyna, T.M., \& Downing, S.M. (1989a). A taxonomy of multiple-choice item-writing rules. Applied Measurement in Education, 1, 37-50.

Haladyna, T.M., \& Downing, S.M. (1989b). The validity of a taxonomy of multiple-choice item-writing rules. Applied Measurements in Education, 1, 51-78.

Hambleton, R.K. (1994). The rise and fall of criterion referenced measurement? Educational Measurement: Issues and Practice, 13(4). 21-26.

Hambleton, R.K. (1984). Validating the test scores. In R.A. Berk (ed.). $A$ guide to criterion-referenced test construction. Baltimore, MD: The John Hopkins University Press, pp. 199-230.

Hambleton, R.K. \& Rogers, H.J. (1991). Advances in criterion-referenced measurement in R. Hambleton \& J. Zaal (eds.) Advances in educational and psychological testing. Boston: Kluwer Academic Publishers.

Hambleton, R.K., Swaminathan, H., Algina, J., \& Coulson, D.B. (1978). Criterion-referenced testing and measurement: A review of technical issues and developments. Review of Educational Research, 48. 1-47. Heim, A.W., \& Watts, K.P. (1967). An experiment on multiple-choice versus open-ended answering in a vocabulary test. British Journal of Educational Psychology, 37, 339-346.

Henrysson, S. (1963). Correction of item-total correlation in item analysis. Psychometrika, 28, 211-218.

Hess, F.M., McGuinn, P.J. (2002). Seeking the Mantle of "Opportunity": Presidential Politics and the Educational Metaphor, 1964-2000. Educational Policy 16(1), 72-95. 
Hivey, W., Patterson, H.L., \& Page, S.A. (1968). A "universe-defined" system of arithmetic achievement test. Journal of Educational Measurement, 5. 275-290.

Holmes, C.T. (1989). Attitudes of student and educators towards repeating a grade in L.A. Shepard and M.L. Smith (Eds.), Flunking Grades: Research and policies on retention (pp. 108-131). Philadelphia, PA: Falmer Press.

Hopkins, K.D., Stanley, J.C., \& Hopkins, B.R. (1990). Educational and psychological measurement and evaluation ( $7^{\text {th }}$ ed.). Englewood Cliffs, NJ: Prentice Hall.

Hochschild, J. \& Scott, B. (1998). Trends: Governance and reform of public education in the United States. Public Opinion Quarterly, 62(1), 79-120. Hoyt, C. (1941). Test reliability estimated by analysis of variance. Psychometrika, 6, 153-160.

Hurst, D., Tan., A., Meek, A., and Sellers, J. (2003). Overview and Inventory of State Education Reforms: 1990 to 2000 (NCES 2003-020).

Janesick, V.J. (2001). The assessment debate: A reference handbook. Santa Barbara, CA: ABC-CLIO.

Johnson, J. \& Immerwarh, J. (1994). First things first: What American's expect from the public schools. New York: Public Agenda.

Jones, M.G., Jones, B.D., \& Hargrove, T.Y. (2003). The unintended consequences of high-stakes testing. New York: Rowman \& Littlefield Publishers.

Jones, M.G., Jones, D., Hardin, B., Chapman, L., Yarbrough, T, \& David, M. (1999). The impact of high stakes testing on teachers and students. Phi Delta Kappan, 81, 199-203. 
Joorabchi, B., \& Chawan, A.R. (1975). Multiple-choice questions- the debate goes on. British Journal of Educational Measurement, 9, 275-280.

Katz, M.B. (1968). The Irony of Early School Reform. Cambridge, Massachusetts: Harvard University Press.

Kean, M.H. (1995). The national testing movement, redux. The Clearing House; Mar 1995; 68, 4; Research Library, 201.

Kliebard, H.M. (1995). The cardinal principles report as archeological deposit in C. Gaylord (ed) Committee of Ten. Cambridge, MA: Harvard University Press.

Kornhaber, M.L., \& Orfield, G. (2001). High-stakes testing policies: Examining their assumptions and consequences in G. Orfield \& M.L. Kornhaber (Eds.), Raising standards or raising barriers? Inequality and high-stakes testing in public education (pp. 1-18). New York: Century Foundation.

Kuder, G. F., and Richardson, M. W. (1937). The theory of the estimation of test reliability. Psychometrika, 2, 151-160.

Lashway, L. (2001). The New Standards and Accountability: Will rewards and sanctions motivate America's schools to peak performance? Eugene, OG: Eric Clearing House on Educational Management.

Lawley, D.N. (1943). On problems connected with item selection and test construction. Proceedings of the Royal Society of Edinburgh 61, 273287.

Levin, H.M. (2001). High-stakes testing and economic productivity in G. Orfield \& M.L. Kornhaber (Eds.), Raising standards or raising barriers? Inequality and high-stakes testing in public education (pp. 19-38). New York: Century Foundation.

Life Magazine. (1958) pp. 25-33. 
Linn, R.L. (2000). Assessment and Accountability. Educational Researcher 29(2), 4-16.

Linn, R.L. (1984). Criterion-referenced measurement: A valuable perspective clouded by surplus meaning. Educational Measurement: Issues and Practice, 13(4). 12-14.

Lord, F.M. \& Novick, M.R. (1968). Statistical theories of mental test scores. Reading, MA: Addison-Wesley.

Madaus, G. F. \& Clarke, M. (2001). The adverse impacts of high-stakes testing on minority students: Evidence from one hundred years of test data in G. Orfield \& M.L. Kornhaber (Eds.), Raising standards or raising barriers? Inequality and high-stakes testing in public education (pp. 85106). New York: Century Foundation.

Madaus, G.F., Airasian, P.W., \& Kellaghan, T. (1980). School effectiveness: A reassessment of the evidence. New York: McGraw-Hill Book Company.

MAGI Educational Service, Inc. (2004). New York's state's Career and technical policy initiative: Evaluation report. White Plains, NY.

Manzo, K.K. (2000). Legacy of the Eight-Year Study in V.B. Edward (ed.) Lessons of a century: A Nation's School Come of Age. Bethesda, MD: Editorial Projects in Education.

Massell, D. (2001). The Theory and Practice of Using Data to Build capacity: State and Local Strategies and their Effects in S.H. Fuhrman (ed.) From the Capital to the Classroom: Standards-based Reform in the States. Chicago, IL: The University of Chicago Press. 
Masters, G.N. (1988). Partial credit models. In J.P. Keeves (Ed.) Educational research methodology, measurements and evaluation (pp. 292-296). Oxford: Pergamon Press.

Markle, S.M., \& Tiemann, P.W. (1970). Really understanding concepts. Champaign, IL: Stipes.

Marschall, M.J., \& McKee, R.J. (2002). From campaign promises to presidential policy: Education reform in the 2000 election. Educational Policy 16(1), 96-117.

McCall, W.A. \& Bixler, H.H. (1928). How to Classify Pupils. New York: Bureau of Publications Teachers College, Columbia University. McDonnell, L.M. (2004). Politics, Persuasion, and Educational Testing. Cambridge, MA: Harvard University Press.

McNeil, L. (2000). Contradictions of school reform: Educational cost of standardized testing. New York: Routledge.

McNeil, L. \& Valenzuela, A. (2001). The harmful impact of the TAAS system of testing in Texas: Beneath the accountability rhetoric in G. Orfield \& M.L. Kornhaber (Eds.), Raising standards or raising barriers? Inequality and high-stakes testing in public education (pp. 127-150). New York: Century Foundation.

Mehrens, W.A. \& Lehmann, I.J. (1987). Using standardized tests in education ( $4^{\text {th }}$ ed.). New York: Longman.

Meeker, M, Meeker, R, \& Roid, (1985). Structure of intellect leaning ability tests. Los Angeles, CA: Western Psychological Services.

Messick, S. (1989). Validity. In R.L. Linn (Ed.), Educational Measurement (3 $3^{\text {rd }}$ ed., pp. 13-104). New York: American Council on Education and Macmillan. 
Messick, S. (1975). The standard problem: Meaning and values in measurement and evaluation. American Psychologist, 30, 955- 966.

Millman, J. (1984). Criterion-referenced testing 30 years later: Promises broken, promises kept. Educational Measurement: Issues and Practice, 13(4). 19-20, 39.

Millman, J., \& Greene, J. (1989). The specification and development of tests of achievement and ability. In R.L. Linn (Ed.) Educational Measurement ( $3^{\text {rd }}$ ed., pp. 335-366). New York: American Council on Education and Macmillan.

Mondale, S \& Patton, S.B. (eds.) (2001). School: The Story of American Public Education. Boston, MA: Beacon Press.

Moe T \& Chubb, J.E. (1990). Politics, markets, and America's schools. Washington, D.C.: Brookings Institution.

Monroe, W.S. (Ed.). (1952). Encyclopedia of Educational Research: A Project of the American Educational Research Association. New York: The Macmillan Company.

Mosier, C.I. (1940). Psychophysics and mental test theory: Fundamental postulates and elementary theorems. Psychological Review, 47, 355366.

Mosier, C.I. (1941). Psychophysics and mental test theory II: The constant process. Psychological Review, 48, 235-239.

Moss, P. (1992). Shifting conceptions of validity in educational measurements: Implications for performance assessment. Review of Educational Research, 62, 229-258.

National Center for Educational Statistics (NCES). (2003) Digest of Educational Statistics. Washington, DC: GPO. 
National Commission on Excellence in Education. (1983) A nation at risk: The imperative for educational reform. A Report to the Nation and the Secretary of Education .

National Committee for Support of Public Schools. (1966). Education and social change. Washington, DC.

National Council for Agricultural Education (2006). Agriculture and natural resources brochure. Retrieved July 7, 2006 from http://www.careerclusters.org/clusters/anr.cfm.

National Council for Agricultural Education (2004). 2004-2006 Strategic Plan. Retrieved August 29, 2005, from http://www.agedhq.org/strategicplan.htm

National Defense Education Act, Public Law 85-864.

National Occupational Competency Testing Institute. (n.d.). Student assessment. Retrieved May 25, 2006, from http://www.nocti.org/student.cfm

National School Boards Association (2004). "Highly Qualified Teacher" Changes to No Child Left Behind. Retrieved July 26, 2004 from http://www.nsba.org/site/doc.asp?TRACKID=\&VID=2\&CID=870\&DID=3 3335

Nickerson, R. S. (1989). New directions in educational assessment. Educational Researcher, 18, 3-7.

Nunnally, J.C., \& Bernstein, I. (1994). Psychometrics Theory (3 ${ }^{\text {rd }}$ ed.). New York: McGraw-Hill.

Osterlind, S.J. (1989). Constructing test items. Boston: Kluwer Academic Publishers. 
Patterson, D.G. (1926). Do new and old type examinations measure different mental funcations? School and Society, 24, 246-248.

Perreault, G. (2000). The classroom impact of high-stakes testing. Education, $120,705-710$.

Peters, G., Woolley, J. (2001). The American Presidency Project. State of the Union Message. Retrieved April 29, 2005 from source http://www.presidency.ucsb.edu/ws/index.php?pid=29643

Peterson, J.J. (1983) The lowa Testing Programs. lowa City, IA: University of lowa Press.

Popham, W.J. (2003). Test better, teach better: The instructional role of assessment. Alexandria, VA: Association for Supervision and Curriculum Development.

Popham, W.J. (1993). Educational evaluation. Boston: Allyn and Bacon.

Popham, W.J. (1990). Modern educational measurement: A practitioner's perspective $\left(2^{\text {nd }}\right.$ ed.). Needham Heights, MA: Allyn and Bacon.

Popham, W.J. (1984). Specifying the domain of content or behaviors in R. Berk (ed.) A guide to criterion-referenced test construction (pp. 29-48). Baltimore, MD: The John Hopkins University Press.

Popham, W.J. (1975). Educational evaluation. Englewood Cliffs, NJ: Prentice-Hall, Inc.

Popham, W.J., \& Husek, T.R. (1969). Implications of criterion-referenced measurement. Journal of Educational Measurement, 6, 1-9.

Rasch, G. (1960). Probabilistic models for some intelligence and attainment tests. Copenhagen, Denmark: Danish Institute for Educational Research. 
Rasch, G. (1961). On general laws and the meaning of measurement in psychology, Proceedings of the Fourth Berkeley Symposium on Mathematical and Statistics and Probability (Vol. 4, pp. 321-333). Berkeley: University of California Press.

Ravitch, D. (2005). Every state left behind in The New York Times. November 7, 2005 from http://www.nytimes.com/2005/11/07/opinion/07ravitch.html accessed on November 11, 2005.

Ravitch, D. (1995). National standards in American education: A citizen's guide. Washington, D.C.: The Brookings Institution.

Ravitch, D. (1983). The troubled crusade: American education, 1945-1980. New York: Basic Books Publishers.

Ravitch, D. \& Viteritti, J.P. (2001). Making Good Citizens: Education and Civil Society. New Haven, CT: Yale University Press.

Resnick, D. (1982). The History of Educational Testing in (A. Wigdor \& W. Garner, eds) Ability Testing: Uses, Consequences, and Controversies Part 2. Washington, DC: National Academy Press.

Rodriguez, M.C. (2002). Choosing an Item Format in G. Tindal \& T.H. Haladyna (eds.) Large-Scale Assessments for all students. Mahwah, $\mathrm{NJ}$ : Lawrence Erlbaum Associates.

Roid, G.H. \& Haladyna, T.M. (1982). A technology for test-item writing. New York: Academy Press.

Rose, L.C., Gallup, A.M., \& Elam, S.M. (1997). The $32^{\text {nd }}$ annual Phi Delta Kappa/Gallup poll of the public's attitudes towards public schools. Phi Delta Kappan, 82(1), 41-57.

Rulon, P. J. (1939). A simplified procedure for determining the reliability of a test by split-halves. Harvard Educational Review, 9, 99-103. 
Rury, J.L. (2005). Education and Social Change- Themes in the History of American Schooling (2 $\left.2^{\text {nd }} e d.\right)$. Mahwah, New Jersey: Lawrence Erlbaum Associates.

Samejima, F. (1979). A new family of models for multiple-choice items.

Research report 79-4 under Office of Naval Research Contract N0001477-C-360, NR 150-402. Austin, TX: University of Texas.

Samejima, F. (1969). Estimation of latent ability using a response pattern of graded scores. Psychometrika, Monograph Supplement No. 17.

Sax, G. (1989). Principles of educational and psychological measurement and evaluation. Belmont, CA: Wadsworth.

Schafer, W.E. \& Olexa, C. (1971) Tracking and Opportunity: The Locking-out process and beyond. Scranton, PA: Chandler Publishing Company.

Schmidt, W.H., McKnight, C.C., \& Raizen, S.A. (1996). A splintered vision: An investigation of U.S. science and mathematics education. East Lansing, MI: US National Research Center for the Third International Mathematics and Science Study.

Schorr, R.Y., \& Firestone, V.A. (2001, April). Changing mathematics teaching in response to a state testing program: A fine grained analysis. Paper presented at the meeting of the American Educational Research Association, Seattle, WA.

Shepard, L, \& Doughtery, K. (1991, April). Effects of high-stakes testing on instruction. Paper presented at the annual meeting of the American Educational Research Association, Chicago, IL. (ERIC Document Reproduction Service NO. ED337468) 
Shock, S.A. \& Coscarelli, W.C. (2000). Criterion-Referenced Test Development (2nd ed.). Silver Springs, MD: International Society for Performance Improvement.

Solomon, P. (2002). The assessment bridge: Positive ways to link tests to learning, standards, and curriculum improvement. Thousand Oaks, CA: Corwin Press, Inc.

SOI Systems Structure of Intellect (n.d.) SOI application areas. from Retrieved February 1, 2005 from http://www.soisystems.com/application.html

Snell, L. (2001) Schoolhouse Crock in J.W. Noll (ed.) Taking Sides: Clashing Views on Controversial Educational Issues (12 ${ }^{\text {th }}$ ed.). Guliford, CT: McGraw-Hill/Dushkin.

Spring, J. (1990). The American School 1642-1993 ( $3^{\text {rd }}$ ed.). New York, NY: McGraw-Hill, Inc.

State Education Department (1987). History of Regents examinations: 18651987. Retrieved September 15, 2005, from http://www.emsc.nysed.gov/osa/hsinfogen/hsinfogenarch/rehistory.htm Stevenson, D. (1995). Goals 2000 and local reform. Teachers College Record, 96(3). P. 458-466.

Texas Education Agency. (nd). Data resources and research. Retrieved May 1, 2006 from http://www.tea.state.tx.us/data.html

Thissen, D., Chen, W., \& Bock, D. (2003). MULTILOG (version 7) [Computer sotware]. Lincolnwood, IL: Scientific Software International.

Thissen, D., Steinberg, L., \& Fitzpatrick, A.R. (1989). Multiple-choice Models: The distractors are also part of the item. Journal of Educational Measurement 26, (2) 161-176. 
Thissen, D \& Steinberg, L. (1984). A response model for multiple-choice items. Psychometrika 49, 501-519.

Thorndike, R.L. (1982). Applied Psychometrics. Boston: Hougton-Mifflin.

Thurstone, L.L. (1927). A law of comparative judgment. Psychological Review, 34, 278-286.

Tiemann, P.W., \& Markle, S.M. (1983). Analyzing instructional content: $A$ guide to instruction and evaluation ( $2^{\text {nd }}$ ed.). Champaign, IL: Stipes.

Thomas, R.M \& Thomas S.M (1965). Individual Differences in the Classroom. New York: David McKay.

Towner, H.A. (1921). Federal Aid to Education. Its Justification, Degree, and Method. In Proceedings of a Conference on The Relation of the Federal Government to Education (pp. 77-88). Urbana, IL: University of Illinois.

Traub, R.E. (1993). On the equivalence of traits assessed by multiple-choice and constructed-response tests. In R.E. Bennett \& W.C. Ward (Eds.), Construction versus choice in cognitive measurement: Issues in constructed response, performance testing, and portfolio assessment (pp. 1-27). Hillsdale, NJ: Lawrence Erlbaum Associates.

Traub, R.E., \& Fisher, C.W. (1997). On the equivalence of constructed responses and multiple-choice tests. Applied Psychological Measurement, 1, 355-370.

Tyack, D. (2003). Seeking Common Ground: Public Schools in a Diverse Society. Cambridge, MA: Harvard University Press.

Tyack, D. (1979). The One Best System: A History of American Urban Education. Cambridge, MA: Harvard University Press. 
Tyack, D (1974). The one best system: A history of American urban education. Cambridge, MA: Harvard University Press.

Tyack, D. \& Cuban L. (1995). Tinkering towards Utopia: A Century of Public School Reform. Cambridge, MA: Harvard University Press.

Tyack, D. \& Hansot, E. (1982). Managers of Virtue: Public Schools in America, 1820-1980. New York: Basic Books.

UCLA Academic Technology Services. (n.d.) SPSS FAQ: What does Cronbach's alpha mean? Retrieved June 1, 2006 from http://www.ats.ucla.edu/STAT/SPSS/faq/alpha.html.

US Department of Commerce, Bureau of Census (1975). Historical Statistics of the United States: Colonial Times to 1970, part 1. Washington, DC: US Government Printing Office.

US Department of Education (2002). The no child left behind act of 2001.

Retrieved June 1, 2006 from http://www.ed.gov/nclb/overview/intro/execsumm.html

US Department of Education (nd. a) NAEP: The nation's report card.

Retrieved August 28, 2006 from http://nces.ed.gov/nationsreportcard/itmrls/

US Department of Education (nd. b) New No Child Left Behind Flexibility: Highly Qualified Teachers. Retrieved July 26, 2005 from http://www.ed.gov/nclb/methods/teachers/hqtflexibility.html

US Department of Education (nd. c) Title I, part A program. Retrieved August 11, 2005 from http://www.ed.gov/programs/titleiparta/index.html. US Office of Education. (nd). Life Adjustment Education for Every Youth. Washington, DC: US Government Printing Office. 
US Office of Education. (1951). Vitalizing Secondary Education: Report of the First Commission on Life Adjustment Education for Youth. Washington, DC: US Government Printing Office.

US Congress Office of Technology Assessment. (1992). Testing in American schools: Asking the right questions. Washington, DC: US Government Printing Office.

Walker, D.F. (2003). Fundamentals of Curriculum: Passion and Professionalism. Mahwah, NJ: Lawrence Erlbaum Associates.

Walsh, M. (2000). Assessment Culture in V.B. Edward (ed.) Lessons of a century: A Nation's School Come of Age. Bethesda, MD: Editorial Projects in Education.

Ward, W.C. (1982). A comparison of free responses and multiple-choice forms of verbal aptitude tests. Applied Psychological Measurement, 6 , $1-11$.

Wainer, H. (1989). The future of item analysis. Journal of Educational Measurement, 26, 191-208.

Ward, A. W., Stoker, H. W., \& Murray-Ward, M. (Eds.). (1996). Educational measurement: Origins, theories, and explications (vols. 1-2). Lanham, MD: University Press of America.

Wechsler, H. (1977). The Qualified Student. New York, NY: John Wiley.

Wesman, A.G. (1971). Writing the test item. In R.L. Thorndike (Ed.) Educational Measurement (2 ${ }^{\text {nd }}$ ed., pp. 99-111). Washington, DC: American Council on Education.

Wideen, M.F., O'Shea, T.. Pye, I., \& Ivany, G.(1997). High-stakes testing and the teaching of science. Canadian Journal of Education, 22, 428-444. 